Portland State University

PDXScholar

Winter 2-11-2019

\title{
Relational Thriving in Context: Examining the Roles of Gratitude, Affectionate Touch, and Positive Affective Variability in Health and Well-Being
}

Alicia Rochelle Starkey

Portland State University

Follow this and additional works at: https://pdxscholar.library.pdx.edu/open_access_etds

Part of the Social Psychology Commons

Let us know how access to this document benefits you.

\section{Recommended Citation}

Starkey, Alicia Rochelle, "Relational Thriving in Context: Examining the Roles of Gratitude, Affectionate Touch, and Positive Affective Variability in Health and Well-Being" (2019). Dissertations and Theses. Paper 4806.

https://doi.org/10.15760/etd.6690

This Dissertation is brought to you for free and open access. It has been accepted for inclusion in Dissertations and Theses by an authorized administrator of PDXScholar. Please contact us if we can make this document more accessible: pdxscholar@pdx.edu. 
Relational Thriving in Context: Examining the Roles of Gratitude, Affectionate Touch, and Positive Affective Variability in Health and Well-Being

by

Alicia Rochelle Starkey

A dissertation submitted in partial fulfillment of the requirements for the degree of

Doctor of Philosophy

in

Applied Psychology

Dissertation Committee:

Cynthia D. Mohr, Chair

Todd Bodner

Leslie Hammer

Jeffrey Robinson

Portland State University

2019 
(C) 2018 Alicia Rochelle Starkey 


\begin{abstract}
Social connection is important to one's health and longevity. However, not only do people need others to survive, we need others to thrive. Researchers call for deeper examination of the functions and processes through which our social partners help us to prosper and thrive, such as through increased physical health and well-being (Feeney \& Collins, 2015; Pietromonaco \& Collins, 2017). Over three studies, I examined phenomena theorized to contribute to long-term thriving including positive emotions (i.e., gratitude and positive affect fluctuation), responsive support, affectionate touch, and physical health (i.e., sleep) within the context of nursing work (Study 1) and military relationships (Study $2 \& 3$ ). Study 1 provides support for the benefits of received gratitude expressions, an understudied component of gratitude interactions. Specifically, nurses receiving more thanks within their work week were associated with feeling more satisfied with their patient care and in turn positive physical health outcomes including higher sleep quality, for example. Thus, not only is feeling grateful important to well-being but receiving thanks from others benefits one's physical health as well. Study 2 extended research describing the impact of the dynamic and fluctuating nature of emotion and physical health to close relationships by examining how positive affect variability (intra-individual standard deviation) and instability (differences between each successive day's mood) promotes or hinders intimacy. The second study found that greater fluctuations in positive affect over time were associated with greater
\end{abstract}


reports of closeness within military couples. Recent research indicates that variability in positive and negative mood contributes to reduced psychological and physical wellbeing; however, when applied to the study of close relationships, Study 2 suggests that variation in positive mood may instead benefit military couples. Finally, Study 3 investigated the degree to which affectionate touch enhances the interrelationships among negative event support, gratitude, and sleep within Veterans and their partners over time. Results offer limited support; however, one key finding indicates that Veteran daily reports of affectionate touch were associated with increased sleep quality for their spouses. In addition, Veteran reports of affectionate touch strengthened the degree to which spouses' perceived responsive support predicted Veteran grateful mood. Study 3 supports research showing that positive interactions with one's partner, such as physical touch and responsive support, contribute to sleep and positive relationship maintenance emotions, such as gratitude. Taken together, these studies offer support for the integral role our social connections play in thriving, particularly within the contexts of nursing and military relationships. 


\section{ACKNOWLEDGEMENTS}

I would like to recognize my committee for their incredible support, guidance, and thoughtful insights along my dissertation journey. I am especially grateful for my graduate advisor, Cynthia Mohr, for her constant support. Thank you for encouraging me to aim high and for teaching me to celebrate the small and big wins! I would also like to thank Todd Bodner, Leslie Hammer, and Jeffrey Robinson. You have all contributed to my growth and scholarship. I am grateful for the chance to work with you all on this project and to learn from you.

Thank you to the SERVe and ONRP teams for your drive and setting the standard for high quality research collaboration.

To my cohort and labmates, thank you for the giggles, silliness, and advocacy that got me through the challenges of grad school. You all inspire me to be a better researcher and friend every day!

To my family, parents (Andrea and Fred), sister (Marcella), dearest friend (Ali), and partner (Peter) thank you for your love, patience, and fierce support. Your understanding and care has set the example of what responsive support looks like in my life. Thank you for helping to lighten my load and brighten my days!

I would also like to thank the U.S. Veterans, their families, and nurses nationwide and abroad for your sacrifice, service, and allowing me a glimpse into your everyday life.

Thank you to all those mentioned here and many more who have helped me to thrive. 
Table of Contents

ACStract

CHAPTER I. INTRODUCTION ..................................................................................

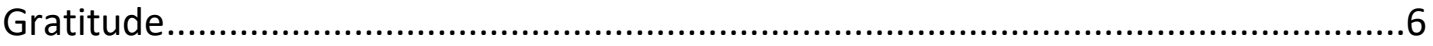

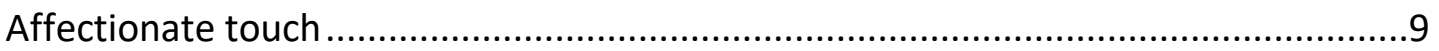

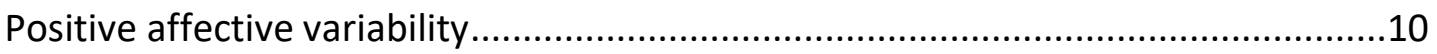

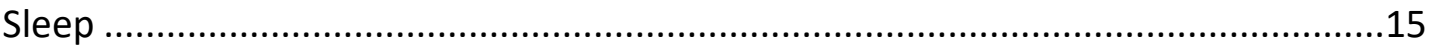

Present Investigation ............................................................................................. 16

Chapter II Overview: Gratitude reception and physical health: Examining the mediating role of satisfaction with patient care in a sample of acute care nurses . 20 Chapter III Overview: Positive affective variability and intimacy in military-

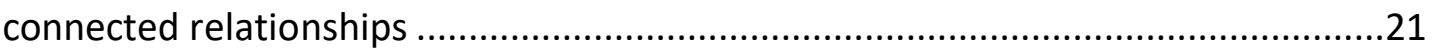

Chapter IV Overview: Relational thriving in military relationships: The role of

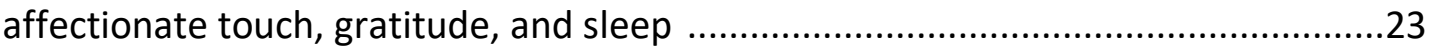

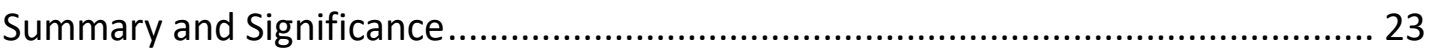

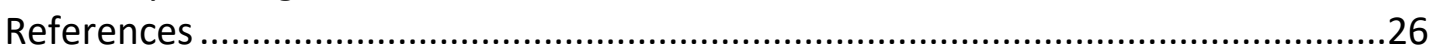

CHAPTER II. MANUSCRIPT I. Gratitude reception and health: Examining the mediating role of satisfaction with patient care in a sample of acute care nurses......................... 46

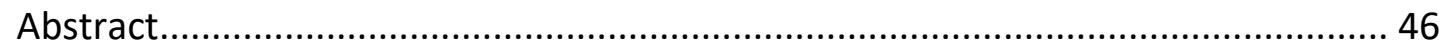

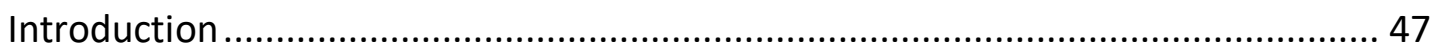

The indirect relation of gratitude and physical health .................................... 48

Gratitude, satisfaction, and physical health in the context of nursing................. 51

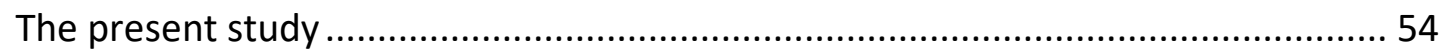

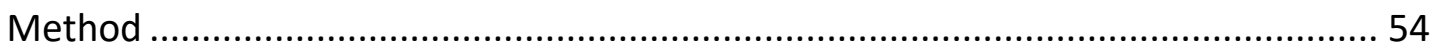

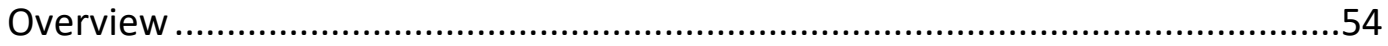

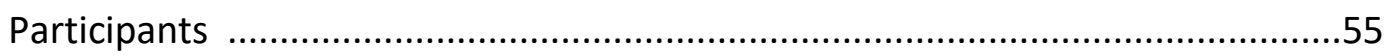

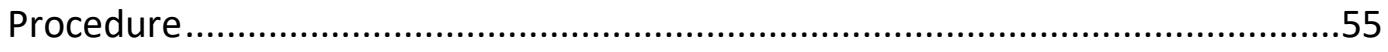

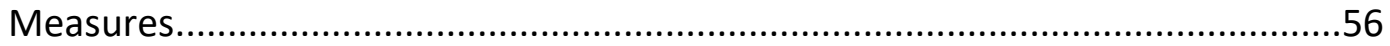

Physical health outcomes .............................................................. 56

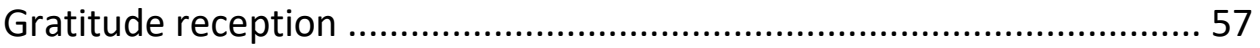

Satisfaction with quality care ......................................................... 57

Demographic and covariate information.......................................... 57

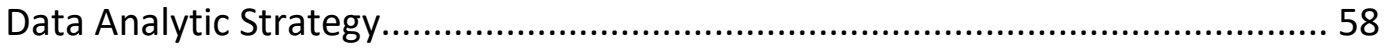

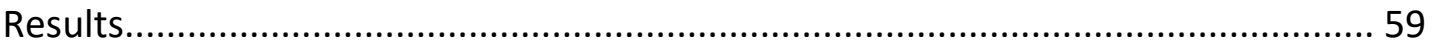




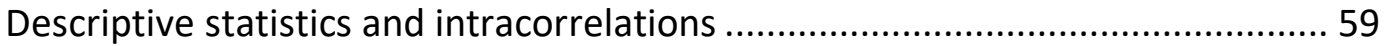

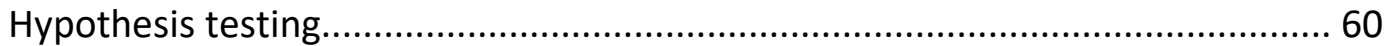

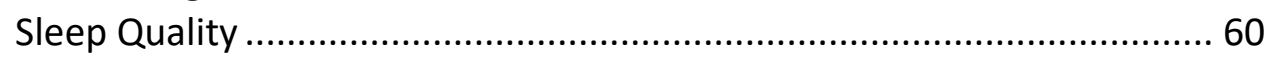

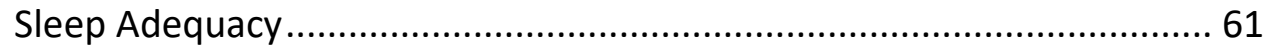

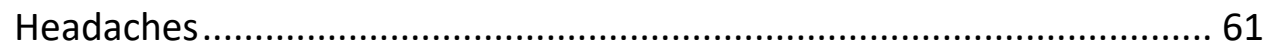

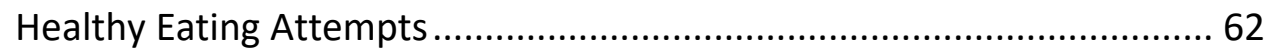

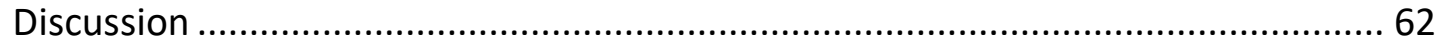

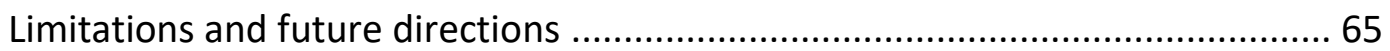

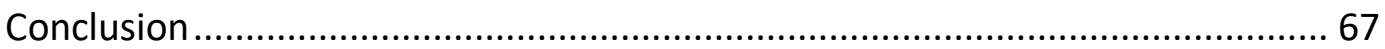

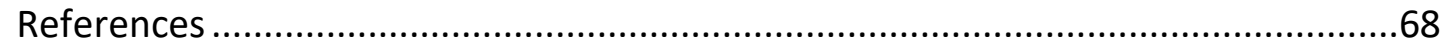

CHAPTER III. MANUSCRIPT II. POSITIVE AFFECT VARIABILITY AND INTIMACY IN MILITARY

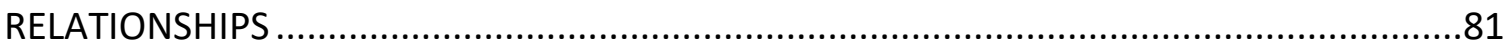

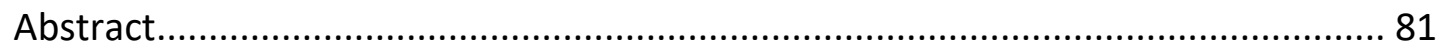

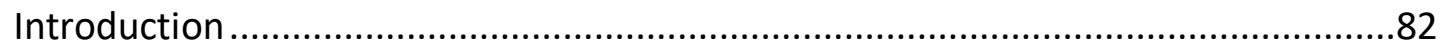

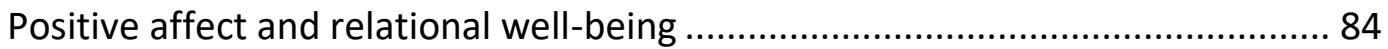

Positive affect dynamics and intraindividual variability .................................. 87

Emotion dynamics in intimate relationships ................................................. 91

Military-connected relationships and relationship outcomes ........................... 92

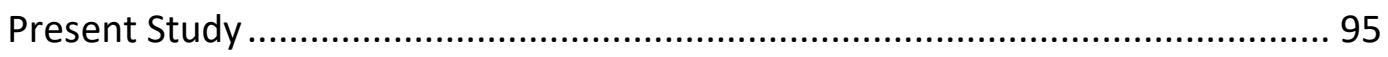

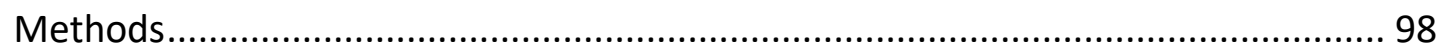

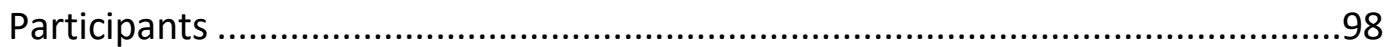

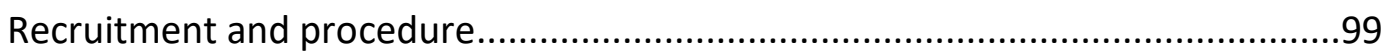

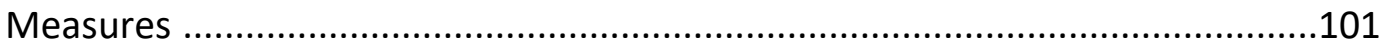

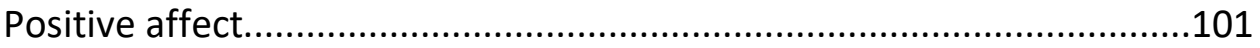

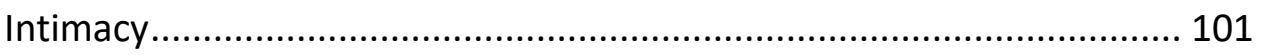

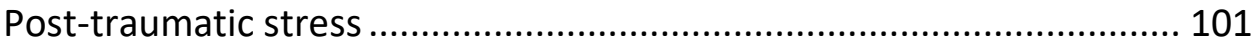

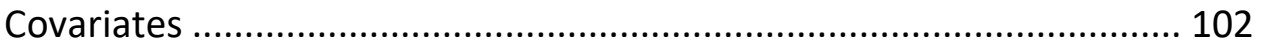

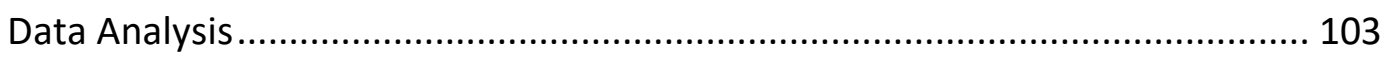

Preprocessing of affective data ....................................................... 103

Preliminary analysis ...................................................................... 104

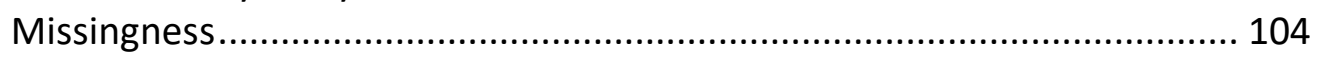

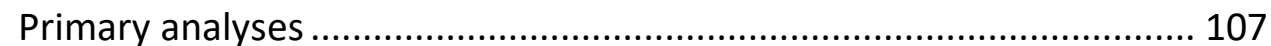

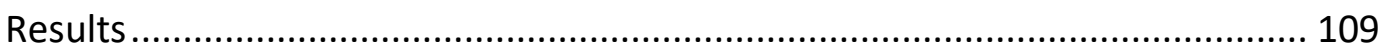

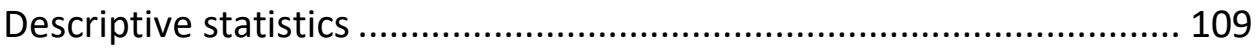

Primary analyses ...................................................................... 110

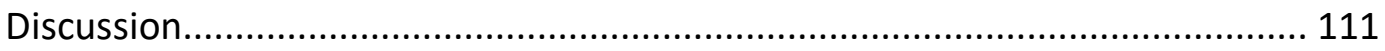

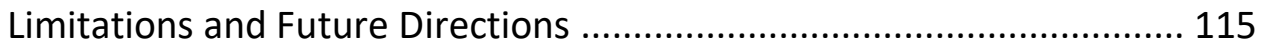

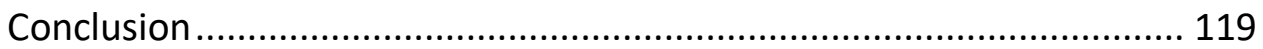

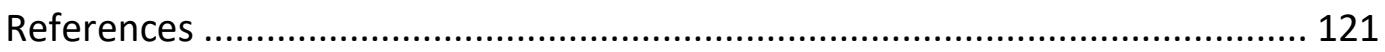


CHAPTER IV. MANUSCRIPT III: RELATIONAL THRIVING IN MILITARY RELATIONSHIPS: THE

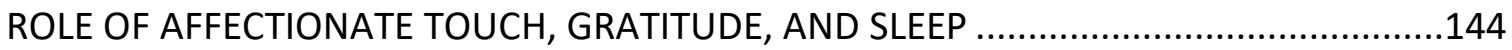

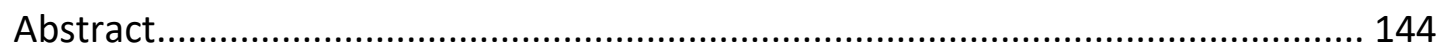

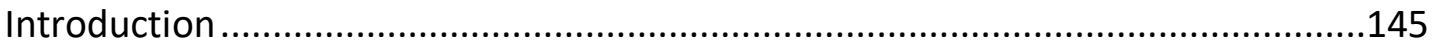

Responsive support, gratitude, and affectionate touch ...................................146

Gratitude, affectionate touch, and sleep.................................................... 151

Military-connected relationships and sleep .................................................154

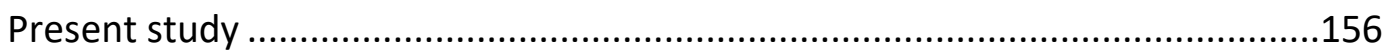

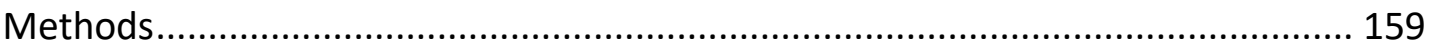

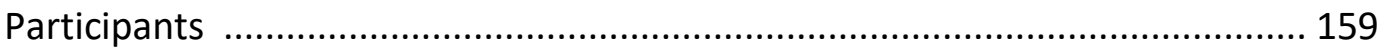

Recruitment and Procedure ...................................................................... 159

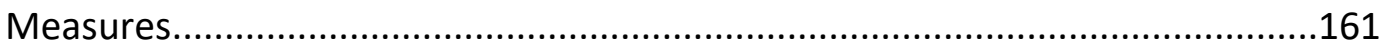

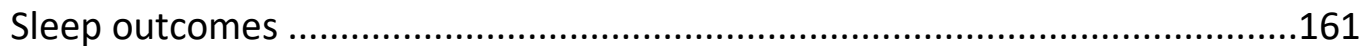

Grateful mood, positive and negative affect.......................................162

Affectionate touch .....................................................................................163

Perceived responsiveness to negative events .....................................163

Demographic variables and covariates ...................................................... 164

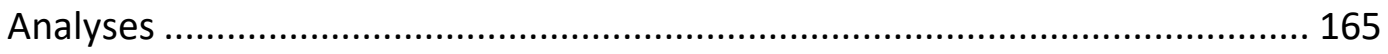

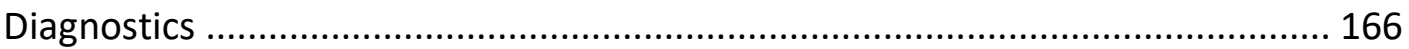

Non-independence ......................................................... 166

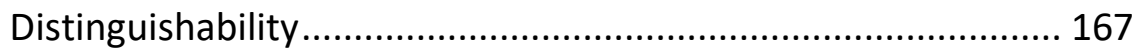

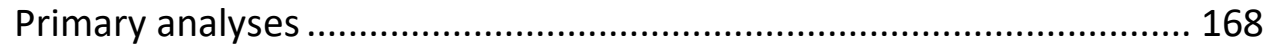

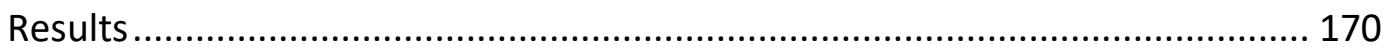

Descriptive statistics ................................................................ 170

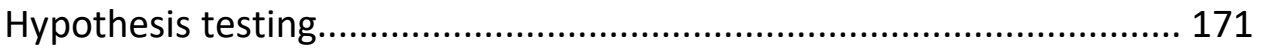

Sleep outcomes ............................................................. 171

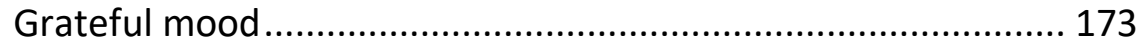

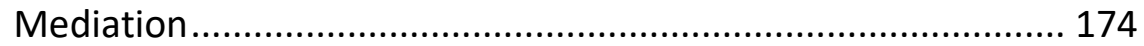

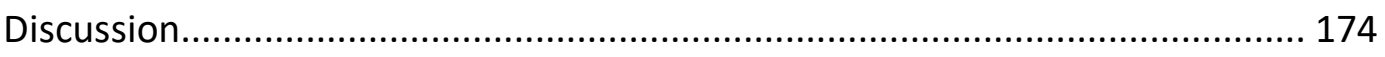

Limitations and Future Directions ................................................. 177

Support for interventions .............................................................. 184

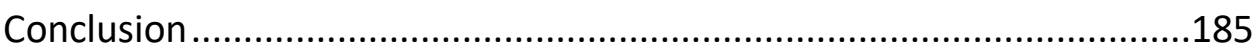

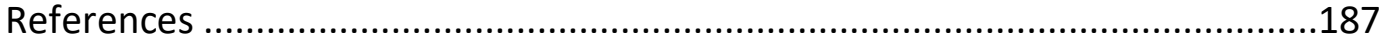

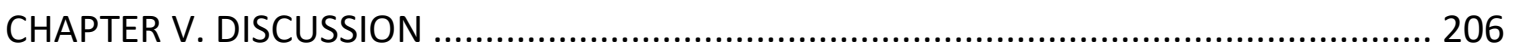

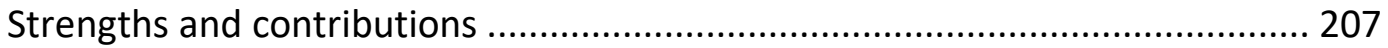

What have we learned about thriving through social connections?................. 211

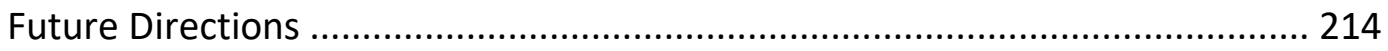

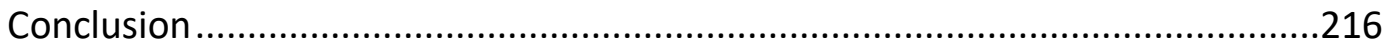

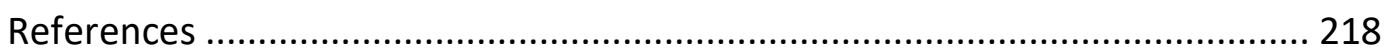




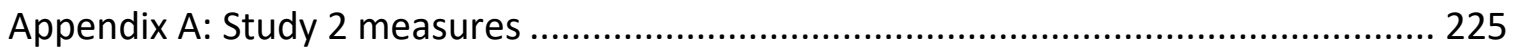

Appendix B: Study 3 measures 


\section{Chapter II}

List of Tables

Table 2.0: Descriptive statistics, intraclass correlations, and bivariate aggregated and weekly correlations

Table 2.1: Multi-level mediation models predicting sleep quality, sleep adequacy, headaches, and eating healthy

Chapter III

Table 3.0: Descriptive statistics and bivariate correlations aggregated across days and within couples

Table 3.1: Multilevel random intercept models predicting person-level intimacy ... 139 Chapter IV

Table 4.0: Veteran, spouse, within-couple correlations and descriptive statistics among study variables aggregated across 32 days.

Table 4.1: Summary of over time actor-partner interdependence model (APIM) multilevel regression coefficients predicting sleep and grateful mood 
Chapter I

\section{List of Figures}

Figure 1.0: Thriving through relationships conceptual model ........................... 44

Figure 1.1: Model of interpersonal processes involved in responsive support ... 45 Chapter II

Figure 2.0: Multilevel structural equation model with fixed slopes predicting physical health outcomes ............................................................................. 80 Chapter III

Figure 3.0: Scatterplot of positive affect (PA) intraindividual standard deviation (iSD) and post-traumatic stress symptoms (PTSS)

Figure 3.1: Scatterplot of weekly positive affect (PA) intraindividual standard deviation (iSDw) and post-traumatic stress symptoms (PTSS)

Figure 3.2: Scatterplot of positive affect (PA) mean square of successive differences (MSSD) and post-traumatic stress symptoms (PTSS)

Chapter IV

Figure 4.0: Conceptual model for actor-partner interdependence moderated mediation model over time 


\section{CHAPTER I: INTRODUCTION}

Meaningful social relationships are critical for survival. Social connection helps satisfy the basic human need of belonging (Deci \& Ryan, 2000) and promotes psychological and physical well-being (Holt-Lunstad, Smith, \& Layton, 2010; Robles, Slatcher, Trombello, \& McGinn, 2014; Uchino, 2006). For example, close relationships increase one's chance of survival by $50 \%$, which is a similar magnitude of mortality risks related to smoking, alcohol use, and obesity (Holt-Lunstad, Smith, \& Layton, 2010). However, the mechanisms through which relationships promote health and well-being are not clearly defined (Pietromonaco \& Collins, 2017). Greater delineation of these processes will help researchers understand how to optimize well-being. Furthermore, in addition to needing others to survive, we need others to thrive.

Thriving is a multidimensional construct signifying personal and relational growth and prosperity. Dimensions of thriving include subjective or hedonic well-being (e.g., happiness), eudaimonic well-being (e.g., personal growth and goal striving), psychological (e.g., emotional), relational (e.g. high-quality relationships), and physical well-being (e.g., sleep and reduced susceptibility to disease; Diener et al., 2010; Feeney \& Collins, 2015; Ryff \& Singer, 1998, 2000; Seligman, Steen, Paker, \& Peterson, 2005). Thriving is thought to be on a continuum, and individuals may be flourishing in some domains but less so in others (Feeney \& Collins, 2015). While social connection is an important component to thriving, current theoretical perspectives suggest that relationships also serve important functions to promote flourishing. As Feeney and 
Collins (2015) describe in their theoretical model of relational thriving (see Figure 1.0), relationships are a "source of strength" when facing stressful experiences and are also a "relational catalyst" for exploration, creativity, and personal growth in the absence of adversity.

Drawing on dominant theoretical perspectives in relationship science, the relational thriving model posits that thriving is a function of interpersonal processes (see Figure 1.1) such that interactions with one's close relationship partner promotes personal growth through pursuing new opportunities and providing fortification during life's trials, leading to long-term thriving (Feeney \& Collins, 2015). Positive interactions with one's partner help to savor success and lead to greater personal and relational well-being, serving a relational catalyst $(\mathrm{RC})$ function. An example of a relational catalyst process is capitalization, or the sharing of good news with one's partner and their supportive response, which promotes seeking new experiences and opportunities (Gable et al., 2004). Conversely, a partner's supportive interactions during a stressful experience that helps one to buffer negative consequences describes using the partner's support as a source of strength (SOS) to promote thriving. For example, social support may help one to be resilient to life's stressors and support growth beyond adversity.

Both RC and SOS functions are supported by literature examining attachment theory, social support, broaden-and-build theory, and responsiveness, among others. For example, attachment theory suggests that people develop strong emotional bonds with caregivers (Bowlby 1969/1982), such as one's romantic partner. Within the 
attachment system, individuals develop expectations about whether support from one's caregiver will be there when they need it. Therefore, caregivers provide a safe haven for individuals that helps restore feelings of security when experiencing adversity. In addition, attachment theory also posits that felt security allows us to explore our environment and participate in new opportunities. Thus, caregivers also serve as a secure base for personal growth (Feeney, 2004). Similarly, when experiencing distress, social support literature hypothesizes that caregiver support may directly affect individual's health and well-being by increasing positive affect, stability and recognition of one's self-worth within close relationships (main effect hypothesis), as well as by reducing the negative impact of stress when partners are perceived to be available (stress buffering hypothesis; Cohen \& Willis, 1985). Furthermore, partner support in the absence of adversity can increase well-being through positive emotions that broaden life's opportunities and build positive resources that support resiliency to later adversity (Frederickson, 2001; Tugade \& Frederickson, 2004). Therefore, attachment theory, social support hypotheses, and the broaden and build theory each provide support for both SOS and RC functions.

Responsiveness is a key relationship mechanism that supports thriving during abundance (e.g., new opportunities; RC function of thriving model) as well as scarcity (e.g. adversity; SOS function). Responsiveness is defined as the degree to which one feels understood, validated, and cared for by one's partner (Reis \& Gable, 2015), and whether they are validating, caring, and understanding of one's partner in return (Clark 
\& Lemay, 2010). Good caregivers within attachment theory, for example, are those who are perceived to be responsive to one's needs whether that may be by providing a secure base for personal growth or a safe haven during life's stressors (Feeney, 2004). Perceived partner responsiveness plays an integral role in capitalization interactions, for example, helping one's partner to savor their good news by responding with enthusiasm (Gable, Reis, Impett, Asher, 2004), as well as restoring security during life's stressors (Feeney, 2004). Likewise, both enacted responsive support and perceived responsiveness are related to increased daily intimacy in couples (Debrot, Cook, Perrez, \& Horn, 2012).

Relationship scientists argue that responsiveness is not a characteristic of the individual, but rather is relationship-specific. For example, responsiveness is a process based in the context of each partner's enduring traits (e.g., personalities) as well as the history of interactions with close others that develops in a unique relational context (Clark \& Lemay, 2010). Gable and Reis (2015) describe responsiveness as, "a fundamentally interpersonal process with intrapersonal origins and consequences" (p. 67), and thus allows us to understand individuals through relationships. For example, Partner A's goals, desires and needs contribute to their intended and expressed responsive behaviors to Partner B. Similarly, Partner B's goals, desires, and needs influences their perception of Partner A's behavior. Therefore, responsiveness supports both intrapersonal and interpersonal well-being processes, such that individuals may thrive through relationships. 
There are several immediate outcomes of responsive support (both RC and SOS) that may lead to thriving over time, including emotional states, healthy life-style behaviors, relational outcomes, and situation-relevant outcomes, to name a few. For example, increased positive emotions and decreased negative emotions tend to accompany responsive support from one's partner (e.g., Collins et al., 2014). Responsive support may also predict health behaviors such as sleep quality. For example, Jakubiak and Feeney (2016a) found that secure base support (i.e., supporting exploration) predicts decreased physical symptoms (e.g., pain, nausea, dizziness) indirectly through personal growth outcomes such as efforts to progress towards one's goals. In addition, goal progress similarly mediated the relationship between responsive support and psychological and relational well-being including, increased positive emotions and relationship quality. Responsive support may lead to immediate outcomes relevant to the situation such as rebuilding of personal resources after adversity and producing a high-quality outcome. For example, those who receive responsive support report increases in positive affect and life satisfaction (Gable et al., 2004), and people with romantic partners who supported exploration during a lab activity showed increased performance and persistence (Feeney \& Thrush, 2010).

It is important to note that support must be appropriate for the situation and partners' needs. Support that is insensitive to the partner's needs or inappropriate for the situation may be ineffective (Collins \& Feeney, 2000) and result in reduced wellbeing (Monin, Feeney, \& Schulz, 2012). Therefore, optimal well-being may be nuanced 
by the individual characteristics, behaviors, or contexts of support. This is consistent with literature describing the negative influence that relationships have on health when a partner is experiencing mental and physical health challenges (Kiecolt-Glaser \& Wilson, 2017).

This dissertation focuses on specific short-term intrapersonal and interpersonal processes that are theorized to contribute to long-term thriving, or lack thereof. For example, this work examines emotional states, health outcomes, relational and situational outcomes that Feeney and Collins (2015) propose to be involved in supporting thriving. Specifically, I investigated the roles of gratitude, affectionate touch, positive affect, and sleep in intrapersonal and interpersonal well-being within work and relationship contexts.

\section{Gratitude}

Gratitude is an affective state that results when an individual acknowledges that they have (a) experienced a positive outcome, and (b) that the benefit is due to an external source (Emmons \& McCullough, 2003). Gratitude can be conceptualized as "benefit-triggered" gratitude as well as "generalized" gratitude (Lambert, Graham, \& Fincham, 2009). For example, benefit-triggered gratitude is an interpersonal process in which an individual attributes his or her positive benefit to an action by another person (e.g., "I am grateful that my partner got up early to walk the dog and let me sleep"), while general gratitude is a global feeling of appreciation in one's life (e.g., "I am grateful for my partner"). While benefit-triggered conceptualizations of gratitude 
describe an interpersonal process, general gratitude describes an intrapersonal process that includes dispositional definitions of gratitude, such as individuals who tend to have a grateful outlook on life (Wood, Froh, \& Gaerty, 2010).

Literature indicates the well-being benefits of both benefit-triggered and general gratitude (Emmons \& McCullough, 2003; McCullough, Kilpatrick, Emmons, \& Larson, 2001; Wood, et al. 2010). For example, general gratitude has been associated with increased positive moods, coping, physical symptoms, and sleep quality (Emmons \& McCullough, 2003) as well as both hedonic and eudaimonic daily well-being (Nezlek, Newman, \& Thrash, 2017). A gratitude intervention in which individuals wrote a letter of appreciation to a close other about a specific benefit they experienced (i.e., benefittriggered gratitude) predicted increased life satisfaction and well-being over time (Boehm, Lyubomirsky, \& Sheldon, 2011). Furthermore, gratitude is theorized to support personal (Armenta, Fritz, \& Lyubomirsky, 2017) and social growth (Algoe, 2012). For example, Armenta and colleagues (2017) suggest that benefit-triggered gratitude promotes self-improvement via key mechanisms such as connectedness to others, feeling uplifted or experiencing an upward spiral of thoughts and feelings, among others. Likewise, gratitude is a bonding agent and builds closer relationships through increased feelings of responsiveness and affection (Algoe, 2012).

While much of the early work on gratitude focused on exchange motivations underlying the emotion, such as supporting reciprocity norms and prosocial behaviors (McCullough et al., 2001), current theoretical perspectives contend that the functions of 
gratitude are relational in nature and extend beyond purely reinforcing reciprocity norms. Algoe (2012) argues that at the core, gratitude functions to promote feelings of responsiveness in daily life. According to the find-remind-and-bind theory of gratitude (Algoe, Haidt, \& Gable, 2008), gratitude begins with a unique relational appraisal of a social situation. When people experience a benefit and attribute their benefit to another person (the key ingredients to promoting gratitude responses), this provides information about one's interpersonal relationship: it signals a social tie. Specifically, gratitude helps to find new relationship partners, or reconnect with current relationship partners and to strengthen these relationships through increased feelings of responsiveness, such as feeling cared for, validated, and understood. Thus, gratitude is a positive emotion that engenders social growth. Therefore, in close relationships, gratitude is one distinct affective experience theorized to be a direct outcome of both source of strength and relational catalyst functions of thriving in relationships (Feeney \& Collins, 2015).

Of import, the social benefits of gratitude often require the expression of such emotion (Algoe \& Stanton, 2012). For example, the mere expression of gratitude signals a communal relationship (i.e., characterized by mutual responsiveness and assuming responsibility for a partner's welfare; Clark, Armentano, Boothby, \& Hirsch, 2017) between the expresser and benefactor (Lambert, Clark, Durtschi, Fincham, \& Graham, 2010). When examined interpersonally, gratitude expressions support feelings of responsiveness for both interaction partners (e.g., benefactor and beneficiary; Algoe \& 
Zhaoyang, 2016). In this way, both the individual experience of gratitude as well as the expression of gratitude to another are important for well-being of individuals and relationship partners.

\section{Affectionate touch}

One characteristic of relationships that communicates positive emotion, reduces stress, and promotes resilience in couples is physical touch. For example, people can communicate distinct emotions such as gratitude, love, happiness, anger, fear and sadness from one second of physical contact with up to $83 \%$ accuracy (Hertenstein, et

al., 2006). Both giving and receiving responsive touch increases positive daily mood and deceases negative mood above and beyond level of intimacy in romantic relationships (Debrot, Schoebi, Perrez, \& Horn, 2013). Ditzen and colleagues (2007) found that touch significantly lowers cortisol and heart rate compared to verbal support. Further, touch from one's partner protects against maladaptive emotion regulation such as suppression (Debrot, Schoebi, Perrez, \& Horn, 2014). Therefore, affectionate touch is a powerful tool for communicating emotion, including gratitude, and promoting relational, psychological, and physical well-being. Jakubiak and Feeney (2017) proposed a theoretical model of affectionate touch receipt arguing that affectionate physical contact in romantic relationships improves psychological, relational, and physical well-being directly from relational-perceptions as well as indirectly through stress buffering mechanisms. For example, affectionate touch from one's partner signals social inclusion and promotes relational-cognitive changes 
such as felt security and responsiveness. Indeed, research indicates that when people experience affectionate touch, they feel more secure (Jakubiak \& Feeney, 2016b), cared for and understood by their partners (Debrot et al., 2013). Touch is theorized to "get under the skin" to predict health in relationships (e.g., Field, 2010; Sbarra \& Hazan, 2008). Cohen, Janicki-Deverts, Turner, and Doyle, (2015) showed that when people receive more hugs they had less susceptibility to cold infection and less severe symptoms if they were infected with the cold. Further, hugs showed stress-buffering effects by attenuating the degree to which interpersonal conflict contributed to cold infection. In addition, simply imagining touch support from one's partner predicts decreased stress responses to a greater degree than imagined verbal support (Jakubiak \& Feeney, 2016c). Taken together, this evidence suggests that the influence of touch in relational interactions can serve as a source of strength in times of stress and a relational catalyst for personal growth through feelings of responsiveness and relational security.

\section{Positive affective variability}

As noted above, positive affect is theorized to be an immediate outcome of responsive support and promotes long-term thriving (Feeney \& Collins, 2015). In fact, positive affect is widely considered one component of subjective well-being (e.g., hedonic well-being; Deiner, Suh, Lucas, \& Smith, 1999) and has important implications for physical health in addition to relationship outcomes. Furthermore, positive affect builds psychological and social resources (Frederickson, 2001). For example, positive 
emotions help people form and maintain intimate relationships (Shiota, Campos, Keltner \& Hertenstein, 2004), promote relationship satisfaction (Lyubomirsky, King, \& Deiner, 2005), encourage positive relationship maintenance behaviors (Gable et al., 2004), and increased intimacy (Debrot et al., 2013).

While increased positive affect seems to benefit well-being for individuals as well as relationships, an existing body of work indicates that positive affect may have some limitations. For example, high levels (e.g., at the $75^{\text {th }}$ percentile) of positive affect is linked to risky behavior (Martin et al., 2002) and poor psychological health (Diener, Colvin, Pavot, \& Allman, 1991). Likewise, high intraindividual variability in positive mood, or the degree to which a person fluctuates in positive mood around their average level, is associated with poor physical and mental health. For example, high positive affect variability predicts lower life satisfaction, and higher depression and anxiety (Gruber, Kogan, Quoidbach, \& Mauss, 2013), decreased eudaimonic well-being (e.g., personal growth; Houben, Van Den Noortgate, \& Kuppens, 2015), greater chronic health conditions (Chan, Zhang, Fung, \& Hagger, 2016), increased alcohol consumption (Mohr, Arpin, \& McCabe, 2015), and unfavorable hypothalamic-pituitary-adrenal axis functioning, a key health indicator (Human et al., 2015). Furthermore, affective variability may be a risk factor for subsequent psychological distress (van de Leemput et al., 2014).

Intraindividual variability refers to the, "relatively short-term changes that are construed as more or less reversible" (Nesselroade, 1991, p. 215). For example, a person 
may vary in feelings of happiness from day to day in which they experience greater feelings of happiness on one day than they felt before and feel less happiness on the following day. The most common measure of within-person variability is estimated by calculating an intraindividual standard deviation (iSD) of a construct over time. This metric assumes that time is unstructured; in other words, iSD measures variability across all repeated measures and does not capture situational information, creating a summary score of overall variability in a single construct. Therefore, researchers distinguish the iSD approach as essentially measuring an individual's characteristic level of lability, or their capacity to change compared to other process-oriented variability (e.g., variability that includes temporal or situational information; Ram \& Gerstorf, 2009). In other words, within-person variability theoretically demonstrates the degree of person-level variation, while dynamic processes demonstrate how variation is happening within people over time. Each conceptualization has merit depending on the phenomenon of interest; in this case, individual variability in positive affect is of focus in the present investigation.

Affective scientists who examine variability in emotions, also referred to as emotion dynamics, define this metric of variability as describing the degree to which an individual is characteristically sensitive to emotional appraisals (Kuppens \& Verduyn, 2015). For example, a person with low variability in positive affect may indicate that they are generally not as susceptible to feelings of happiness below or beyond their average level, while high positive affect variability may indicate that a person is very 
susceptible to the highs and lows of happiness emotional responses. Therefore, positive affective variability measures the degree to which an individual is sensitive to positive emotional appraisals that they encounter across all situations and times. Researchers argue that while this depiction of variability does not specifically examine the process of emotional changes across time, such as emotion regulation, this approach lays a foundation for regulation (Kuppens \& Verduyn, 2015). In other words, an individual's characteristic amount of variability in positive mood describes the emotive landscape within which regulatory processing must function.

However, how is affective variability relevant to thriving through relationships? Emotions are key to forming our relationships and relationships shape our emotions (Schoebi \& Randall, 2015). For example, the disclosure of emotions helps build intimacy with others. According to Reis and Shaver's (1988) interpersonal model of intimacy, by expressing emotions (whether explicitly or subtlety), we allow others to know our inner self which is conceptualized as an affective core that develops over time. Furthermore, affective expression allows one's interaction partner the opportunity be responsive in a way that communicates care, understanding, and validation. Over time, responsiveness to emotional disclosures builds intimacy within relationships. Further, relationship partners over time display coordinated emotional patterns such as affective synchrony and co-regulation, which may have immediate and downstream effects on health and well-being (Saxbe \& Repetti, 2010; Sbarra \& Hazan, 2008; Slatcher \& Schoebi, 2017). However, emotional interdependence may not characterize all relationships; rather, 
couples may be more or less emotionally interdependent with each other. For example, when couples are emotionally interdependent in their day-to-day lives, they report more life satisfaction; however, this effect is not found when couples display more independent emotional patterns (Sels, Ceulemans, Bulteel, \& Kuppens, 2016). Taken together, theory and empirical evidence suggests that emotions must be examined within the context of relationships. Yet it is unclear how patterns of positive affect variability promote or hinder relational well-being.

To reiterate, sensitivity to positive affective appraisals, measured by variability, may be a vulnerability for individual well-being, while sensitivity to one's partner's emotions and needs is important for responsive support and building intimacy. Slatcher and Schoebi (2017) argue that individuals who have higher emotional variability may benefit from a partner who is sensitive to their emotions but also emotionally expressive themselves. Therefore, variability in positive affect is necessary for responsiveness to occur; on the other hand, highly variable positive affect or very little positive affect variation may be considered inappropriate for the situation or unresponsive to one's partner. This lends itself to examining ways in which positive affect variability may be optimal compared to fragile within the context of intimate relationships. In sum, this literature suggests that high positive affect may not be synonymous with optimal positive affect. Rather, positive affect is nuanced and additional work must examine what may differentiate the people, relationships, or contexts in which positive affect promotes or hinders relational well-being. 


\section{Sleep}

According to the thriving model, another immediate outcome of responsive support is healthy lifestyle behaviors, including sleep. Sleep is critical to health and wellbeing, and is associated with a multitude of health outcomes such as obesity, cardiovascular health, accident risk, among others (for reviews see Itani, Jike, Watanabe, \& Kaneita, 2017; Luyster, Strollo, Zee, \& Walsh, 2012). Sleep literature tends to examine sleep as an individual process; however, the majority of adults share a bed with their romantic partner (National Sleep Foundation, 2013). Therefore, sleep has been conceptualized as a dyadic behavior in which sleep duration and quality, for examples, covary between partners (Lee et al., 2017).

Based on this more ecologically valid conceptualization of sleep, Troxel, Robles, Hall, and Buysse (2007) argue that sleep is fundamentally a part of the attachment system. For example, high quality sleep requires the down-regulation of arousal and a general a sense of security and comfort. Based on empirical evidence, the authors propose a theoretical model of the bidirectional relationship between sleep and relationship quality among adults. Research indicates that poor sleep predicts increased relationship conflict (Chen \& Gordon, 2014). Further, couples with higher relationship satisfaction tend to show a reduced risk of sleep problems as well as better sleep quality (Ko, Chen, Wang, \& Su, 2014; Troxel, Buysse, Hall, \& Matthews, 2009). Troxel and colleagues (2007) suggest that this bidirectional relationship may be explained through psychological, physiological, and behavioral mechanisms. For example, specific 
relationship behaviors or interactions may promote sleep through psychological processes, such as emotions. One recent example from Selcuk, Stanton, Slatcher, and Ong (2017) suggests that perceived partner responsiveness predicts lower sleep problems via reduced anxiety and depression symptoms. Furthermore, specific relationship behaviors may have an independent effect on sleep outcomes in couples. Kane, Slatcher, Reynolds, Repetti, and Robles (2014) found that couples who tended to disclose their thoughts and feelings to their partner before bed had better self-reported and physiological assessments of sleep outcomes, even after accounting for relationship satisfaction. This evidence supports the thriving model in that it describes the immediate health outcomes of relationship maintenance behavior and emphasizes the importance of examining health, well-being, and psychological mechanisms within a relational context.

\section{Present Investigation}

In order to optimize well-being, researchers have begun focusing their attention on the key mechanisms through which relationships influence health and encourage thriving (Feeney \& Collins, 2015; Pietromonaco \& Collins, 2017). However, a thorough understanding is needed of the specific behaviors and processes of relationship functioning that support thriving, namely gratitude, affectionate touch, and positive affect variability, and the unique contributions of one's personal context to thriving, such as one's occupational experiences or interdependent relationship. I examine thriving within the context of nursing work and military relationships. 
Both samples offer unique opportunities to study thriving. For example, nurses are the largest group of health care professionals in the United States (U.S. Department of Labor, 2018), and are embedded in the delivery of healthcare services often interacting with patients, patients' families, colleagues, and other health professionals to accomplish job tasks. Therefore, nursing work requires a great deal of interpersonal interaction in routine as well as "high-stakes" work situations. Unsurprisingly, nursing work is demanding and the profession is associated with high risk of burnout (Aiken et al., 2002) as well as increased pressures related to aging populations, and greater expectations regarding quality of care (Aiken et al., 2012). Nurses' burnout is associated with negative outcomes for themselves as well as their patients. For example, higher rates of burnout reported by health professionals is associated with lower quality of care and patient safety (Halbesleben \& Rathert, 2008). Indeed, nurses' higher job demands are related to poor sleep (Hasson \& Gustavson, 2010; Winwood \& Lushington, 2006), psychosomatic symptoms such as headaches (Lin, Huang, \& Wu, 2007), poor nutrition (Tucker, Harris, Pipe, \& Stevens, 2010), and lower job satisfaction (Cho, Park, Jeon, Chang, \& Hong, 2014). On the other hand, nurses report that the most satisfying parts of their job is interacting with patients and fellow nurses (Adams \& Bond, 2000; Newman \& Maylor, 2002). Therefore, nurses may experience positive outcomes related to social interactions in their workplace that help build resources that support thriving beyond demanding work conditions. 
U.S. military service is another occupation associated with high job demands, especially in relation to deployment. Since 2001, almost 3 million military service members have been deployed in service of Operation Enduring Freedom (OEF), and Operation Iraqi Freedom (OIF), and Operation New Dawn (OND; Wenger, O'Connell, \& Cottrell, 2018). Military couples report experiencing adversity related to deployments and post-deployment reintegration. For example, couples may experience stress related to household and parenting challenges and concerns about their Veteran partner's safety (Segal, 1989; Warner, Appenszeller, Warner, \& Grieger, 2009). During the reintegration period upon return from deployment, couples report difficulty getting back into a routine (Knoblach \& Theiss, 2012) and trouble rekindling intimacy and closeness (Bowling \& Sherman, 2008). Post-deployment challenges may be more severe when couples face mental health concerns as result from combat experiences, including depression, anxiety, and post-traumatic stress disorder (PTSD; Allen, Rhoades, Stanley, \& Markman, 2010; Goff, Crow, Resibig, \& Hamilton, 2007; Renshaw \& Campbell, 2017). It is important to note, however, that the stressors that military couples report do not necessarily translate into relationship decline and dissolution. For example, Karney and Crown $(2007,2012)$ show that military marriages are not dissolving at a higher rate than civilian marriages. A recent study found that when accounting for combat exposure, PTSD symptoms, and other military demographics, marital satisfaction was reduced for couples in which the Veteran had never deployed compared to couples in which Veteran partners had undergone multiple deployments (Karney \& Trail, 2017). In other 
words, while initial deployments may have a negative impact on relationships, subsequent deployments may not have the same effect for military couples. This research indicates that deployment and military service in general is not necessarily a "home wrecker", but rather military-connected relationships may endure and be strengthened over time. Therefore, intimate relationships in which one member is serving or has served in the armed forces may be able to uniquely inform the ways in which relationships support thriving through adversity.

While nursing tends to be associated with high rates of burnout and retention problems (Aiken et al., 2002), the sample collected for Study 1 was currently employed nurses working in acute care medical facilities and has an average occupational tenure of 14 years. Likewise, whereas some Veterans may face employment and mental health challenges, the Veterans sampled in Studies 2 and 3 are employed at least part time and the majority have been separated from the military though some are still actively serving in the National Guard and Reserves. When considering relational thriving within this sample, the majority of the couples were married (see Hammer, Wan, Brockwood, Mohr \& Carlson, 2017) and report being in a romantic relationship together for about 12 years. Thus, these samples are composed of group members who have most likely experienced adversity associated with their group, such as combat exposure for military Veterans and symptoms of burnout for nurses, but have endured. This provided an opportunity to study resources that nurses and military couples draw upon to thrive in their respectively unique contexts. 
Overview of Chapter II: Gratitude reception and physical health: Examining the mediating role of satisfaction with patient care in a sample of acute care nurses

The first study is a manuscript in press at the Journal of Positive Psychology. This study is part of the Oregon Nurse Retention Project that partnered with a professional nursing organization to learn more about nurses' work experiences. Using a longitudinal weekly assessment of nurses' work events, Study 1 examined mechanisms that contribute to health and well-being such as receiving expressions of gratitude. Specifically, this study targets an under-examined piece of gratitude interactions and its effect on health: how receiving expressions of gratitude predicts physical well-being through intrapersonal resources, such as satisfaction with the quality of care one provided. Until recently, gratitude has been studied as an individual process that contributes to prosocial behaviors (McCullouth et al., 2001), health (Emmons \& McCullough, 2003), and well-being (Bohem et al., 2011), however, recent studies and theory emphasize that gratitude promotes well-being for both the expresser of gratitude as well as the person who is receiving the expressions (Algoe, 2012; Algoe \& Zhaoyang, 2016). For example, in romantic couples, partners who received gratitude expressions for a particular pro-relationship behavior report perceiving their partner as more responsive (Algoe, Frederickson, \& Gable, 2013). In addition, expressions of gratitude promote individual psychological resources (Algoe \& Zhaoyang, 2016). Therefore, this study examined whether nurses' weekly reports of receiving gratitude (e.g., from patients and coworkers) predicted increased resources, such as one's 
satisfaction with support provided, which in turn contributed to improved health outcomes such as sleep, headaches, and healthy eating.

\section{Overview of Chapter III: Positive affective variability and intimacy in military relationships}

Study 2 examined how intrapersonal emotion dynamics may extend to relational well-being within military service members and their romantic partners. Positive affective experiences tend to be related to better well-being (Fredrickson, 2001; Fredrickson \& Losada, 2005; Pressman \& Cohen, 2005). Although, some variability in positive affect can be expected day-to-day, greater lability in positive mood is associated with poor mental health (Gruber et al., 2013) and physical health outcomes (e.g., Hardy \& Segerstrom, 2017; Human et al, 2015). While affective scientists have demonstrated the association between emotional variability and psychological and physical well-being as well as the importance of studying the emotion dynamics within couples (e.g., Butler, 2015), few studies have examined how intraindividual affect dynamics predict relational-well-being in romantic partners. Furthermore, military-connected couples (e.g., those in which one partner is currently serving has served in the armed forces) may experience additional challenges with regards to emotion dynamics and psychological well-being (e.g., Price, Monson, Callahan, \& Rodriguez, 2006). For example, the degree to which positive affect variability affects how close Veterans and spouses feel to each other may depend on Veterans' post-traumatic stress symptoms. 
Study 2 examined how individual positive affect variability predicts withinperson average intimacy in Veterans and spouses. In addition, I hypothesized that the effect of positive mood variability on intimacy will vary as a function of the Veteran's post-traumatic stress symptoms. Literature examining emotion dynamics have somewhat conflicting conceptualizations of variability. For example, high variability may be maladaptive because the degree of positive mood is inappropriate for the situation or is emotionally taxing, whereas low variability when the situation calls for increased positive emotion may also be seen as inappropriate or unresponsive. Therefore, an additional aim of this study was to examine how positive affect fragility, or the degree to which individual's variability depends on higher or lower average levels of positive emotion, predicts intimacy in military couples. For example, a Veteran partner, Tim, may generally feel a high level of happiness, yet his feelings of happiness swing high and low day-to-day to a great degree (high average level, high variability). Tim's experience of swinging fluctuations in mood, may make it difficult to savor positive emotions and be emotionally taxing for Tim and Tim's partner, Jen, who attempts to console or capitalize with him, making it harder for Tim and Jen to feel close to each other. This study was based on literature examining positive affect variability and health outcomes (e.g., Human et al., 2015) as well as theoretical conceptualizations of emotion dynamics in individuals (Kuppens \& Verduyn, 2015; Ong \& Ram, 2017) and intimate relationships (Butler 2015; Schoebi \& Randall, 2015). 


\section{Overview of Chapter IV: Relational thriving in military relationships: The role of} affectionate touch, gratitude, and sleep

Drawing on the relational thriving model proposed by Feeney and Collins (2015), Study 3 aims to investigate the interpersonal effects of gratitude, affectionate touch, and sleep. Feeney and Collins (2015) theorize that feelings of gratitude are an immediate outcome of responsive support during adversity (e.g., source of strength) as well as life opportunity (e.g. relational catalyst), and thus is important to consider as a mediator of support responsiveness and health. However, for the purposes of this study, only key components of interpersonal processes (highlighted in Figure 1.1) within the source of strength arm of the relational thriving model (Figure 1.0) were of interest. In addition to gratitude, the quality of the provided support is particularly important within this model as well (Feeney \& Collins, 2015). As described by Shiota et al. (2017) affectionate touch serves several important functions including bonding, soothing, and providing rewards and, therefore, is critical in the study of romantic relationships. I examined the degree to which affectionate touch enhances the relation between negative event support, gratitude, and sleep within Veterans and their partners. To my knowledge, this is the first study to investigate the interdependence of both gratitude and affectionate touch and their role within relational thriving. Additional work is needed to evaluate how responsive support, affectionate touch, and gratitude improve health and well-being for military families.

\section{Summary and Significance}


These studies extend current literature in several ways. For example, Study 1 investigates how gratitude expressions predict health via individual resources. Gratitude literature has traditionally focused on the study of individual experiences of gratitude and subsequent health and well-being, while recent researchers have begun to examine how interpersonal expressions of gratitude not only contribute to personal well-being but the well-being of the person to which one is expressing their gratitude. Study 1 extends this literature by examining how people receiving gratitude expressions for help that they provided increases individual well-being and health. Furthermore, this study examines this process within a sample of acute care nurses who may face interpersonal and job-related challenges (Aiken et al., 2002).

Study 2 extends research on emotion dynamics, such as variability in positive mood, to specific relationship outcomes within romantic couples. This study helps to address calls for research on intraindividual variability and interpersonal contexts (e.g., Butler, 2015; Schoebi \& Randall, 2015). In addition, this work aims to examine these patterns within military couples and extend the work on affective variability and posttraumatic stress symptoms. Moreover, a recent meta-analysis indicated that the effect size of emotional variability on psychological well-being is similar to that of average levels of emotions (Houben, Van Den Noortgate, \& Kuppens, 2015). Given the pervasiveness of affective mechanisms theorized to promote well-being (e.g., Deiner et al., 1999; Frederickson, 2001) and health (e.g., Slatcher \& Schoebi, 2017), researchers should consider including variability in emotions in current theoretical models. 
Finally, Study 3 examined dyadic sleep reports in military couples, a group considered at-risk of sleep problems (e.g., Holliday \& Troxel, 2017) and aimed to support recent research examining the unique effect that relationship-specific behaviors and emotions have on sleep, in this case gratitude and affectionate touch. Moreover, this study addresses a gap in research examining affectionate touch and sleep in romantic couples. Both affectionate touch and sleep are theorized to be fundamental attachment behaviors (e.g., Jakubiak \& Feeney, 2017; Troxel, 2010; Troxel et al., 2007) and support the down-regulation of arousal in adults. To my knowledge, Study 3 is the first to examine how affectionate touch predicts sleep in couples. Furthermore, while past research shows that affectionate touch and gratitude may be linked, for example to the degree that touch may communicate gratitude, few studies have explicitly examined how physical touch and gratitude interact to predict well-being. Therefore, this study extends literature examining the interpersonal interactions of gratitude, affectionate touch, and sleep within the context of relationships. In sum, all three studies examine intrapersonal and interpersonal processes that contribute to well-being within the context of work-place interactions and unique relationships. These processes inform the avenues through which people and their close others may thrive. 


\section{References}

Adams A. \& Bond S. (2000). Hospital nurses' job satisfaction, individual and organizational characteristics. Journal of Advanced Nursing 32, 536-543. doi:10.1046/j.13652648.2000.01513.x

Aiken L.H., Clarke S.P., Sloane D.M., Sochalski J. \& Silber J.H. (2002). Hospital nursing staffing and patient mortality, nurse burnout and job dissatisfaction. Journal of the American Medical Association, 23, 1987-1993.

doi:10.1001/jama.288.16.1987

Aiken L.H., Sermeus W., Van den Heede K., Sloane D.M., Busse R., McKee M., ... KutneyLee A. (2012). Patient safety, satisfaction and quality of hospital care: cross sectional surveys of nurses and patients in 12 countries in Europe and the United States. British Medical Journal, 344, e1717. doi:10.1136/bmj.e1717

Algoe, S. B. (2012). Find, remind, and bind: The functions of gratitude in everyday relationships. Social and Personality Psychology Compass, 6, 455-469. doi:10.1111/j.1751-9004.2012.00439.x

Algoe, S. B., \& Stanton, A. L. (2012). Gratitude when it is needed most: Social functions of gratitude in women with metastatic breast cancer. Emotion, 12(1), 163-168. doi:10.1037/a0024024

Algoe, S. B., \& Zhaoyang, R. (2016). Positive psychology in context: Effects of expressing gratitude in ongoing relationships depend on perceptions of enactor 
RELATIONAL THRIVING IN CONTEXT

responsiveness. The Journal of Positive Psychology, 11(4), 399-415.

doi:10.1080/17439760.2015.1117131

Algoe, S. B., Fredrickson, B. L., \& Gable, S. L. (2013). The social functions of the emotion of gratitude via expression. Emotion, 13, 605-609. doi:10.1037/a0032701

Algoe, S. B., Haidt, J., \& Gable, S. L. (2008). Beyond reciprocity: Gratitude and relationships in everyday life. Emotion, 8(3), 425-429. doi:10.1037/1528-

3542.8.3.425

Allen, E. S., Rhoades, G. K., Stanley, S. M., \& Markman, H. J. (2010). Hitting home: relationships between recent deployment, posttraumatic stress symptoms, and marital functioning for Army couples. Journal of Family Psychology, 24(3), 280288. doi:10.1037/a0019405

Armenta, C. N., Fritz, M. M., \& Lyubomirsky, S. (2017). Functions of positive emotions: Gratitude as a motivator of self-improvement and positive change. Emotion Review, 9(3), 183-190. doi:10.1177/1754073916669596

Arpin, S. N., Starkey, A. R., Mohr, C. D., Greenhalgh, A.D., \& Hammer, L. (2018). "A well spent day brings happy sleep": Dyadic study of capitalization support in militaryconnected couples. Journal of Family Psychology, 32(7), 975-985. http://dx.doi.org.proxy.lib.pdx.edu/10.1037/fam0000469

Boehm, J. K., Lyubomirsky, S., \& Sheldon, K. M. (2011). A longitudinal experimental study comparing the effectiveness of happiness-enhancing strategies in Anglo 
RELATIONAL THRIVING IN CONTEXT

Americans and Asian Americans. Cognition \& Emotion, 25, 1263-1272.

doi:10.1080/02699931.2010.541227

Bowlby, J. (1982). Attachment and loss: Vol. 1. Attachment. New York: Basic Books.

(Original work published 1969)

Bowling, U. B., \& Sherman, M. D. (2008). Welcoming them home: Supporting service members and their families in navigating the tasks of reintegration. Professional Psychology: Research and Practice, 39(4), 451-458. doi:10.1037/0735-

7028.39.4.451

Butler, E. A. (2015). Interpersonal affect dynamics: It takes two (and time) to tango. Emotion Review, 7(4), 336-341. doi:10.1177/1754073915590622

Chan, D. K., Zhang, X., Fung, H. H., \& Hagger, M. S. (2016). Affect, affective variability, and physical health: results from a population-based investigation in China. International journal of behavioral medicine, 23(4), 438-446. doi:10.1007/s12529-015-9510-2

Cho, S. H., Park, M., Jeon, S. H., Chang, H. E., \& Hong, H. J. (2014). Average hospital length of stay, nurses' work demands, and their health and job outcomes. Journal of Nursing Scholarship, 46(3), 199-206. doi:10.1111/jnu.12066

Clark, M. S., Armentano, L. A., Boothby, E. J., \& Hirsch, J. L. (2017). Communal relational context (or lack thereof) shapes emotional lives. Current opinion in psychology, 17, 176-183. https://doi.org/10.1016/j.copsyc.2017.07.023 
Clark, M.S. \& Lemay, E.P. (2010). Close relationships. In S.T. Fiske, D.T. Gilbert, \& G. Lindzey (Eds.), Handbook of social psychology, (pp. 898-940). doi:10.1002/9780470561119.socpsy002025

Cohen, S., \& Wills, T. A. (1985). Stress, social support, and the buffering hypothesis. Psychological Bulletin, 98, 310-357. doi: 10.1037/00332909.98.2.310

Cohen, S., Janicki-Deverts, D., Turner, R. B., \& Doyle, W. J. (2015). Does hugging provide stress-buffering social support? A study of susceptibility to upper respiratory infection and illness. Psychological Science, 26, 135-147.

Collins, N. L., \& Feeney, B. C. (2000). A safe haven: An attachment theory perspective on support-seeking and caregiving in adult romantic relationships. Journal of Personality and Social Psychology, 78, 1053-1073. doi:10.1037/00223514.78.6.1053

Collins, N. L., Kane, H. S., Metz, M. A., Cleveland, C., Khan, C., Winczewski, L., . . Prok, T. (2014). Psychological, physiological, and behavioral responses to a partner in need: The role of compassionate love. Journal of Social and Personal Relationships, 31, 601-629. doi:10.1177/0265407514529069

Debrot, A., Cook, W. L., Perrez, M., \& Horn, A. B. (2012). Deeds matter: Daily enacted responsiveness and intimacy in couples' daily lives. Journal of Family Psychology, 26(4), 617-627. doi:10.1037/a0028666 
Debrot, A., Schoebi, D., Perrez, M., \& Horn, A. B. (2013). Touch as an interpersonal emotion regulation process in couples' daily lives: The mediating role of psychological intimacy. Personality and Social Psychology Bulletin, 39, 13731385. doi:10.1177/0146167213497592

Deci, E. L., \& Ryan, R. M. (2000). The "what" and "why" of goal pursuits: Human needs and the self-determination of behavior. Psychological Inquiry, 11, 227-268. doi:10.1207/S15327965PLI1104_01

Diener, E., Colvin, C. R., Pavot, W. G., \& Allman, A. (1991). The psychic costs of intense positive affect. Journal of Personality and Social Psychology, 61(3), 492-503. doi:10.1037/0022-3514.61.3.492

Diener, E., Suh, E. M., Lucas, R. E., \& Smith, H. L. (1999). Subjective well-being: Three decades of progress. Psychological Bulletin, 125(2), 276-302. doi:10.1037/00332909.125.2.276

Diener, E., Wirtz, D., Tov, W., Kim-Prieto, C., Choi, D., Oishi, S., \& Biswas-Diener, R. (2010). New well-being measures: Short scales to assess flourishing and positive and negative feelings. Social Indicators Research, 97, 143-156. doi:10.1007/s11205-009-9493-y

Ditzen, B., Neumann, I. D., Bodenmann, G., von Dawans, B., Turner, R. A., Ehlert, U., \& Heinrichs, M. (2007). Effects of different kinds of couple interaction on cortisol and heart rate responses to stress in women. Psychoneuroendocrinology, 32, 565-574. doi:10.1016/j.psyneuen.2007.03.011 
Emmons R.A. \& McCullough M.E. (2003) Counting blessings versus burdens: an experimental investigation of gratitude and subjective well-being in daily life. Journal of Personality and Social Psychology, 84 (2), 377-389. doi:10.1037/00223514.84.2.377

Feeney, B. C. (2004). A secure base: Responsive support of goal strivings and exploration in adult intimate relationships. Journal of Personality and Social Psychology, 87, 631-648. doi:10.1037/0022-3514.87.5.631

Feeney, B. C., \& Collins, N. L. (2015). A new look at social support: A theoretical perspective on thriving through relationships. Personality and Social Psychology Review, 19(2), 113-147. doi:10.1177/1088868314544222

Feeney, B. C., \& Thrush, R. L. (2010). Relationship influences on exploration in adulthood: The characteristics and function of a secure base. Journal of Personality and Social Psychology, 98, 57-76. doi:10.1037/a0016961

Field, T. (2010). Touch for socioemotional and physical well-being: A review. Developmental Review, 30, 367-383. doi:10.1016/j.dr.2011.01.001

Field, T. (2012). Relationships as regulators. Psychology, 3, 467-479. doi:10.4236/psych.2012.36066

Fredrickson, B. L. (2001). The role of positive emotions in positive psychology: The broaden-and-build theory of positive emotions. American Psychologist, 56, 218 226. doi:10.1037/0003-066X.56.3.218 
Fredrickson, B. L., \& Losada, M. F. (2005). Positive affect and the complex dynamics of human flourishing. American Psychologist, 60(7), 678-686. doi:10.1037/0003066X.60.7.678

Gable, S. L., Reis, H. T., Impett, E. A., \& Asher, E. R. (2004). What do you do when things go right? The intrapersonal and interpersonal benefits of sharing positive events. Journal of Personality and Social Psychology, 87, 228-245. doi: $10.1037 / 0022-3514.87 .2 .228$

Goff, B. S. N. ,Crow, J. R., Reisbig, A. M. J., \& Hamilton, S. (2007). The impact of individual trauma symptoms of deployed soldiers on relationship satisfaction. Journal of Family Psychology, 21(3), 344-353. doi:10.1037/0893-3200.21.3.344

Gordon, A. M., \& Chen, S. (2014). The role of sleep in interpersonal conflict: do sleepless nights mean worse fights?. Social Psychological and Personality Science, 5(2), 168-175. doi:10.1177/1948550613488952

Gruber, J., Kogan, A., Quoidbach, J., \& Mauss, I. B. (2013). Happiness is best kept stable: Positive emotion variability is associated with poorer psychological health. Emotion, 13(1), 1-6. doi:10.1037/a0030262

Halbesleben, J.R.B., \& Rathert, C. (2008). Linking physician burnout and Patient outcomes: Exploring the dyadic relationship between physicians and patients. Health Care Manag. Rev. 33, 29-39. doi:10.1097/01.HMR.0000304493.87898.72 Hammer, L., Wan, W., Brockwood, K., Mohr, C., \& Carlson, K. (2017). Military, work, and health characteristics of separated and active service members from the Study 
RELATIONAL THRIVING IN CONTEXT

for Employment Retention of Veterans (SERVe). Military Psychology, 29(6), 491512. http://dx.doi.org/10.1037/mil0000196

Hardy, J., \& Segerstrom, S. C. (2017). Intra-individual variability and psychological flexibility: Affect and health in a National US sample. Journal of research in personality, 69, 13-21. doi:10.1016/j.jrp.2016.04.002 0092-6566

Hasson, D., \& Gustavsson, P. (2010). Declining sleep quality among nurses: a populationbased four-year longitudinal study on the transition from nursing education to working life. PloS one, 5(12), e14265. doi:10.1371/journal.pone.0014265

Hertenstein, M. J., Keltner, D., App, B., Bulleit, B. A., \& Jaskolka, A. R. (2006). Touch communicates distinct emotions. Emotion, 6(3), 528. doi:10.1037/1528-

3542.6.3.528

Holliday, S. B., \& Troxel, W. (2017). Relationship Quality: Implications for Sleep Quality and Sleep Disorders. In S. M. McHale, V. King \& O. M. Buxton (Eds.), Family Contexts of Sleep and Health Across the Life Course (pp. 53-84). Cham: Springer. doi:10.1007/978-3-319-64780-7_3

Holt-Lunstad, J., \& Smith, T. B. (2012). Social relationships and mortality. Social \& Personality Psychology Compass, 6, 41-53. doi:10.1111/j.17519004.2011.00406.x

Holt-Lunstad, J., Smith, T. B., \& Layton, J. B. (2010). Social relationships and mortality risk: a meta-analytic review. PLoS medicine, 7(7), e1000316. doi:10.1371/journal.pmed.1000316 
Houben, M., Van Den Noortgate, W., \& Kuppens, P. (2015). The relation between shortterm emotion dynamics and psychological well-being: A metaanalysis. Psychological Bulletin, 141(4), 901-930. doi:10.1037/a0038822

Human, L. J., Whillans, A. V., Hoppmann, C. A., Klumb, P., Dickerson, S. S., \& Dunn, E. W. (2015). Finding the middle ground: Curvilinear associations between positive affect variability and daily cortisol profiles. Emotion, 15(6), 705-720. doi:10.1037/t03592-000

Itani, O., Jike, M., Watanabe, N., \& Kaneita, Y. (2017). Short sleep duration and health outcomes: a systematic review, meta-analysis, and meta-regression. Sleep medicine, 32, 246-256. doi:10.1016/j.sleep.2016.08.006

Jakubiak, B. K., \& Feeney, B. C. (2016a). Daily goal progress is facilitated by spousal support and promotes psychological, physical, and relational well-being throughout adulthood. Journal of personality and social psychology, 111(3), 317. doi:10.1037/pspi0000062

Jakubiak, B. K., \& Feeney, B. C. (2016b). A sense of security: Touch promotes state attachment security. Social Psychological and Personality Science, 7(7), 745-753. doi:10.1177/1948550616646427

Jakubiak, B. K., \& Feeney, B. C. (2016c). Keep in touch: The effects of imagined touch support on stress and exploration. Journal of Experimental Social Psychology, 65, 59-67. doi:10.1177/0265407517702012 
Jakubiak, B. K., \& Feeney, B. C. (2017). Affectionate touch to promote relational, psychological, and physical well-being in adulthood: A theoretical model and review of the research. Personality and Social Psychology Review, 21(3), 228-252. doi:10.1177/1088868316650307

Kane, H. S., Slatcher, R. B., Reynolds, B. M., Repetti, R. L., \& Robles, T. F. (2014). Daily self-disclosure and sleep in couples. Health Psychology, 33(8), 813-822. doi:10.1037/hea0000077

Karney, B. R., \& Crown, J. S. (2007). Families under stress: An assessment of data, theory, and reseach on marriage and divorce in the military (Vol. 599). Rand Corporation.

Karney, B. R., \& Trail, T. E. (2017). Associations between prior deployments and marital satisfaction among army couples. Journal of Marriage and Family, 79(1), 147160. doi:10.1111/jomf.12329

Karney, B. R., Loughran, D. S., \& Pollard, M. S. (2012). Comparing marital status and divorce status in civilian and military populations. Journal of Family Issues, 33(12), 1572-1594. doi:10.1177/0192513X12439690

Kiecolt-Glaser, J. K., \& Wilson, S. J. (2017). Lovesick: How couples' relationships influence health. Annual Review of Clinical Psychology, 13, 421-443. doi:10.1146/annurevclinpsy-032816-045111

Knobloch, L. K., \& Theiss, J. A. (2012). Experiences of US military couples during the postdeployment transition: Applying the relational turbulence model. Journal of 
RELATIONAL THRIVING IN CONTEXT

Social and Personal Relationships, 29(4), 423-450.

doi:10.1177/0265407511431186

Ko, S. H., Chen, C. H., Wang, H. H., \& Su, Y. T. (2014). Postpartum women's sleep quality and its predictors in Taiwan. Journal of Nursing Scholarship, 46(2), 74-81. doi:10.1111/jnu.12053

Kuppens, P., \& Verduyn, P. (2015). Looking at emotion regulation through the window of emotion dynamics. Psychological Inquiry, 26(1), 72-79.

doi:10.1080/1047840X.2015.960505

Lambert, N. M., Clark, M. S., Durtschi, J., Fincham, F. D., \& Graham, S. M. (2010). Benefits of expressing gratitude: Expressing gratitude to a partner changes one's view of the relationship. Psychological Science, 21(4), 574-580. doi:10.1177/0956797610364003

Lambert, N. M., Graham, S. M., \& Fincham, F. D. (2009). A prototype analysis of gratitude: Varieties of gratitude experiences. Personality and Social Psychology Bulletin, 35(9), 1193-1207. doi:10.1177/0146167209338071

Lee, S., Martire, L. M., Damaske, S. A., Mogle, J. A., Zhaoyang, R., Almeida, D. M., \& Buxton, O. M. (2018). Covariation in couples' nightly sleep and gender differences. Sleep Health: Journal of the National Sleep Foundation, 4(2), 201208. doi:10.1016/j.sleh.2017.10.009 
Lin, K. C., Huang, C. C., \& Wu, C. C. (2007). Association between stress at work and primary headache among nursing staff in Taiwan. Headache: The Journal of Head and Face Pain, 47(4), 576-584. doi:10.1111/j.1526-4610.2007.00759.x

Luyster, F. S., Strollo, P. J., Zee, P. C., \& Walsh, J. K. (2012). Sleep: a health imperative. Sleep, 35(6), 727-734. doi:10.5665/sleep.1846

Lyubomirsky, S., King, L., \& Diener, E. (2005). The Benefits of Frequent Positive Affect: Does Happiness Lead to Success? Psychological Bulletin, 131(6), 803-855. http://dx.doi.org/10.1037/0033-2909.131.6.803

Martin, L. R., Friedman, H. S., Tucker, J. S., Tomlinson-Keasey, C., Criqui, M. H., \& Schwartz, J. E. (2002). A life course perspective on childhood cheerfulness and its relation to mortality risk. Personality and Social Psychology Bulletin, 28(9), 1155 1165. doi:10.1177/01461672022812001

McCullough, M. E., Kilpatrick, S. D., Emmons, R. A., \& Larson, D. B. (2001). Is gratitude a moral affect?. Psychological bulletin, 127(2), 249. doi:10.1037/00332909.127.2.249

Mohr, C. D., Arpin, S., \& McCabe, C. T. (2015). Daily affect variability and context-specific alcohol consumption. Drug and alcohol review, 34(6), 581-587. doi:10.1111/dar.12253

Monin, J. K., Feeney, B. C., \& Schulz, R. (2012). Attachment orientation and reactions to anxiety expression in close relationships. Personal Relationships, 19, 535-550. doi:10.1111/j.1475-6811.2011.01376.x 
National Sleep Foundation. (2013). International bedroom poll: Summary of Findings. Arlington, VA: Author.

Nesselroade, J. R. (1991). Interindividual differences in intraindividual change. In L. M. Collins \& J. L. Horn (Eds.), Best methods for the analysis of change: Recent advances, unanswered questions, future directions (pp. 92-105). Washington, DC, US: American Psychological Association. http://dx.doi.org/10.1037/10099-006

Newman K. \& Maylor U. (2002) Empirical evidence for "the nurse satisfaction, quality of care and patient satisfaction chain. International Journal of Health Care Quality Assurance 15, 80-88. doi:10.1108/09526860210421482

Nezlek, J.B., Newman, D. B., \& Thrash, T. M. (2017). A daily diary study of relationships between feelings of gratitude and well-being. The Journal of Positive Psychology., 12(4), 323-332. doi:10.1080/17439760.2016.1198923

Pietromonaco, P. R., \& Collins, N. L. (2017). Interpersonal mechanisms linking close relationships to health. American Psychologist, 72(6), 531-542. doi:10.1037/amp0000129

Pressman, S. D., \& Cohen, S. (2005). Does positive affect influence health?. Psychological bulletin, 131(6), 925-971. doi:10.1037/0033-2909.131.6.925

Price, J. L., Monson, C. M., Callahan, K., \& Rodriguez, B. F. (2006). The role of emotional functioning in military-related PTSD and its treatment. Journal of Anxiety Disorders, 20(5), 661-674. doi:10.1016/j.janxdis.2005.04.004 
Ram, N., \& Gerstorf, D. (2009). Time-structured and net intraindividual variability: Tools for examining the development of dynamic characteristics and processes. Psychology and aging, 24(4), 778-791. doi:10.1037/a0017915

Reis, H. T., \& Gable, S. L. (2015). Responsiveness. Current Opinion in Psychology, 1, 6771. doi:10.1016/j.copsyc.2015.01.001

Reis, H. T., \& Shaver, P. (1988). Intimacy as an interpersonal process. Handbook of personal relationships, 24(3), 367-389

Renshaw, K. D., \& Campbell, S. B. (2017). Deployment-Related Benefit Finding and Postdeployment Marital Satisfaction in Military Couples. Family process, 56(4), 915-925. doi:10.1111/famp.12249

Robles, T. F., Slatcher, R. B., Trombello, J. M., \& McGinn, M. M. (2014). Marital quality and health: A meta-analytic review. Psychological bulletin, 140(1), 140-187. doi:10.1037/a0031859

Ryff, C. D., \& Singer, B. H. (1998). The contours of positive human health. Psychological Inquiry, 9, 1-28. doi:10.1207/s15327965pli0901_1

Ryff, C. D., \& Singer, B. H. (2000). Interpersonal flourishing: A positive health agenda for the new millennium. Personality and Social Psychology Review, 4, 30-44. doi:10.1207/S15327957PSPR0401_4

Saxbe, D., \& Repetti, R. L. (2010). For better or worse? Coregulation of couples' cortisol levels and mood states. Journal of Personality and Social Psychology, 98(1), 92103. doi:10.1037/a0016959 
Sbarra, D. A., \& Hazan, C. (2008). Coregulation, dysregulation, self-regulation: An integrative analysis and empirical agenda for understanding adult attachment, separation, loss, and recovery. Personality and Social Psychology Review, 12, 141-167. doi:10.1177/1088868308315702

Schoebi, D., \& Randall, A. K. (2015). Emotional dynamics in intimate relationships. Emotion Review, 7(4), 342-348. doi:10.1177/1754073915590620

Segal, M. W. (1989). The nature of work and family linkages: A theoretical perspective. In G. L. Bowen \& D. K. Orthner (Eds.), The organization family: Work and family linkages in the U. S. military (pp. 3-36). New York: Praeger.

Selcuk, E., Stanton, S. C., Slatcher, R. B., \& Ong, A. D. (2017). Perceived partner responsiveness predicts better sleep quality through lower anxiety. Social Psychological and Personality Science, 8(1), 83-92. doi:10.1177/1948550616662128

Seligman, M. E. P., Steen, T. A., Park, N., \& Peterson, C. (2005). Positive psychology progress: Empirical validation of interventions. American Psychologist, 60, 410421. doi:10.1037/t02942-000

Sels, L., Ceulemans, E., Bulteel, K., \& Kuppens, P. (2016). Emotional interdependence and well-being in close relationships. Frontiers in psychology, 7, 283. doi:10.3389/fpsyg.2016.00283 
Shiota, M. N., Campos, B., Keltner, D., \& Hertenstein, M. J. (2004). Positive emotion and the regulation of interpersonal relationships. In P. Philippot, \& R.S. Feldman (Eds.), The regulation of emotion (pp. 127-155). New York: Taylor \& Francis.

Shiota, M. N., Campos, B., Oveis, C., Hertenstein, M. J., Simon-Thomas, E., \& Keltner, D. (2017). Beyond happiness: Building a science of discrete positive emotions. American Psychologist, 72(7), 617-643. doi:10.1037/a0040456

Slatcher, R. B., \& Schoebi, D. (2017). Protective processes underlying the links between marital quality and physical health. Current opinion in psychology, 13, 148-152. doi:10.1016/j.copsyc.2016.09.002

Troxel, W. M. (2010). It's more than sex: Exploring the dyadic nature of sleep and implications for health. Psychosomatic medicine, 72(6), 578.

Troxel, W. M., Buysse, D. J., Hall, M., \& Matthews, K. A. (2009). Marital happiness and sleep disturbances in a multi-ethnic sample of middle-aged women. Behavioral Sleep Medicine, 7(1), 2-19. doi:10.1080/15402000802577736

Troxel, W. M., Robles, T. F., Hall, M., \& Buysse, D. J. (2007). Marital quality and the marital bed: Examining the covariation between relationship quality and sleep. Sleep Medicine Reviews, 11(5), 389-404. doi:10.1016/j.smrv.2007.05.002

Tucker, S. J., Harris, M. R., Pipe, T. B., \& Stevens, S. R. (2010). Nurses' ratings of their health and professional work environments. AAOHN journal, 58(6), 253-267. doi:10.3928/08910162-20100526-03 
Tugade, M. M., \& Fredrickson, B. L. (2004). Resilient individuals use positive emotions to bounce back from negative emotional experiences. Journal of Personality and Social Psychology, 86(2), 320-333. doi:10.1037/0022-3514.86.2.320

Uchino, B. N. (2006). Social support and health: a review of physiological processes potentially underlying links to disease outcomes. Journal of behavioral medicine, 29(4), 377-387.

U.S. Department of Labor, Bureau of Labor Statistics. (2018). Occupational Outlook Handbook. Washington, D.C.: GPO, U.S. Bureau of Labor Statistics. Retrieved from http://www.bls.gov/ooh/healthcare/registered-nurses.htm van de Leemput, I. A., Wichers, M., Cramer, A. O., Borsboom, D., Tuerlinckx, F., Kuppens, P., ... \& Derom, C. (2014). Critical slowing down as early warning for the onset and termination of depression. Proceedings of the National Academy of Sciences, 111(1), 87-92. doi:10.1073/pnas.1312114110

Warner, C. H., Appenzeller, G. N., Warner, C., \& Grieger, T. (2009). Psychological effects of deployments on military families. Psychiatric Annals, 39(2), 56-63. doi:10.3928/00485713-20090201-11

Winwood, P. C., \& Lushington, K. (2006). Disentangling the effects of psychological and physical work demands on sleep, recovery and maladaptive chronic stress outcomes within a large sample of Australian nurses. Journal of advanced nursing, 56(6), 679-689. doi:10.1111/j.1365-2648.2006.04055.x 
Wood, A. M., Froh, J. J., \& Geraghty, A. W. (2010). Gratitude and well-being: A review and theoretical integration. Clinical psychology review, 30(7), 890-905. doi:10.1016/j.cpr.2010.03.005

Wright, R. R., Mohr, C. D., \& Sinclair, R. R. (2014). Conflict on the treatment floor: an investigation of interpersonal conflict experienced by nurses. Journal of Research in Nursing, 19(1), 26-37. doi:10.1177/1744987113485577 


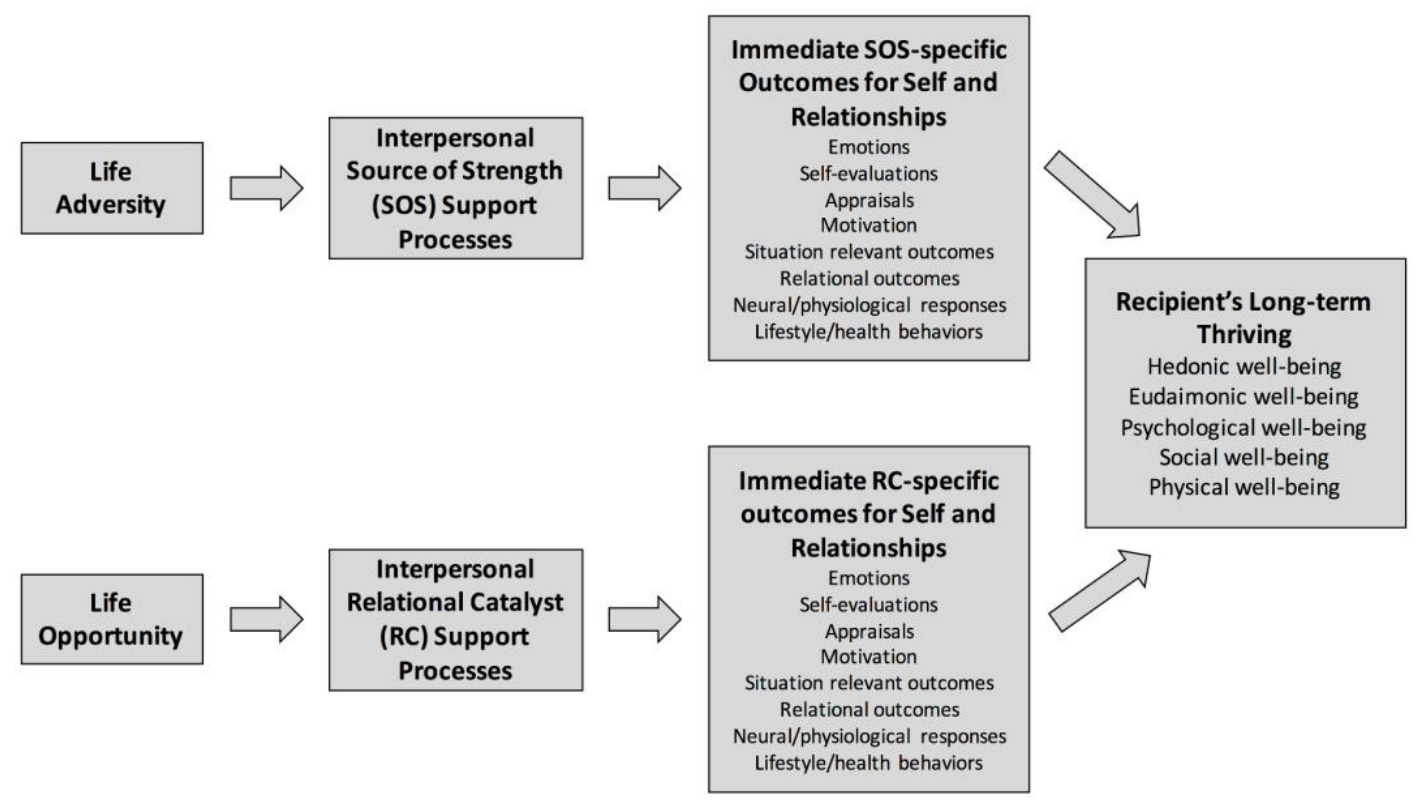

Figure 1.0. Thriving through relationships conceptual model proposed by Feeney \& Collins (2015). 


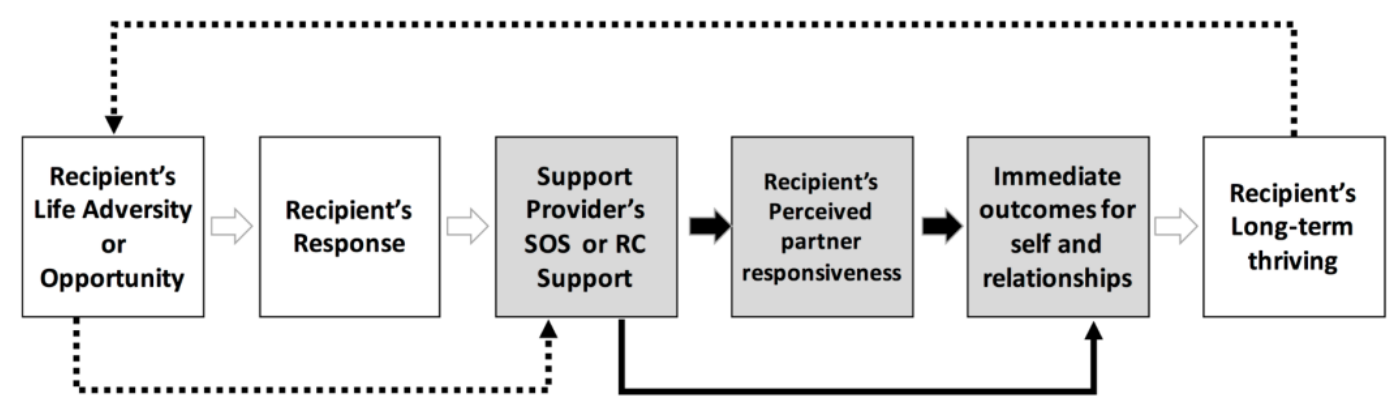

Figure 1.1. Model of interpersonal processes involved in responsive support based on Feeney \& Collins (2015). Gray boxes and solid lines/arrows indicate the components of interest in the current investigation. 
CHAPTER II. MANUSCRIPT I. GRATITUDE RECEPTION AND PHYSICAL HEALTH: EXAMINING THE MEDIATING ROLE OF SATISFACTION WITH PATIENT CARE IN A SAMPLE OF ACUTE CARE NURSES

NOTE: This manuscript has been accepted for publication at the Journal of Positive Psychology. Please see current citation below:

Starkey, A. R., Mohr, C. D., Cadiz, D., \& Sinclair, R. R. (In-press). Gratitude reception and physical health: Examining the mediating role of satisfaction with patient care in a sample of acute care nurses. Journal of Positive Psychology.

\begin{abstract}
Literature examining well-being benefits of gratitude experiences is currently thriving in psychological science. However, evidence of the physical health benefits of gratitude remains limited. Research and theory in affective science suggests an indirect relationship between gratitude and physical health. This study examines how receiving expressions of gratitude predicts physical health outcomes in a sample of acute care nurses over time. Registered nurses $(N=146)$ practicing in Oregon completed weekly surveys over 12 consecutive weeks describing their positive and negative events, health, and work-related experiences. Multilevel mediation models revealed that being thanked more often at work was positively related to a nurse's satisfaction with the care they provided within that week, which subsequently predicted sleep quality, sleep adequacy, headaches, and attempts to eat healthy. These findings contribute to literature demonstrating the health benefits of gratitude by indicating that benefactors may experience improvements in subjective physical health through positive domain-relative satisfaction.
\end{abstract}




\section{Introduction}

Gratitude has been studied as a personality trait, emotional state, and moral value, among other conceptualizations (Emmons, McCullough, \& Tsang, 2003). When conceptualized as an emotion, gratitude signals that a person has benefited or received a positive outcome from an external source (Emmons \& McCullough, 2003). Thus, gratitude is a positive affective experience that typically follows another's beneficial and caring gesture towards the self, particularly when the gesture is perceived to be costly or valuable, intentional, and voluntary (McCullough, Kimeldorf \& Cohen, 2008). Consequently, gratitude is distinct from other positive emotions such as optimism or happiness (Wood et al., 2010). This other-focused, interpersonal-emotional definition is what Lambert, Graham, and Fincham (2009), termed "benefit-triggered gratitude" and is of particular interest in this study, as opposed to "generalized gratitude" (e.g., an individual's broad state of thankfulness or trait gratitude). Viewing gratitude within an interpersonal framework, not only is the experience of gratitude important, but the expression of gratitude becomes critical to understanding state gratitude's link to wellbeing.

Expressed gratitude holds positive outcomes for both the expresser and benefactor. For example, expressed gratitude is related to increased life satisfaction and well-being over time for the expresser of gratitude (Lyubomirsky, Dickerhoof, Boehm, \& Sheldon, 2011). While the majority of literature examining gratitude has focused on the expresser (i.e., the person who benefits and then expresses their gratitude toward a 
benefactor), more recent work has examined the impact of gratitude for those receiving expressions of gratitude (i.e., the benefactor). For example, Grant and Gino (2010) found being the target of gratitude from strangers strengthens one's sense of social worth and spurs additional helping behaviors. In close relationships, when caregivers receive thanks from their romantic partner, they view their partner as more caring, understanding, and validating which predicts later positive psychological outcomes (Algoe, Kurtz, \& Hillaire, 2016). Extant research documents the psychological and social well-being outcomes related to receiving gratitude expressions, yet few studies have examined gratitude reception and physical health outcomes. Researchers suggest that affect such as gratitude shares an indirect relationship with physical health (DeSteno, Gross, \& Kubzansky, 2013). Extending this literature, the current study targets one personal well-being resource, satisfaction, as a mechanism through which gratitude expressions predict physical health.

\section{Indirect relation of gratitude and physical health}

Positive emotions, including gratitude, are theorized to build a variety of social and psychological resources (Fredrickson, 2004). Recent work hypothesizes that expressions of gratitude not only have social benefits that help build high quality relationships, but also predict increased psychological resources (Algoe, 2012). Algoe and Zhaoyang (2016) found that expressed gratitude predicted psychological well-being outcomes in a daily study, including increased life satisfaction, resilience, positive emotions and decreased negative emotions. Further, the explicit expression of gratitude 
may strengthen these benefits over time (Algoe \& Stanton, 2012). For example, benefactors who received a gratitude expression from their partner showed increased relationship satisfaction up to 6 months later (Algoe, Fredrickson, \& Gable, 2013), indicating that benefactors may experience lasting effects of gratitude expressions. Based on these findings, we expect that expressions of gratitude will support increases in psychological resources that will, in turn, spill over to benefit physical health.

While evidence linking gratitude expression and physical health is limited, literature examining 'generalized gratitude' (including trait gratitude; Lambert et al., 2009) has focused attention on the links between gratitude, well-being, and physical health outcomes. In their seminal work, Emmons and McCullough (2003) found a direct relationship between gratitude and health such that people who were induced to feel more grateful showed reduced illness symptoms and increased hours of exercise. Further, evidence suggests that generalized gratitude predicts better subjective psychological well-being, physical health, and healthy behavior, such as the propensity to exercise and eat healthy (Hill, Allemand, \& Roberts, 2013). People who are more grateful or induced to feel more gratitude have fewer negative physical symptoms (e.g., pain), exhibit healthier behaviors (e.g., eating nutritious foods), show better physiological outcomes such as blood pressure (Jackowska, Brown, Ronaldson, \& Steptoe, 2015), and report increased sleep quality (Wood, Joseph, Lloyd, \& Atkins, 2009). 
In addition to a direct relationship, research on generalized gratitude has begun to identify psychological mechanisms linking gratitude and health. For example, people who are more grateful report reduced loneliness and, in turn, better physical health (O'Connell, O'Shea, \& Gallagher, 2016). Further, Wood and colleagues (2009) found that positive cognitions, such as relishing recently experienced positive events, before bed mediated the relationship between generalized gratitude and better sleep. In turn, psychological mechanisms may be particularly important for the interpretation and benefit of gratitude expressions. For example, researchers argue that gratitude does not operate purely behaviorally (e.g., through interpersonal expression) but rather, an individual must interpret the expression through a positive lens (Wood et al., 2010). People must be oriented towards the positive in life in order to reap the benefits of gratitude. This work suggests that orienting oneself to the positive aspects about one's present state, such as feeling satisfied, may be one mechanism of gratitude. For example, Lambert, Fincham, Stillman, and Dean (2009) found that satisfaction with life mediated the relationship between trait gratitude and decreased materialism (i.e. striving to increase personal possessions). Taken together, previous research on both generalized gratitude and other-focused expressions of gratitude show that gratitude relates to increased psychological well-being resources. Literature on generalized gratitude suggests that increased psychological well-being resources, predicted by gratitude, is associated with positive physical health outcomes. Drawing on generalized and other-focused gratitude research, this study addresses a gap in literature related to 
the physical health and intrapersonal benefits of expressed gratitude by examining how receiving gratitude expressions predicts nurses' physical well-being via work-related satisfaction.

\section{Gratitude, satisfaction, and physical health in the context of nursing}

Nursing is a helping profession comprising the largest group of health-care professionals in the U.S. (U.S. Department of Labor, 2018). Nurses are central to the delivery of health-care services in a system facing increased pressures including aging populations, and greater expectations regarding quality of care (Aiken et al., 2012). Nurses engage in many work behaviors which may evoke gratitude from coworkers, supervisors, patients, and patients' families-from simply completing tasks efficiently and empathetically to helping an overloaded colleague. Given that people spend a significant portion of their lives at work, satisfaction with one's work should have a significant impact on one's physical health. Moreover, nurses, in particular, view being in the nursing profession as a part of their personal identity and calling (Eley, Eley, Bertello, \& Rogers-Clark, 2012). However, nursing work is demanding and nurses may be more susceptible to adverse physical health outcomes.

Indeed, nurses' job demands are linked to poor sleep (Hasson \& Gustavson, 2010; Winwood \& Lushington, 2006), psychosomatic symptoms such as headaches (Lin, Huang, \& Wu, 2007), and poor nutrition (Tucker, Harris, Pipe, \& Stevens, 2010). Nurses' poor physical health (e.g., poor sleep quality) is related to fatigue, resulting in greater risk of mistakes and patient safety concerns (Lockley et al., 2007). Furthermore, nurses 
describe feeling unsupported and underappreciated at work (Morrison \& Korol, 2014). This lack of appreciation for health-care providers can subsequently predict sleep problems and poor self-perceived physical health (Meier, Tschudi, Meier, Dvorak \& Zeller, 2015). Broadly, this research suggests that increased expression of gratitude towards nurses may help alleviate associated adverse physical health symptoms.

Recent evidence suggests gratitude expressed towards nurses may promote well-being outcomes. Nurses who received gratitude expressions from patients had lower symptoms of emotional exhaustion, depersonalization, and increased feelings of personal accomplishment (Converso, Loera, Viotti \& Martini, 2015). Further, supportive positive events that nurses may encounter, including received expressions of gratitude from colleagues and physicians, predict positive work outcomes such as engagement (Sinclair, et al., 2015). Relatedly, nurses' perceived appreciation by their organization predicts higher work-related satisfaction (Adriaenssens, De Gucht, Van Der Doef, \& Maes, 2011). Based on this evidence, we expect that work-related satisfaction may be one mechanism through which received gratitude expressions at work relate to physical health.

Well-established theoretical perspectives regarding positive emotions and workrelated resources provide support for these claims. Conservation of Resources theory (COR; Hobfoll, 1989) has received considerable attention as an explanatory mechanism for how work demands affect occupational health (Hobfoll, 2001). COR theory proposes that people strive to retain, protect, and build resources, while aiming to avoid potential 
or actual loss of these valued resources (Hobfoll, 1989). COR theory can be applied in the context of received gratitude because, similar to social support, receiving thanks can facilitate gains in psychological resources such as positive self-image (Hobfoll, 1989). For example, nurses who received gratitude expressions may recover resources that have been lost over the course of a demanding work week. Thus, gratitude received by nurses likely generate work-related psychosocial resources that support their physical health.

Positive emotions serve a restorative function and provide opportunities for growth. Specifically, positive experiences help build resources and broaden one's approach to future experiences (Fredrickson, 2001). Thus, receiving expressions of gratitude may increase psychological well-being such as satisfaction with one's care of others and in turn, better physical health. Recent evidence suggests that satisfaction with work and perceptions of quality care are worldwide concerns in the field of nursing (Aiken et al., 2012; You et al., 2013). However, positive interactions with patients, families, and co-workers may improve nurses' quality of work life. For example, nurses describe that when they provide high-quality care, they have stronger connections with their patients, and are more satisfied with their work (Perry, 2005). In addition, to previously mentioned evidence specific to satisfaction and health reported by nurses, a meta-analysis by Faragher, Cass, and Cooper (2005) found a small-to-medium association between job satisfaction and self-reported physical health indicating that feeling satisfied at work may contribute to one's physical health outcomes. Taken together, this evidence supports that nurses' satisfaction with their care of patients may 
be one mechanism through which positive emotions such as gratitude predict physical health.

\section{The present study}

This study extends literature examining the relationship between gratitude and physical health by investigating health benefits of receiving gratitude expressions. We examine gratitude reception in the context of nursing, a helping profession associated with demanding work and reduced physical health. We address how receiving gratitude at work predicts physical symptoms and health behaviors through nurses' satisfaction with patient care. In addition, we examine this process over time: testing mediation patterns both within-person and between-persons. See Figure 1 for the proposed model based on Preacher, Zhang, and Zyphur (2011). We hypothesize that gratitude reception will predict increased satisfaction with patient care within-person (path $a_{i j}$ ) and between persons (path $\mathrm{a}_{\mathrm{j}}$ ). In turn, we predict that increased satisfaction with care will be associated with increased subjective physical health outcomes within-person (path $b_{i j}$ ) and between persons (path $b_{j}$ ). Further, this relationship will remain controlling for gratitude reception across (path $c_{j}$ ) and within nurses (path $c_{i j}$ ) over time.

\section{Methods}

\section{Overview}

Data for this study were drawn from the Oregon Nurse Retention Project (ONRP) examining nurses' work-related experiences, occupational health, and retention. The research team collaborated with a nurse's professional organization to recruit acute 
care nurses working in urban, suburban, and rural areas in Oregon. ONRP consisted of 3 waves of surveys, with an opt-in weekly survey taking place over 12 weeks in between Waves 1 and 2 . The current analyses focuses on the weekly survey component of the project. For more information about ONRP, see Sinclair and colleagues (2009; Sinclair et al., 2015).

\section{Participants}

Of the 428 acute-care nurses who were recruited for the first wave, 146 nurses opted to participate in the weekly survey. The majority were female ( $91.1 \%$ female), White $(89.7 \%)$, and on average 44 years old $(S D=10.71)$. Most of the participating nurses were married (68.5\%). About half received their bachelors in nursing $(48.6 \% ; 14 \%$ other bachelors), $26 \%$ received an associate degree in nursing, and $6 \%$ received a graduate degree. Nurses in this sample worked mostly full-time (63\%), 31.5\% worked part-time, and had been a nurse for about 17 years on average (SD = 11.9).

\section{Procedure}

On Sunday, each week for 12 weeks, participants were provided a link to a webbased survey via email that took approximately 20 minutes to complete. Participants were given a 48-hour time window to finish the survey, and were sent a reminder email if they missed two or more consecutive weeks. Participants received $\$ 5$ for each survey completed. Nurses' identifying information was removed after survey collection and stored separately from survey responses. Participation in this study was voluntary and an institutional review board (IRB) approved all activities. On average, participants 
completed 9 out of 12 surveys (SD =2.8), resulting in a $77 \%$ compliance rate typical of longitudinal diary studies (e.g., Bakker, Vergel, \& Kuntze, 2015; Totterdell, Wood \& Wall, 2006).

\section{Measures}

Physical Health outcomes. Two items were used to measures weekly sleep outcomes, adapted from the Pittsburgh Sleep Quality Index (PSQI; Buysse, Reynolds, Monk, Berman, \& Kupfer, 1989): sleep quality and sleep adequacy. Sleep quality, “How would you rate your sleep quality for the past 7 days overall?" was rated on a 4-point scale ranging from 1 (very bad) to 4 (very good). Sleep adequacy, "In the past 7 days/nights, how many nights/days have you received adequate sleep?" was rated on an 8-point scale ranging from 1 ( 0 days) to 8 ( 7 days). Other health items came from a health event checklist used by Carney, Armeli, Tennen, Affleck, and O'Neil (2000), including "How often have you experienced headaches in the past 7 days?," and "How often have you tried to eat healthy over the past 7 days?" Both the headache item and healthy-eating attempts item were rated on a 5-point scale from 1 (never) to 5 (very often). Single-items measures of health are considered to be reliable and valid (e.g., Andrews \& Withey 1976). Further, specific survey items that focus on discrete behaviors or experiences are likely more accurate than global assessments (see Reis, Gable, \& Maniaci, 2014). In addition, previous diary studies of similar health outcomes have employed single-item measures (e.g., Lee, Crain, McHale, Almeida, \& Buxton, 2017). 
Gratitude reception. Reception of gratitude expressions was assessed using 5 items in which participants were asked how many shifts they were thanked by their patient, patient's family, charge nurse, physician, or coworker, during the past 7 days, with response options ranging from 0 ( 0 shifts) to 6 ( 6 or more shifts). These items were created with the help of subject matter experts, and content analysis following focus groups with practicing nurses, which demonstrated the face-validity, practical significance and importance of these items to the population of interest (Sinclair et al., 2015). The gratitude items were presented as an events checklist, and thus can be considered a formative measurement for which assessment of internal consistency is not meaningful (Diamantopolos \& Winklhofer, 2001). See previous work from ORNP collaborators regarding the formative validity of the nurse events measure (Sinclair et al., 2015).

Satisfaction with quality care. The 3-item Satisfaction with Quality Care scale (SQC; Hinshaw \& Atwood, 1984) was adapted to measure nurses' positive evaluations with work-related tasks over the past 7 days. For example, participants were asked items including "The patient care I gave this week met my own standards of good patient care." Items were rated on a 5-point scale from 1 (strongly disagree) to 5 (strongly agree). The measure demonstrated good internal consistency across the 12 weeks ( $\alpha$ range across the 12 weeks $=.92-.98$ ).

Demographic and covariate information. Demographic information, including age, gender, ethnicity, education, relationship status, and work variables were collected 
during Wave 1 of data collection prior to the weekly survey. In addition, we measured a set of covariates to allow for testing of alternate explanations for our results. When examining indirect effects, the direction of mediation models must be supported by theory and account for covarying variables that may contribute to outcomes in addition to meeting assumptions regarding measurement error (Judd \& Kenny, 2010). Therefore, number of shifts, night shift, and optimism were controlled for in all models ${ }^{1}$. The number of work shifts was calculated for each week from a shift log, and included as a within-person control variable. Whether nurses completed at least one night shift (Yes/No) was also included as a within-person control. We included optimism as a between-persons covariate because, while a distinct construct, optimism may show a similar pattern to gratitude in terms of increasing a life orientation which subsequently relates to physical health (Carver, Scheier, \& Segerstrom, 2010; Wood et al., 2010). Optimism was measured at Wave 1 using 5 items adapted from the Life Orientation Test (Scheier, Carver, \& Bridges, 1994; $\alpha=.76)$.

\section{Data Analytic Strategy}

Preliminary analyses included descriptive statistics, bivariate correlations, and intraclass correlations. Due to the mixed-level nature of the over-time data, correlations were calculated between variables measured repeatedly over the study weeks $\left(r_{i j}\right)$ as

\footnotetext{
${ }^{1}$ Age, gender, occupational tenure, self-efficacy, and neuroticism were also tested as covariates. However, these variables did not emerge as significant predictors of physical health outcomes or satisfaction with care and did not change the substantive conclusions, thus, were removed from the final analyses. These preliminary analyses may be available upon request.
} 
well as between aggregated variables ( $r_{j}$; representing a nurse's average across weeks). Our primary data analytic approach was based on the 1-1-1 multilevel mediation model described by Krull and McKinnon (2001), in which the independent variable, mediator, and outcome are all time-varying. We examined indirect effects of gratitude reception on health via SQC. Thus, there were 4 models tested, one for each of the health outcomes, whereby gratitude reception was the independent variable and SQC was the mediator. Following expert recommendations (Preacher, Zyphur, \& Zhang, 2010; Preacher et al., 2011), multilevel mediation models were tested with fixed slopes using structural equation modelling (SEM) in Mplus (version 5.1; Muthén \& Muthén, 2008) which accounted for nesting of weeks within participants (see Figure 1). This approach accounts for potentially differing within-person (weekly-level) and between-person (individual-level) processes by estimating indirect effects for each level of the model. Within and between indirect effects were estimated using maximum likelihood estimation methods that are robust against missing data, non-independence of observations, unbalanced clustering, and non-normality concerns.

\section{Results}

\section{Descriptive Statistics and Intracorrelations}

Descriptive information as well as bivariate and intraclass correlations are presented in Table 1. Bivariate correlations showed that gratitude reception was positively related to SQC scores at the weekly level $\left(r_{i j}=.15, p<.01\right)$; however, the aggregated correlation was not significant $\left(r_{j}=.13, p=.12\right)$. SQC was significantly 
correlated with the sleep quality $\left(r_{j}=.24, p<.01\right)$, sleep adequacy $\left(r_{j}=.29, p<.01\right)$, headaches $\left(r_{j}=-.20, p<.05\right)$, and healthy eating attempts $\left(r_{j}=.26, p<.01\right)$ at the aggregated level as well as the weekly level $\left(r_{i j}=.16, p<.01 ; r_{i j}=.17, p<.01 ; r_{i j}=-.15, p\right.$ $<.01 ; r_{i j}=.18, p<.01$, respectively). Gratitude reception did not have strong correlations with the physical health outcome variables at either the aggregate or weekly level (see Table 1).

\section{Hypothesis testing}

Multilevel mediation effects testing the hypothesized paths for all 4 models, predicting sleep quality, sleep adequacy, headaches and attempts to eat healthy are presented in Table 2. All models were just-identified; thus, fit indices are not reported.

Sleep Quality. Multilevel SEM analyses revealed that gratitude reception predicted SQC at the between-person level $\left(a_{j}=.23, p=.005\right)$, such that nurses who tended to report receiving more gratitude also reported higher levels of satisfaction with care, accounting for covariates. The between-person effects between SQC and sleep quality $\left(b_{j}=.14, p=.19\right)$ and between gratitude reception and sleep quality $\left(c_{j}=\right.$ $.06, p=.39)$ were not significant.

At the within-person level, gratitude reception predicted SQC $\left(\mathrm{a}_{\mathrm{ij}}=.09, p=.009\right)$. In turn, SQC predicted greater sleep quality $\left(b_{i j}=.08, p=.006\right)$ within week. Analyses revealed a significant indirect effect of gratitude reception predicting increased sleep 
quality $\left(a b_{i j}=.01,95 \% \mathrm{Cl}:[.00, .01]\right)^{2}$, indicating that when nurses received more thanks, they were more satisfied with the care they provide their patients, which in turn predicted better subjective sleep that week. However, gratitude reception did not directly predict sleep quality at the within-person level $\left(c_{i j}=.01, p=.63\right)$.

Sleep Adequacy. At the individual (between-persons) level, gratitude reception predicted SQC across weeks $\left(a_{j}=.23, p=.005\right)$. In turn, SQC predicted sleep adequacy $\left(b_{j}\right.$ $=.54, p=.04)$, indicating that nurses who tended to be more satisfied across time reported more nights of adequate sleep on average. Gratitude reception did not predict sleep adequacy controlling for SQC at the between person level $\left(c_{\mathrm{j}}=.13, p=.54\right)$. Further, a between-persons mediation effect did not emerge $\left(a_{j} b_{j}=.12,95 \% \mathrm{Cl}\right.$ : $[-.01$, $.24])$.

Within-person effects indicated that receiving gratitude predicted increased SQC $\left(\mathrm{a}_{\mathrm{ij}}=.09, p=.009\right)$, and SQC was associated with more reports of adequate night's sleep within a given week $\left(b_{i j}=.20, p=.019\right)$. Similar to reports for sleep quality, gratitude reception did not predict sleep adequacy directly $\left(c_{i j}=-.10, p=.17\right)$. Rather, being thanked more in a week predicted more adequate sleep nights that week as a function of greater satisfaction with quality care $\left(\mathrm{a}_{\mathrm{ij}} \mathrm{b}_{\mathrm{ij}}=.02,95 \% \mathrm{Cl}:[.00, .03]\right)^{2}$.

Headaches. Gratitude reception predicted increased SQC at the aggregate level $\left(\mathrm{a}_{\mathrm{j}}=.23, p=.005\right)$. However, no other significant between-person effects between

\footnotetext{
2 The ".00" value within the $95 \%$ confidence interval is due to decimal point rounding within the Mplus software; outputs report the indirect effect as $p$-value $<.05$.
} 
gratitude reception and headaches $\left(b_{j}=-.21, p=.09\right)$ or between SQC and headaches $\left(c_{j}\right.$ $=-.04, p=.73)$ emerged.

Following a similar pattern to sleep, receiving gratitude was associated with increased SQC scores $\left(a_{i j}=.09, p=.009\right)$ at the within-person level. SQC, in turn predicted decreased headaches within week $\left(b_{i j}=-.13, p=.004\right)$. While gratitude reception did not directly reduce headaches $\left(c_{i j}=.01, p=.84\right)$, there was a significant indirect effect via SQC $\left(\mathrm{a}_{\mathrm{ij}} \mathrm{b}_{\mathrm{ij}}=-.01,95 \% \mathrm{Cl}:[-.02, .00]\right)^{2}$.

Healthy Eating Attempts. Gratitude reception predicted increased SQC $\left(a_{j}=.23\right.$, $p=.005)$, and SQC was associated with healthy eating attempts $\left(b_{\mathrm{j}}=.39, p=.006\right)$ between-persons. Nurses who received more thanks reported being more satisfied over time, and nurses who were more satisfied on average tried to eat healthy. However, similar to the direct effect between gratitude reception and eating health $\left(c_{\mathrm{j}}=-.10, p=\right.$ $.36)$, the indirect effect for healthy eating attempts was not significant $\left(a_{j} b_{j}=.09,95 \%\right.$ $\mathrm{Cl}:[-.01, .18])$ between nurses.

Consistent with above within-person results, being thanked more on average within a week was associated with increased SQC scores $\left(a_{i j}=.09, p=.009\right)$. Further, SQC scores predicted attempting to eat healthy more often within a given week $\left(b_{i j}=\right.$ $.12, p=.001)$. Weekly gratitude reception did not uniquely predict healthy eating that same week $\left(c_{i j}=.03, p=.28\right)$. Yet, SQC mediated the relationship between receiving gratitude and trying to eat healthy $\left(\mathrm{a}_{\mathrm{ij}} \mathrm{b}_{\mathrm{ij}}=.01,95 \% \mathrm{Cl}:[.00, .02]\right)^{2}$.

\section{Discussion}


Consistent with literature on generalized gratitude experiences, this study found that receiving expressions of gratitude predicts better physical health via psychological well-being, specifically through work-related satisfaction. Receiving more thanks within a week was related to greater nurse satisfaction with the care they provided, and in turn better sleep quality, sleep adequacy, decreased headaches, and healthy eating intentions. In most cases, the mediation processes operated only within week, rather than at the individual-level. For example, gratitude reception was associated with satisfaction with care at the between-persons level, indicating that nurses who received more thanks on average reported experiencing higher levels of satisfaction with care compared to nurses who received less gratitude on average.

However, satisfaction with care and gratitude reception did not consistently predict health outcomes at the individual level. While this finding may be surprising given research examining the relation between individual-level (i.e., trait or generalized gratitude) gratitude and psychological well-being (e.g., Wood et al., 2010) and the mediation of individual-level gratitude and health via psychological resources (e.g., O'Connell et al., 2016; Wood et al., 2009), the process of receiving rather than experiencing gratitude may be context-dependent. For example, the effects of receiving gratitude and feeling satisfied with one's work may be due to work-related experiences or conditions that nurses encounter week-to-week and may not manifest at the personal level. In other words, the in-vivo interactions with patients, families, and coworkers that contribute to a particularly satisfying experience may be more beneficial 
to one's health than the accumulation of "thank you's" or satisfying experiences over time. Finally, multilevel mediation results indicated that weekly gratitude was not directly related to any of the health outcomes. This is consistent with our argument that received gratitude has an indirect relationship with physical health and extends previous literature concerning the indirect effects of gratitude on physical health (e.g., DeSteno et al., 2013).

Consistent with COR Theory (Hobfoll, 1989; 2001) our work highlights the health benefits of receiving thanks, particularly for those in helping jobs, such as nursing. When nurses are thanked for their care, they may feel more satisfied with the care they provided, and thus experience better physical health. This is also supported by broadenand-build theory (Fredrickson 2001; 2004); increases in gratitude emotion expressions may increase nurses' positive resources resulting in higher satisfaction with patient care that they provide and potential health benefits. Thus, being thanked seems to be a source of positive feedback or recognition about nurses' performance that leads to individual psychological and physical well-being outcomes.

Our findings underscore the importance of the examining expressions of gratitude and their relative impact on the benefactor of care provisions. This work extends literature demonstrating the positive outcomes of expressions of gratitude. One's 'thank you's do not go unnoticed, nor do they lack consequences for individual well-being and physical health. This study may inform health-care organizations interested in implementing programs to improve the well-being of nurses. For example, 
organizations should consider policies that promote increased appreciation for nursing care in addition to initiatives aimed at creating a culture of interpersonal gratitude for health-care professionals' hard work. This is supported by research indicating that gratitude and support for health-care professions promotes a better organizational climate (Bennet, Ross, \& Sunderland, 1996), reduces burnout symptoms (Converso et al., 2015), and improves physical health (Pisanti, van der Doef, Maes, Lazzari, Bertini, \& 2011).

\section{Limitations and future directions}

Our study has many strengths, most notably the weekly surveys enabling us to examine the relationships of interest both within- and between-persons. However, we also note some important limitations that should be addressed in future research. First, our health outcome variables were assessed using single-item measures. Though multiitem assessments are typically preferred, single-item measures for physical health have been shown to perform comparably well as multi-item scales and tend to indicate predictive validity for mortality and undiagnosed diseases (see McDowell, 2006). Furthermore, single-item measures have the advantage of being face valid and brief to administer, which is helpful for reducing participant fatigue (e.g., Larsen \& Fredrickson, 1999) in intensive longitudinal studies such as weekly surveys.

Second, this study cannot account for causal relationships between gratitude reception, satisfaction with care, and physical health. While other studies have examined the temporal precedence between trait gratitude and psychology well-being 
(e.g., Wood et al., 2008) as well as subjective well-being and health (Feist, Bodner, Jacobs, Miles, \& Tan, 1995), we based our hypotheses on theory and empirical evidence suggesting the current directional model within the context of nursing.

Our sample was comprised of experienced nurses in their mid-forties, on average, which may not generalize to the experience of younger, less-experienced nurses. However, our findings were not attenuated when age was included in the models. It is noteworthy that receiving gratitude in an older, more experienced sample of nurses indirectly predicted physical health, given that older nurses may experience a greater degree of strain over the years compared to younger, less-experienced counterparts. Future work should examine differences in gratitude in nurses across a wider range of age and experience. Furthermore, this work could be extended to occupations beyond health-care, including other helping professions such as civil servants or military personnel.

Moreover, the present study was limited in the variety of mechanisms through which gratitude may predict physical health. This study examined a work-relevant measure of satisfaction; however, satisfaction with life, or positive and negative affect, for examples, could be additional intraindividual mechanisms of received gratitude expression and physical health. Furthermore, strong evidence supports the social function of gratitude expressions (e.g., Wood et al., 2010); gratitude expressions can help people find new high-quality relationships as well as strengthen and maintain one's current close relationships, most likely through perceived responsiveness (Algoe, 2012). 
Future studies should extend this work to relationships in health-care (e.g., Reis et al., 2008).

\section{Conclusion}

This study extends gratitude literature by examining how expressions of gratitude contribute to physical well-being for support providers, in this case, nurses-a field that is characterized by the provision of caring behaviors as well as its demanding work conditions. Results indicated that receiving thanks at work was indirectly associated with better subjective physical health via satisfaction with patient care within-week. Our findings indicate that receiving expressions of gratitude may increase individual physical health through building psychological resources. Gratitude interventions, particularly those interested in organizational outcomes, may consider the impact of acknowledging gratitude towards care providers. 
RELATIONAL THRIVING IN CONTEXT

\section{References}

Adriaenssens, J., De Gucht, V., Van Der Doef, M., \& Maes, S. (2011). Exploring the burden of emergency care: Predictors of stress-health outcomes in emergency nurses. Journal of Advanced Nursing, 67(6), 1317-1328.

Aiken L.H., Sermeus W., Van den Heede K., Sloane D.M., Busse R., McKee M., ... KutneyLee A. (2012). Patient safety, satisfaction and quality of hospital care: cross sectional surveys of nurses and patients in 12 countries in Europe and the United States. BMJ, 344, e1717.

Algoe, S. B. (2012). Find, remind, and bind: The functions of gratitude in everyday relationships. Social and Personality Psychology Compass, 6, 455-469.

Algoe, S. B., \& Stanton, A. L. (2012). Gratitude when it is needed most: Social functions of gratitude in women with metastatic breast cancer. Emotion, 12(1), 163-168.

Algoe, S. B., \& Zhaoyang, R. (2016). Positive psychology in context: Effects of expressing gratitude in ongoing relationships depend on perceptions of enactor responsiveness. The journal of positive psychology, 11(4), 399-415.

Algoe, S. B., Fredrickson, B. L., \& Gable, S. L. (2013). The social functions of the emotion of gratitude via expression. Emotion, 13, 605-609.

Algoe, S., Kurtz, S., \& Hilaire, L. (n.d.). (2016). Putting the "You" in "Thank You": Examining Other-Praising Behavior as the Active Relational Ingredient in Expressed Gratitude. Social Psychological \& Personality Science, 7(7), 658-666. 
Andrews, F., \& Withey, S. B. (1976). Social indicators of well-being: Americans' perceptions of life quality. New York: Plenum Press.

Bakker, A. B., Vergel, A. I. S., \& Kuntze, J. (2015). Student engagement and performance: A weekly diary study on the role of openness. Motivation and Emotion, 39(1), 4962.

Bennett, L., Ross, M. W., \& Sunderland, R. (1996). The relationship between recognition, rewards and burnout in AIDS caring. Aids care, 8(2), 145-154.

Buysse, D. J., Reynolds III, C. F., Monk, T. H., Berman, S. R., \& Kupfer, D. J. (1989). The Pittsburgh Sleep Quality Index: a new instrument for psychiatric practice and research. Psychiatry research, 28(2), 193-213.

Carney, M. A., Armeli, S., Tennen, H., Affleck, G., \& O'neil, T. P. (2000). Positive and negative daily events, perceived stress, and alcohol use: A diary study. Journal of Consulting and Clinical Psychology, 68(5), 788-798.

Carver, C. S., Scheier, M. F., \& Segerstrom, S. (2010). Optimism. Clinical Psychology Review, 30, 879-889.

Converso, D., Loera, B., Viotti, S., \& Martini, M. (2015). Do positive relations with patients play a protective role for healthcare employees? Effects of patients' gratitude and support on nurses' burnout. Frontiers in psychology, 6, 1-11.

DeSteno, D., Gross, J. J., \& Kubzansky, L. (2013). Affective science and health: The importance of emotion and emotion regulation. Health Psychology, 32(5), 474486. 
Diamantopoulos, A., \& Winklhofer, H. M. (2001). Index construction with formative indicators: An alternative to scale development. Journal of Marketing Research, $38,269-277$.

Eley, D., Eley, R., Bertello, M., \& Rogers-Clark, C. (2012). Why did I become a nurse? Personality traits and reasons for entering nursing. Journal of advanced nursing, 68(7), 1546-1555.

Emmons R.A. \& McCullough M.E. (2003) Counting blessings versus burdens: an experimental investigation of gratitude and subjective well-being in daily life. Journal of Personality and Social Psychology, 84 (2), 377-389.

Emmons, R. A., McCullough, M. E., \& Tsang, J.-A. (2003). The assessment of gratitude. In S. J. Lopez \& C. R. Snyder (Eds.), Positive psychological assessment: A handbook of models and measures (pp. 327-341). Washington, DC, US: American Psychological Association.

Faragher, E., Cass, M., \& Cooper, C. (2005). The Relationship between Job Satisfaction and Health: A Meta-Analysis. Occupational and Environmental Medicine, 62(2), 105-112.

Feist, G. J., Bodner, T. E., Jacobs, J. F., Miles, M., \& Tan, V. (1995). Integrating top-down and bottom-up structural models of subjective well-being: A longitudinal investigation. Journal of Personality and Social Psychology, 68, 138 -150. 
Fredrickson, B. L. (2001). The role of positive emotions in positive psychology: The broaden-and-build theory of positive emotions. American Psychologist, 56, 218 226.

Fredrickson, B. L. (2004). Gratitude, like other positive emotions, broadens and builds. In Emmons, R. \& McCullough M. (Eds.), The psychology of gratitude (145-166). New York: Oxford University Press.

Grant, A. M., \& Gino, F. (2010). A little thanks goes a long way: Explaining why gratitude expressions motivate prosocial behavior. Journal of personality and social psychology, 98(6), 946-955.

Hasson, D., \& Gustavsson, P. (2010). Declining sleep quality among nurses: a populationbased four-year longitudinal study on the transition from nursing education to working life. PloS one, 5(12), e14265.

Hill, Allemand, \& Roberts. (2013). Examining the pathways between gratitude and selfrated physical health across adulthood. Personality and Individual Differences, 54(1), 92-96.

Hinshaw A.S., \& Atwood J.R. (1984). Nursing Staff Turnover, Stress, and Satisfaction: Models, Measures, and Management. In: Werley H.H., Fitzpatrick J.J. (eds) Annual Review of Nursing Research. Springer, Berlin, Heidelberg.

Hobfoll, S. (1989). Conservation of resources: A new attempt at conceptualizing stress. American Psychologist, 44, 513-524. 
Hobfoll, S. (2001). The influence of culture, community, and the nested-self in the stress process: Advancing conservation of resources theory. Applied Psychology: An International Review, 50, 337-369.

Jackowska, M., Brown, J., Ronaldson, A., \& Steptoe, A. (2015). The impact of a brief gratitude intervention on subjective well-being, biology and sleep. Journal of Health Psychology, 21(10), 2207-2217.

Judd, C. M., \& Kenny, D. A. (2010). Data analysis in social psychology: Recent and recurring issues. In S.T. Fiske, D.T. Gilbert, \& G. Lindzey (Eds.), Handbook of social psychology, (pp. 115-142). Hoboken, NJ: John Wiley \& Sons, Inc.

Krull, J. L., \& MacKinnon, D. P. (2001). Multilevel modeling of individual and group level mediated effects. Multivariate behavioral research, 36(2), 249-277.

Lambert, N. M., Graham, S. M., \& Fincham, F. D. (2009). A prototype analysis of gratitude: Varieties of gratitude experiences. Personality and Social Psychology Bulletin, 35(9), 1193-1207.

Lambert, N. M., Fincham, F. D., Stillman, T. F., \& Dean, L. R. (2009). More gratitude, less materialism: The mediating role of life satisfaction. The Journal of Positive Psychology, 4(1), 32-42.

Larsen, R.J., \& Fredrickson, B.L. (1999). Measurement issues in emotion research. In D. Kahneman, E. Diener,\& N. Schwarz (Eds.), Well-being: The foundations of hedonic psychology (p. 40-60). New York: Russell Sage Foundation. 
Lee, S., Crain, T. L., McHale, S. M., Almeida, D. M., \& Buxton, O. M. (2017). Daily antecedents and consequences of nightly sleep. Journal of sleep research, 26(4), 498-509.

Lin, K. C., Huang, C. C., \& Wu, C. C. (2007). Association between stress at work and primary headache among nursing staff in Taiwan. Headache: The Journal of Head and Face Pain, 47(4), 576-584.

Lockley, S. W., Barger, L. K., Ayas, N. T., Rothschild, J. M., Czeisler, C. A., \& Landrigan, C. P. (2007). Effects of health care provider work hours and sleep deprivation on safety and performance. The Joint Commission Journal on Quality and Patient Safety, 33, 7-18.

Lyubomirsky, S., Dickerhoof, R., Boehm, J. K., \& Sheldon, K. M. (2011). Becoming happier takes both a will and a proper way: An experimental longitudinal intervention to boost well-being. Emotion, 11(2), 391-402.

McCullough, M. E., Kimeldorf, M. B., \& Cohen, A. D. (2008). An adaptation for altruism? The social causes, social effects, and social evolution of gratitude. Current Directions in Psychological Science, 17(4), 281-285.

McDowell, I. (2006). Measuring health: A guide to rating scales and questionnaires (Third ed.). Oxford: Oxford University Press. Meier, L. L., Tschudi, P., Meier, C. A., Dvorak, C., \& Zeller, A. (2014). When general practitioners don't feel appreciated by their patients: prospective effects on 
well-being and work-family conflict in a Swiss Longitudinal Study. Family practice, 32(2), 181-186.

Morrison, K. B., \& Korol, S. A. (2014). Nurses' perceived and actual caregiving roles: identifying factors that can contribute to job satisfaction. Journal of clinical nursing, 23(23-24), 3468-3477.

Muthén, L. K., \& Muthén, B. O. (2008). Mplus (Version 5.1). Los Angeles, CA: Muthén \& Muthén.

O'Connell, B.H., O'Shea, D., \& Gallagher, S. (2016). Mediating effects of loneliness on the gratitude-health link. Personality and Individual Differences, 98, 179-183.

Perry, B. (2005). Core nursing values brought to life through stories. Nursing Standard (through 2013), 20(7), 41-48.

Pisanti, R., van der Doef, M., Maes, S., Lazzari, D., \& Bertini, M. (2011). Job characteristics, organizational conditions, and distress/well-being among Italian and Dutch nurses: a cross-national comparison. International Journal of Nursing Studies, 48(7), 829-837.

Preacher, K. J., Zhang, Z., \& Zyphur, M. J. (2011). Alternative methods for assessing mediation in multilevel data: The advantages of multilevel SEM. Structural Equation Modeling, 18(2), 161-182.

Preacher, K. J., Zyphur, M. J., \& Zhang, Z. (2010). A general multilevel SEM framework for assessing multilevel mediation. Psychological methods, 15(3), 209-233. 
Reis, H. T., Clark, M. S., Pereira Gray, D. J., Tsai, F. F., Brown, J. B., Stewart, M., \& Underwood, L. G. (2008). Measuring responsiveness in the therapeutic relationship: A patient perspective. Basic and Applied Social Psychology, 30(4), $339-348$

Reis H., Gable, S., \& Maniaci, M. (2014). Methods for studying everyday experience in its natural context. In Reis, H., \& Judd, C. M. (Eds.), Handbook of research methods in social and personality psychology (pp. 373-403). New York, NY: Cambridge University Press.

Scheier, M. F., Carver, C. S., \& Bridges, M. W. (1994). Distinguishing optimism from neuroticism (and trait anxiety, self-mastery, and self-esteem): a reevaluation of the Life Orientation Test. Journal of personality and social psychology, 67(6), 1063-1078.

Sinclair, R. R., Mohr, C. D., Davidson, S., Sears, L. E., Deese, M. N., Wright, R. R., Waitsman, M., Jacobs, L., Cadiz, D. (2009). The Oregon Nurse Retention Project Final Report to the Northwest Health Foundation. Portland, OR: Northwest Health Foundation.

Sinclair, R. R., Sliter, M., Mohr, C. D., Sears, L. E., Deese, M. N., Wright, R. R., ... \& Jacobs, L. (2015). Bad versus good, what matters more on the treatment floor? Relationships of positive and negative events with nurses' burnout and engagement. Research in nursing \& health, 38(6), 475-491. 
Totterdell, P., Wood, S., \& Wall, T. (2006). An intra-individual test of the demandscontrol model: A weekly diary study of psychological strain in portfolio workers. Journal of Occupational and Organizational Psychology, 79(1), 63-84.

Tucker, S. J., Harris, M. R., Pipe, T. B., \& Stevens, S. R. (2010). Nurses' ratings of their health and professional work environments. AAOHN journal, 58(6), 253-267.

U.S. Department of Labor, Bureau of Labor Statistics. (2018). Occupational Outlook Handbook. Washington, D.C.: GPO, U.S. Bureau of Labor Statistics. Retrieved from http://www.bls.gov/ooh/healthcare/registered-nurses.htm

Winwood, P. C., \& Lushington, K. (2006). Disentangling the effects of psychological and physical work demands on sleep, recovery and maladaptive chronic stress outcomes within a large sample of Australian nurses. Journal of advanced nursing, 56(6), 679-689.

Wood, A. M., Froh, J. J., \& Geraghty, A. W. (2010). Gratitude and well-being: A review and theoretical integration. Clinical psychology review, 30(7), 890-905.

Wood, A. M., Joseph, S., Lloyd, J., \& Atkins, S. (2009). Gratitude influences sleep through the mechanism of pre-sleep cognitions. Journal of Psychosomatic Research, $66(1), 43-48$.

Wood, A. M., Maltby, J., Gillett, R., Linley, P. A., \& Joseph, S. (2008). The role of gratitude in the development of social support, stress, and depression: Two longitudinal studies. Journal of Research in Personality, 42(4), 854-871. 
You, L. M., Aiken, L. H., Sloane, D. M., Liu, K., He, G. P., Hu, Y., ... \& Shang, S. M. (2013).

Hospital nursing, care quality, and patient satisfaction: cross-sectional surveys of nurses and patients in hospitals in China and Europe. International journal of nursing studies, 50(2), 154-161. 
Table 2.0. Descriptive statistics, intraclass correlations, and bivariate aggregated and weekly correlations

\begin{tabular}{|c|c|c|c|c|c|c|c|c|c|c|c|}
\hline & $M$ & $S D$ & $I C C$ & 2 & 3 & 4 & 5 & 6 & 7 & 8 & 9 \\
\hline \multicolumn{12}{|l|}{ Wave 1 Measure } \\
\hline 1. Optimism & 3.75 & .58 & --- & .10 & $.28^{* *}$ & $.27^{* *}$ & $.19^{*}$ & $-.19^{*}$ & .13 & .02 & -.14 \\
\hline \multicolumn{12}{|l|}{ Weekly Measures } \\
\hline 2. Gratitude Reception & 1.38 & .92 & .48 & --- & .13 & .11 & .09 & .01 & .06 & $.26^{* *}$ & $-.22^{* *}$ \\
\hline 3. SQC & 4.08 & .76 & .56 & $.15^{* *}$ & --- & $.24^{* *}$ & $.29^{* *}$ & $-.20^{*}$ & $.26^{* *}$ & -.03 & -.01 \\
\hline 4. Sleep Quality & 2.90 & .67 & .45 & $.08^{* *}$ & $.16^{* *}$ & --- & $.85^{* *}$ & $-.38^{* *}$ & .10 & -.08 & -.06 \\
\hline 5. Sleep Adequacy & 4.67 & 1.80 & .55 & .05 & $.17^{* *}$ & $.73^{* *}$ & --- & $-.36^{* *}$ & .12 & -.05 & -.03 \\
\hline 6. Headaches & 2.15 & 1.13 & .53 & -.01 & $-.15^{* *}$ & $-.27^{* *}$ & $-.26^{* *}$ & --- & -.06 & $.22^{* *}$ & -.05 \\
\hline 7. Tried to Eat Healthy & 3.79 & 1.00 & .67 & .04 & $.18^{* *}$ & $.08^{*}$ & $.07^{*}$ & -.04 & --- & -.03 & $-.20^{*}$ \\
\hline 8. Number of shifts & 2.42 & 1.77 & .25 & $.45^{* *}$ & -.04 & -.02 & $-.08^{* *}$ & $.08^{* *}$ & .05 & --- & -.16 \\
\hline 9. Night Shift & .39 & .49 & .73 & $-.12^{* *}$ & -.01 & $-.11^{* *}$ & $-.11^{* *}$ & -.02 & $-.15^{* *}$ & -.03 & --- \\
\hline
\end{tabular}

Note. Above the diagonal, correlations are between aggregated variables ( $r_{j}$; nurses' average across weeks; $N=146$ ) below the diagonal, correlations are between weekly variables $\left(r_{i j} ; N=1752\right) . M=$ mean; $S D=$ standard deviation; ICC= intraclass correlation. ${ }^{*} p<.05,{ }^{* *} p<.01$. 
Table 2.1. Multi-level mediation models predicting sleep quality, sleep adequacy, headaches, and eating healthy.

\begin{tabular}{|c|c|c|c|c|c|c|c|c|}
\hline \multirow[b]{2}{*}{ Parameter } & \multicolumn{2}{|c|}{ Sleep quality } & \multicolumn{2}{|c|}{ Sleep Adequacy } & \multicolumn{2}{|c|}{ Headaches } & \multicolumn{2}{|c|}{ Eating healthy } \\
\hline & Estimate & SE & Estimate & SE & Estimate & SE & Estimate & SE \\
\hline \multicolumn{9}{|l|}{ Between level } \\
\hline Intercept & $1.79^{* * *}$ & .43 & 1.64 & 1.13 & $3.21^{* * *}$ & .68 & $2.37^{* *}$ & .70 \\
\hline $\mathrm{GR} \rightarrow \mathrm{SQC}\left(\mathrm{a}_{\mathrm{j}}\right)$ & $.23^{* *}$ & .08 & $.23^{* *}$ & .08 & $.23^{* *}$ & .08 & $.23^{* *}$ & .08 \\
\hline $\mathrm{SQC} \rightarrow \mathrm{PHO}\left(\mathrm{b}_{\mathrm{j}}\right)$ & .14 & .10 & $.54^{*}$ & .26 & $-.21^{+}$ & .12 & $.39^{* *}$ & .14 \\
\hline $\mathrm{GR} \rightarrow \mathrm{PHO}\left(\mathrm{c}_{\mathrm{j}}\right)$ & .06 & .07 & .13 & .21 & -.04 & .12 & -.10 & .11 \\
\hline Indirect effect & .03 & .02 & $.12^{+}$ & .07 & -.05 & .03 & $.09^{+}$ & .05 \\
\hline Residual variance outcome & $.18^{* * *}$ & .03 & $1.57^{* * *}$ & .22 & $.58^{* * *}$ & .08 & $.58^{* * *}$ & .07 \\
\hline Residual variance SQC & $.29^{* * *}$ & .05 & $.29^{* * *}$ & .05 & $.29^{* * *}$ & .05 & $.29^{* * *}$ & .05 \\
\hline \multicolumn{9}{|l|}{ Within level } \\
\hline $\mathrm{GR} \rightarrow \mathrm{SQC}\left(\mathrm{a}_{\mathrm{ij}}\right)$ & $.09^{* *}$ & .03 & $.09^{* *}$ & .03 & $.09^{* *}$ & .03 & $.09^{* *}$ & .03 \\
\hline $\mathrm{SQC} \rightarrow \mathrm{PHO}\left(\mathrm{b}_{\mathrm{ij}}\right)$ & $.08^{* *}$ & .03 & $.20^{*}$ & .08 & $-.13^{* *}$ & .05 & $.12^{* *}$ & .04 \\
\hline $\mathrm{GR} \rightarrow \mathrm{PHO}\left(\mathrm{c}_{\mathrm{ij}}\right)$ & .01 & .03 & -.10 & .07 & .01 & .05 & .03 & .03 \\
\hline Indirect effect & $.01^{*}$ & .00 & $.02^{*}$ & .01 & $-.01^{*}$ & .01 & $.01^{*}$ & .01 \\
\hline Residual variance outcome & $.25^{* * *}$ & .02 & $1.50^{* * *}$ & .09 & $.63^{* * *}$ & .04 & $.32^{* * *}$ & .04 \\
\hline Residual variance SQC & $.27^{* * *}$ & .03 & $.27^{* * *}$ & .03 & $.27^{* * *}$ & .03 & $.27^{* * *}$ & .03 \\
\hline
\end{tabular}

Note. All models controlled for number of shifts worked within week, night shift, and optimism. The paths refer to Figure 1. $\mathrm{GR}=$ gratitude reception; $\mathrm{SQC}=$ satisfaction with care; $\mathrm{PHO}=$ physical health outcome (specified in column headings). ${ }^{+} p<.10,{ }^{*} p<.05,{ }^{*} p<.01,{ }^{* * *} p<.001$. 


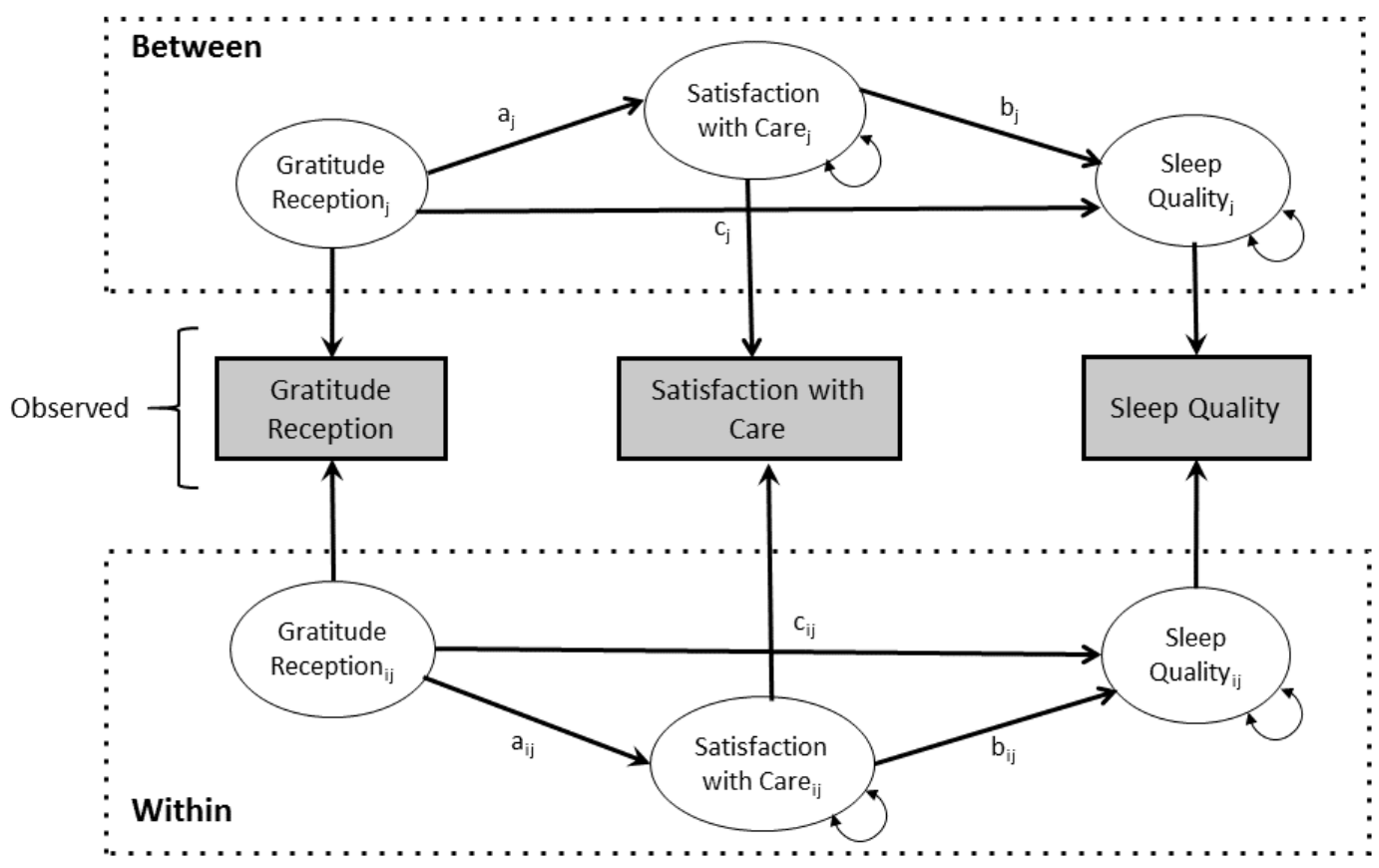

Figure 2.0. Multilevel structural equation model with fixed slopes predicting health outcomes (sleep quality, sleep adequacy, headaches, and trying to eat healthy) in separate models. 
CHAPTER III. MANUSCRIPT II. POSITIVE AFFECT VARIABILITY AND INTIMACY IN MILITARY RELATIONSHIPS.

\begin{abstract}
While increased positive mood tends to be associated with benefits to health and wellbeing, a growing body of research indicates that intraindividual variability in positive affect is associated with poor psychological (Hardy \& Segerstrom, 2017) and physical well-being outcomes (Human et al., 2015). This study examined how intraindividual positive affect (PA) relates to relational well-being, specifically, intimacy in military couples. Post-9/11 military Veterans and their spouses ( $N=159$ dyads; mean relationship length $=12$ years) completed a 32-day online survey probing daily moods and intimacy. PA variability scores were estimated using three calculation methods: (1) an intraindividual standard deviation (iSD) for each participant across the 32 days, (2) an averaged within-person standard deviation across the weeks of the study (iSDw), and (3) the mean square of successive differences (MSSD) which measures the instability of positive mood. Multilevel analyses examined the degree to which person-level positive affect variability, average positive affect, and Veteran posttraumatic stress symptoms predict intimacy within military couples. Results indicated that intraindividual variability (iSD) in positive affect predicted greater intimacy in military couples. However, no other relationships were revealed. This study extends literature examining PA variability to relationship outcomes.
\end{abstract}




\section{Introduction}

Positive affect is important for intimate relationship formation, development, and maintenance (Shiota, Campos, Keltner \& Hertenstein, 2004). Likewise, positive affect is widely considered one component of subjective well-being (Deiner, Suh, Lucas, \& Smith, 1999) and has implications for physical health in addition to relationship outcomes. For example, positive emotions are restorative (Frederickson, 2001), build resilience to adversity (Tugade \& Frederickson, 2004), and are an essential component of thriving by encouraging personal growth and prosperity (Feeney \& Collins, 2015). Within romantic relationships, positive affect is associated with relationship satisfaction (Lyubomirsky, King, \& Deiner, 2005), positive relationship maintenance behaviors (Gable, Reis, Impett, \& Asher, 2004), and increased intimacy (Debrot, Schoebi, Perrez, \& Horn, 2013).

While there is considerable literature linking increased positive affect (PA) to well-being, a growing body of research indicates that PA also has limitations. For example, high levels of PA (e.g., above $75^{\text {th }}$ percentile) is linked to risky behavior (Martin et al., 2002) and psychological distress (Diener, Colvin, Pavot, \& Allman, 1991). Similarly, research indicates that variability in PA, the extent to which the highs and lows of dayto-day positive mood deviates from one's average level, is linked to poor well-being outcomes. Higher affective variability may be a risk factor for psychological distress (van de Leemput et al., 2014) and poor physical health (Hardy \& Segerstrom, 2017; Human et al., 2015). This literature suggests that individual variability in positive mood is associated with decreased psychological and physical well-being. However, few studies 
have examined the degree to which individual variation in positive mood predicts relational well-being, defined as a perceptions or behaviors supporting meaningful social relationships (e.g., Feeny \& Collins, 2015). This study aims to extend literature on variability in positive affect and well-being to intimate relationships, particularly within a sample of military couples.

Military couples may face unique challenges related to deployments and postdeployment reintegration. Since 2001, almost 3 million military service members have been deployed to operations in Iraq and Afghanistan (Wenger, O'Connell, \& Cottrell, 2018). Whereas stressors during deployments may include maintaining household and parenting difficulty, trouble communicating with deployed partner, concerns for safety while in combat zone, and loneliness (Segal, 1989; Warner, Appenszeller, Warner, \& Grieger, 2009), post-deployment stress may be associated with difficulty reintegrating into one's family routine (Knoblach \& Theiss, 2012) and regaining closeness and intimacy with one's partner (Bowling \& Sherman, 2008).

Relational well-being may be further at risk for couples in which the Veteran partner experiences combat-related mental health concerns, including depression, anxiety, and post-traumatic stress disorder (PTSD; Allen, Rhoades, Stanley, \& Markman, 2010; Goff, Crow, Resibig, \& Hamilton, 2007; Renshaw \& Campbell, 2017). For example, both Veterans and their partners report reduced marital satisfaction when the Veteran endorses increased PTSD symptoms (Allen, Rhoades, Stanley, \& Markman, 2010). 
Further, partners of Veterans diagnosed with PTSD report emotional distress and social isolation (Murphy, Palmber, Hill, Ashwick, \& Busuttil, 2017).

Negative affect dynamics (e.g., variation of negative emotions over time) have been recently included as a diagnostic symptom cluster within the Diagnostic and Statistical Manual of Mental Disorders ( $5^{\text {th }}$ ed.; DSM-5; American Psychiatric Association, 2013) and, thus, strongly correlated with PTSD symptoms. However, the relation between positive mood and PTSD remains unclear. A recent study by Brown and colleagues (2016) showed that average PA was not associated with PTSD. This could potentially be due to emotional numbing and anhedonia, or the inability to feel pleasure (Kashdan, Elhai, \& Frueh, 2006), as well as emotional suppression to maintain affective control (Price, Monson, Callahan, \& Rodriguez, 2006) associated with PTSD symptoms. Whereas, current research has focused on the association of mean level positive affect, little work to my knowledge has examined the degree to which positive mood variability relates to PTSD symptoms. The present study attempts to contribute to this area of work by examining how positive mood variability relates to relational well-being and explores the degree to which posttraumatic stress symptoms (PTSS) alters this association within military-connected relationships.

\section{Positive Affect and Relational Well-being}

Prominent theoretical perspectives within positive psychology and relationship science posit that increased positive affect contributes to relational well-being. For example, broaden-and-build theory suggests that positive affect is restorative and builds 
resources for the self to pursue new opportunities. When applied to couples, the theory suggests that positive emotions, like love and joy, may lead people to seek social opportunities such as growing or maintaining relationships (Frederickson, 2001). Within the process of capitalization (e.g., attempting to savor positive events and emotions by sharing them with others), the sharing of positive news boosts positive mood over and above that of the positive affect associated with the news itself (Gable et al., 2004). In addition, the interpersonal process model of intimacy puts forth that emotional expression between partners helps to build intimacy (Reis \& Shaver, 1988). For example, partners guided by their own personal goals and desires engage in exchanges in which one partner discloses feelings, either explicitly or subtlety via non-verbal communication, and their partner responds in a responsive manner which leads to increased feelings of intimacy. These theories argue that repeated positive experiences between partners build expectancies that serve as relational resources, which contribute to the stability of relational well-being (i.e., relationship satisfaction) over time. Thus, the more often partners express positive emotions with each other the more likely positive resources are built over time that support well-being.

Recent studies examining fluctuations in relationship-relevant evaluations such as attachment security and relationship satisfaction are beginning to challenge this assumption of stability (in terms of enduring relational well-being due to repeated positive experiences over time). For example, research examining early stages of romantic relationships indicates that variability in relationship satisfaction or 
commitment is associated with relationship dissolution (e.g., Daily et al., 2017). People who showed more frequent ups and downs in their relationship satisfaction early in their dating relationship were more likely to break-up months later (Arriaga, 2001). In established relationships, variability in a partner's evaluations of relational security predicted decreased relationship satisfaction over time, especially for securely attached individuals (e.g., those who believe they are worthy of love and support over time; Girme et al., 2017). In other words, people who began the study feeling that their partner was generally responsive to their needs were less satisfied with their relationship when their sense of security varied over time. Similarly, individuals tend to expect their partner's happiness to be stable. As such, when a person underestimates the degree to which their partner's happiness fluctuates, their relationship satisfaction is reduced (Hülür et al., 2016). This evidence is consistent with literature describing that the link between static levels of positive affect and individual well-being, while important, may overlook the dynamic, fluctuating nature of emotion and its relation to well-being (Houben, Van Den Noortgate, \& Kuppens, 2015; Ong \& Ram, 2017). For example, a recent meta-analysis of emotion dynamics (e.g., how emotions fluctuate and regulate over time) and well-being suggests that variability in positive and negative affect has a comparable effect size to mean level affect for individual well-being outcomes such as life satisfaction, anxiety, depression, self-esteem and others (Houben et al., 2015). Thus, it is commensurably important to study both people's average level of emotion as well as how their feelings fluctuate and change over time in order to 
further understand well-being. The current study argues that this rationale also extends to relational well-being. Therefore, applying arguments put forth by affective scientists (Houben et al., 2015; Ong \& Ram, 2017), interpreting levels of positive mood as favorable or unfavorable for relationships is insufficient; rather, the effect of positive mood may be nuanced relative to the degree of within-person fluctuation.

\section{Positive affect dynamics and intraindividual variability}

Within-person variability can be conceptualized in a variety of ways. Nesselroade (1991) defines intraindividual variability as, "relatively short-term changes that are construed as more or less reversible," (p. 215). Based on this definition of intraindividual variability, Ram and Gerstorf (2009) defined two sub-classes: dynamic processes and dynamic characteristics. Dynamic processes are systematic patterns of change that describe an individual's movement from one moment in time to the next (e.g., emotion regulation). Dynamic characteristics describe the individual's capacity, susceptibility, or potential for change, such as the flexibility of emotional expression across situations, or in this case, positive mood variability. Dynamic characteristics may be measured in a variety of ways, all of which help to capture the diversity of behaviors or states across time; however, the most common measure is the individual standard deviation (iSD) of a given construct. The iSD estimates the standard deviation of repeated measures across the course of a longitudinal study. Therefore, this variability measure does not take into account the time-ordered nature of the measurement occasions (e.g., day-to-day situational processes), but rather provides a global view of 
variability across times. Other estimates such as the mean square of successive differences (MSSD) measures within-person fluctuation, taking into account variation from one measurement occasion to the next. The MSSD, therefore, captures the instability of constructs measured within a longitudinal study. Studies employing variability (iSD) and instability (MSSD) indicators tend to account for an individual's mean level of the construct, in effect measuring an individual's characteristic variability or instability beyond their average level.

The emotional dynamics literature builds upon this intra-individual variability framework by describing the ways in which emotional dynamic characteristics and emotion regulation (i.e., dynamic processes) are interrelated (Kuppens \& Verduyn, $2015,2017)$. Specifically, emotional intra-individual variability is theorized to capture the sensitivity of the emotion appraisal system that helps to generate as well as regulate affective responses (Kuppens \& Verduyn, 2015). In other words, a person may experience higher or lower happiness depending on their likelihood to evaluate day-today events or interactions more or less positively, which helps to generate and regulate feelings of happiness. Highly sensitive individuals may experience more rapid fluctuations in positive emotions such as happiness, whereas less sensitive individuals may evaluate day-to-day events and interactions about the same resulting in less fluctuation in happiness over time. Therefore, an individual's tendency to be sensitive to positive emotions (measured by variability or instability) helps lay a foundation for regulation processes and provides a snapshot of emotional functioning. 
It is important to note that positive emotions are functionally independent from negative emotions (Watson, Weise, Vaidya, \& Tellegen, 1999). For example, negative emotions are associated with a narrowing of focus in order to attend and react to threats, whereas positive emotions are related to a broadening of one's perspective necessary for personal growth (Frederickson, 2001). Reis and Gable (2003) argue that positive and negative emotions are embedded within reward and inhibition systems that, independently, underlie our motivations, self-regulation, and personality. For example, positive emotions may be more associated with approach motives, such as seeking nurturance, whereas negative emotions may be associated with avoidance, such as avoiding threats to security. Higgins (1997) describes that when people are motivated by promotion (i.e., approach) regulatory goals, they are more sensitive to the presence or absence of positive events and emotions and conceptualize changes as gains or nongains. On the other hand, when people are motivated by prevention (i.e., avoidance) goals they are more sensitive to the presence or absence of negative outcomes and emotions, and conceptualize changes as non-losses or losses. The independence of positive and negative processes extends to processes within relationships. For example, interactions such as interpersonal conflict and criticism between partners is considered an aversive process that leads to negative outcomes for the couple and individual. Similarly, appetitive processes are those that help develop and support relationship maintenance such as social support or sharing good news with one's partner. Aversive and appetitive processes are independent such that the presence of positive 
interactions such as social support does not necessitate that negative interactions, such as conflict, are absent (Gable \& Reis, 2003). This extends to emotions as well: the presence of positive emotions does not suggest the absence of negative emotions, and the absence of positive emotions does not mean the presence of negative emotions. Therefore, fluctuations in positive affect may describe an individual's sensitivity to the gains or non-gains of positive emotional appraisals. While these fluctuations are not necessarily indicative of negative events or emotions (e.g., inferring that when positive mood is low, negative mood is high), variability in positive affect may yet explain nuances in well-being outcomes.

As eluded to earlier, literature examining positive emotion dynamics shows that variability in positive affect relates to well-being. Specifically, increased positive affect variability predicts lower life satisfaction, and higher depression and anxiety (Gruber, Kogan, Quoidbach, \& Mauss, 2013), greater chronic health conditions such as chest pain (Chan, Zhang, Fung, \& Hagger, 2016), increased alcohol consumption (Mohr, Arpin, \& McCabe, 2015), and unfavorable hypothalamic-pituitary-adrenal axis functioning, a key health indicator (Human et al., 2015). With respect to health outcomes, researchers theorize variability may be stressful (Human et al., 2013), signal poor coping strategies (Eizenman, Nesselroade, Featherman, \& Rowe, 1997), and this serves as one pathway leading to decreased well-being. For example, when individuals are more reactive to stressful events, they may experience poor sleep (Ong et al., 2013), increased inflammation (Sin, Graham-Engeland, Ong, Almeida, \& 2015) and increased mortality 
risk (Mroczek et al., 2013). Given the restorative function of positive affect, frequent fluctuations in positive mood may not allow an individual to savor their emotions, and thus contribute to wear and tear of health and well-being over time. Given the importance of positive emotions for relationship maintenance, variability and instability of positive emotions may not only prevent an individual from reaping the benefits of positive emotion, but also limit their ability to share their positive emotions or respond to partner's emotions in return. Thus, variability in positive emotions may block individual resource restoration and relationship maintenance interactions.

\section{Emotion dynamics in intimate relationships}

Intimate relationships form our emotional experiences and our emotional experiences form our intimate relationships (Schoebi \& Randall, 2015). In fact, this is a fundamental feature of close relationships (Kelly et al., 1983; Rusbult \& Van Lange, 2003). Such emotional interdependence as defined by Sels and colleagues (2016), has been well-documented, including phenomena such as co-regulation (Butler \& Randall, 2013), emotion contagion (Thompson \& Bolger, 1999), suppression (Chervonsky \& Hunt, 2017), and susceptibility (Randall \& Schoebi, 2015), to name a few. For example, emotions within couples tend to covary and in turn help regulate emotional responses to daily experiences over time (Butler, 2011). Suppression within couple interactions, in which one partner suppresses their emotional reaction to their partner, has been linked to increased avoidance-oriented physiological threat response as well as decreased perceived partner responsiveness and reduced intimacy (Peters \& Jameison, 2016). 
Importantly, suppression is not limited to negative emotions: individuals also tend to suppress positive emotions, which is in turn related to poor relational outcomes (Gross \& John, 2003). One study showed that interdependent patterns in positive emotions predicted increased individual and relational well-being whereas negative emotion interdependence was not related to well-being (Sels, Ceulemans, Bulteel, \& Kuppens, 2016). Taken together, literature in emotion dynamics and emotion interdependence suggest that individual emotion dynamics tend to coordinate changes that shape one's own well-being as well as the well-being of intimate partners (Schoebi \& Randall, 2015). Therefore, emotion dynamics including individual fluctuation in positive mood should be examined within the context of relationships.

\section{Military-connected relationships and relationship outcomes}

Affective variability and relational well-being may be of particular relevance for military relationships. As noted previously, qualitative and quantitative research describes challenges that military relationships face, particularly when posttraumatic stress is present. However, archival data suggests that more time spent deployed was associated with lower risk of divorce (Karney et al., 2012; Karney \& Trail, 2017) suggesting that while relationships may be challenged by military service, serving in the armed forces does not necessarily set a relationship on the path towards dissolution. In fact, the divorce rate of military couples is similar to civilian couples and couples may draw on various resources to endure through military-related challenges (Karney \& Crown, 2007). 
Evidence suggests that military relationships may be protected by positive emotions and cognitions. For example, spouses who experience more positive emotions while their Veteran partner is deployed tend to report less depressive symptoms and employ more adaptive coping strategies (Dolphin, Steinhardt, \& Cance, 2015). Military Veterans tend to be more satisfied with their relationship when their spouses take a positive perspective of military experiences (Renshaw \& Campbell, 2017). In sum, military relationships, as in other relationships, may benefit from developing resources that serve as protective factors against challenges to relational well-being, such as experiencing and sharing positive emotions.

Likewise, affective scientists suggest that emotional dynamics can be an important protective or risk factor for well-being outcomes (Kuppens \& Verduyn, 2017). Individual differences in positive mood variability, in particular, has the potential to promote and prevent well-being over time (Ong \& Ram, 2017). A recent study examining the concept of experiential avoidance, or resisting to engage with unpleasant feelings, within military couples suggests that such emotional suppression relates to reduced marital quality, even after accounting for couples' communication behaviors (Zamir, Gerwertz, Labella, DeGarmo, Snyder, 2018). For example, say Veteran partner, Paul, tends be afraid of his feelings because they make him uncomfortable or lack selfcontrol so he tries to shake off his emotions by trying to think different thoughts or by changing the subject of conversation with his wife, Anna. Paul's avoidance of emotion may lead to both Paul and Anna to feeling that their marriage is poorly functioning, even 
though they were not especially critical of each other and seemed to compromise when discussing conflicts. In other words, emotional expression may be important for relational well-being beyond that of specific behavioral interactions. Similarly, one study of military couples during reintegration after a deployment cycle found that Veterans and spouses who tend to express their emotions reported increased psychological health (Marini, MacDermid Wadsworth, Christ, \& Franks, 2017). However, in the context of high Veteran combat exposure, spouses' emotion expression predicted negative psychological health in Veterans, indicating that emotionality may both promote or hinder military-connected relationships depending on combat- or military-related challenges, such as posttraumatic stress.

Drawing from recent literature, variability in positive mood at high levels may relate to low perceptions of intimacy with one's partner, while lower variability may be suggestive of emotional numbing and related to lower intimacy within Veterans and their spouses as well. Ong and Ram (2017) note that there may be discrepancy in the degree to which positive mood variability is helpful or harmful. The authors suggest that one way to examine the nuances of positive affect variability is to examine the "fragility" of variation by investigating the degree to which individual variability depends on one's mean level. For example, people who have high average positive affect and are also highly variable or more unstable in positive mood, may show greater decreases in intimacy than those with less variability. Therefore, studying fragility of positive affect provides a unique view of positive emotion dynamics and its relation to individual and 
relational well-being. In addition, military-related challenges such as Veteran's posttraumatic stress symptoms (PTSS) may additionally qualify the effect of positive mood variability on intimacy within military relationships. For example, Veterans with higher PTSS and are highly variable in positive emotion may report lower rates of intimacy than those who report less PTSS; however, the relation between positive affective variability and PTSS has been largely understudied. The present study aimed to explore the association between PTSS and variability in positive mood.

\section{Present study}

Research suggests positive affect has both benefits and costs to well-being over time. Considering the degree to which one fluctuates around one's mean level of positive mood provides a nuanced perspective on how positive affect promotes or hinders well-being (Ong \& Ram, 2017). For example, current perspectives in emotion dynamics suggest that fluctuations in positive affect may lead to wear and tear in wellbeing over time (Kuppens \& Verduyn, 2017), and prohibit the restorative nature of positive emotions. Such emotional dynamics are not only relative to one's own wellbeing but are also dependent on one's intimate relationship partner's dynamics as well (Schoebi \& Randall, 2015). Therefore, the primary focus of this study is to examine the degree to which positive affect variability and instability reduces intimacy for Veterans and their partners.

The present study is part of the Study for Employment Retention of Veterans (SERVe; Hammer, Wan, Brockwood, Mohr, \& Carlson, 2017; Mohr et al., 2018). SERVe is 
a randomized controlled trial (RCT) evaluating a supportive supervisor training designed to increase employment and well-being outcomes for military Veterans, funded by the Department of Defense. As part of this study, Veterans and their spouses completed surveys prior to intervention as well as 3- and 9- months following the intervention. In addition, Veterans and their partners who agreed to participate in SERVe were asked to take part in a 32-day daily study called the Daily Family Study (DFS) prior to intervention. This study utilizes daily data from the DFS to examine mood variability and well-being in military-connected couples.

It is important to note that emotion dynamics are typically studied via intensive longitudinal designs either through self-report measures or observed and coded by others. Longitudinal designs employing sampling techniques taking place multiple times a day, once a day or at least once a week are generally more preferable for the study of emotion and mood than longer intervals between observations (e.g., once per month; Houben et al., 2015) due to identified patterns of daily and weekly mood (e.g., Egloff et al., 1995; Larsen and Kasimatis, 1990). Further, many studies examining positive affect variability have examined fluctuations in observations from data collected over 7 days on average (e.g., Hardy \& Segerstrom, 2017; Human et al., 2015; Koval et al., 2013), whereas few studies have employed designs that collect data across 30 or more consecutive days (e.g., Rocke, Li, \& Smith, 2009). Therefore, measuring positive affect variability across 32 observation days, as in this study, may allow for increased information regarding fluctuations in daily mood than other emotion dynamics studies. 
Variability in the current study was measured in two ways: first, using an individual standard deviation (iSD) across all daily study observations; and, second, by estimating the average of individual standard deviations calculated at the end of every week within the daily study, resulting in an individual's average weekly standard deviation (iSDw). Instability was estimated by using the mean square of successive difference (MSSD) which calculates the deviations in scores from day-to-day across the daily observations.

The second aim of the current study is to investigate the degree to which fragile positive affect contributes to intimacy between Veteran and spouses. Thus, the interaction between positive affect variability (iSD, iSDw, MSSD) and individual mean levels of positive mood was examined to address this aim. As mentioned previously, literature regarding PTSS and positive affect variability is sparse and lacks support for direct hypotheses. Therefore, the final aim of this study is to explore the degree to which PTSS may additionally qualify the relation between positive affect fluctuation and intimacy. Therefore, I posed the following hypotheses and research questions.

First, drawing from literature showing the negative consequences of positive mood variability and well-being in mental and physical health, I expected that intraindividual positive affect variability, measured by iSD ( $\mathrm{H} 1 \mathrm{a})$ and iSDw (H1b) and instability (H1C; measured by MSSD) will predict lower intimacy, and that the effect of positive mood variability $(\mathrm{H} 2 \mathrm{a}$ and $\mathrm{H} 2 \mathrm{~b})$ and instability $(\mathrm{H} 2 \mathrm{c})$ on intimacy will depend on partner role, Veteran or spouse. Based on literature describing the context in which variability and instability in positive emotion may be the most detrimental (Ong \& Ram, 
2017), positive affect fragility is expected to be negatively associated with intimacy. Specifically, the interaction between positive affect variability and individual's mean level ( $\mathrm{H} 3 \mathrm{a}$ and $\mathrm{H} 3 \mathrm{~b})$ will predict decreased intimacy particularly for those with fragile high (high variable, high mean) positive mood. A similar effect is hypothesized for positive mood instability $(\mathrm{H} 3 \mathrm{c})$. The interactions for positive affect variability $(\mathrm{H} 4 \mathrm{a}$ and $\mathrm{H} 4 \mathrm{~b})$ and instability $(\mathrm{H} 4 \mathrm{c})$, respectively, are expected to differ for Veterans and spouses. Similarly, posttraumatic stress symptoms (PTSS) tend to negatively impact relationships, thus, I hypothesize that Veteran's PTSS will predict lower intimacy ( $\mathrm{H} 5 \mathrm{a})$ and that this will differ for Veterans and partners ( $\mathrm{H} 5 \mathrm{~b})$.

Interestingly, positive affect has been inconsistently related to PTSS (e.g., Brown

et al., 2016). Thus, I explored the following research questions: how does PTSS relate to positive affect variability and instability in Veterans and spouses (RQ1)? Further, does the relation between intimacy and positive affect variability and instability depend on Veteran's PTSS (RQ2)? Does this potential interaction between positive mood fluctuation and PTSS differ for Veterans and spouses in their reports of intimacy (RQ3)?

\section{Methods}

\section{Participants}

Participant demographics for this sample ( $N=159$ dyads) were reported previously in published manuscripts or those under review using SERVe and DFS data. The sample is diverse with regard to military experience and demographics. For example, the majority of the sample was separated from military service including those 
separated from active duty as well as national guard and reservists (NG/R), with a smaller proportion of active NG/R (18\%). In addition, $88.3 \%$ of the military sample reported completing at least one deployment, and most of the couples in this sample were married or in a civil union (89.9\%); therefore, similar to other SERVe-related publications and documentation, I refer to the military participants collectively as "Veterans," their partners as "spouses," and describe the couples as in "militaryconnected" relationships. Couples reported being together for 11.90 years on average $(S D=8.59)$, with $69.2 \%$ of the couples indicating that they had dependent children living in the home. Veterans were majority male (89.3\%) and Caucasian (83.0\%). Likewise, most spouses were female (89.9\%) and Caucasian (81.1\%). On average, Veterans were 38.16 years old $(S D=9.12$; range $23-67)$ and spouses were on average 36.22 years old (SD 9.036; range $20-61$ ). The median household gross income range was $\$ 50,000-$ $\$ 74,999$ per year in the sample. About half of Veterans (47.2\%) and spouses $(50.3 \%)$ completed college or technical school.

\section{Recruitment and Procedure}

Veteran participants who were recruited for SERVe were invited to participate in the DFS with their spouses. To be eligible for the SERVe study, Veterans must have been working at least part-time, or over 20 hours per week, and have served in the U.S. Military (including all branches and National Guard or Reserves) after 9/11. Eligible couples must have been in a cohabitating relationship. From the Veterans and spouses participating in SERVe, 260 were matched couples and eligible for the DFS. Of these, 173 
matched couples consented into both the baseline survey and DFS study and completed at least 1 day of surveys. Nine couples who participated in a pilot version of the DFS were removed due to incompatible data (e.g., survey scales and format differed between pilot and final study surveys). Finally, 3 couples reported in a different timing window from their partners and consequently were removed from these analyses. Thus, the final analysis sample drew from these 159 couples.

Shortly after the SERVe baseline survey, participants began the DFS. For 32 consecutive days, participants were emailed a secure link to complete their daily survey which took about 5 to 10 minutes to complete. Participants were required to complete the survey within a 6-hour window between 5:00 PM and 11:00 PM. The DFS surveys were designed to be taken after work but before bedtime. In order to accommodate participants (18\%) with an irregular work schedule (e.g., night shift), qualifying participants who indicated working evening or night shifts were sent surveys between 5:00 AM and 11:00 AM, instead, as were their spouses. Participants reported information about their work day, health behaviors, mood, relationship and family. A total of 7,916 daily surveys were completed over the course of the DFS; participants completed up to 24 survey days on average out of 32 , resulting in a $78 \%$ compliance rate. Participants could earn up to $\$ 90$ for their continued participation in the daily study. In addition, participation in SERVe and the DFS was voluntary; all research procedures were approved by Portland State University's Institutional Review Board (IRB), as well as co-investigating IRBs (i.e., Portland Veterans Affairs Hospital and Oregon 
Health and Sciences University) and the U.S. Army Medical Research and Material Command, Human Research Protection Office.

\section{Measures}

Positive Affect (PA). PA was measured using 5 items selected from the Positive and Negative Affect Schedule-Expanded form (PANAS-X; Watson, Clark, \& Tellegen, 1988; Watson \& Clark, 1994), mood circumplex model (Larsen \& Diener, 1992), and 1 item measuring grateful mood from Emmons and McCullough (2003) collected across 32 consecutive daily surveys. Participants rated the degree to which they presently felt Happy, Relaxed, Active, Grateful, and Focused on a scale from (1) "Not at all" to (5) "Extremely." Composites were created following tests of internal consistency. Cronbach's alphas estimated for survey days 3,10, and 26 ranged from .74 to .76 within survey day. PA items were summed to create daily composite scores.

Intimacy. Intimacy was measured with 1 item asking participants, "Over the past 24 hours, how close did you feel to your spouse or partner?" The item was rated on a 5point scale ranging from (1) "Not at all close" to (5) "Extremely close." Previous research has used similar one-item measures in daily dairy methodology to study day-to-day evaluations of intimacy among couples (Laurenceau, Barrett, \& Rovine, 2005). Higher scores indicate greater endorsement of intimacy.

Post-traumatic stress symptoms (PTSS). PTSS was measured using the Posttraumatic Stress Disorder Checklist, Military version (PCL-M; Bliese et al., 2008; Weathers, Huska \& Keane, 1991). This measure primarily serves as a screening tool for 
military-related post-traumatic stress. At baseline, Veterans were asked 4 items regarding their posttraumatic stress symptoms during the past 30 days. For example, Veterans rated items probing how much they have been bothered by "repeated disturbing memories, thoughts, or images of the stressful experience," on a scale of (1) "Not at all" to (5) "Extremely." Items were averaged to create a composite of PTSD symptomology.

Covariates. Negative affect (NA) mean level, NA variability, NA instability, relationship length, gender, parent status, day of the week, and shift work were included as covariates. While independent, negative affect and positive affect tend to moderately covary (Reich, Zautra, \& Davis, 2003), thus, experts recommend controlling for an individual's negative affect in order to help rule out that the variability may be due to change in negative mood, for example. Similar to PA, NA items were selected from the PANAS-X (Watson et al., 1988; Watson \& Clark, 1994) and measured during the 32-day DFS. Participants rated the degree to which they currently felt Angry, Guilty, Ashamed, Nervous, Lonely and Sad on a scale from (1) "Not at all" to (5) "Extremely." NA mean scores, variability, and instability scores were created and included as covariates. Research indicates that men and women tend to report different outcomes for relational well-being (e.g., Laurenceau et al., 2005). In addition, longer relationships (e.g., Kurdek, 1993) and parents with children in the home may be subject to declines in perceived intimacy (O’Brien \& Peyton, 2002). Thus, relationship length (in years), gender, and parent status were included as covariates. In addition, moods (Ryan, 
Bernstein, \& Brown, 2010) and intimate interactions (Milek, Butler, \& Bodenmann, 2015) between partners tend to vary over days of the week. Finally, in order to account for differences among intimacy reports due to an alternate schedule, shift work (e.g., those who took the surveys during the alternative time window) was included in models as a covariate.

\section{Data Analysis}

Preprocessing of affective data. As noted previously, positive affect variability was calculated in three ways. First, the intraindividual standard deviation (iSD), a reliable and commonly-used metric to study individual differences in affect variability (Eid \& Diener, 1999; Ong \& Ram, 2017; Ram \& Gerstorf, 2009), was created by calculating standard deviations of each individual's positive affect composite scores over the course of the 32 days. Second, an across week standard deviation (iSDw) was estimated by averaging the intraindividual standard deviations from each week of the daily study. Lastly, each individual's mean square of successive difference (MSSD; Jahng, Wood, \& Trull, 2008) across the 32-days was calculated using the formula below, where $i$ is the observation day:

$$
M S S D=\frac{1}{N-1} \sum_{i=1}^{N-1}\left(x_{i+1}-x_{i}\right)^{2}
$$

One of the criticisms of using iSDs to examine intraindividual variability is that this metric assumes that the repeated observations are independent of time. Therefore, it is helpful to examine variability in which the time-structured data is taken into 
account. The MSSD reflects the amplitude and frequency of positive affect variability in which changes between consecutive observations are weighted based on the degree of variation. Therefore, this index measures both the variability of positive affect but also the temporal dependency across time, and thus, highlights the instability of positive affect. These three methods of measuring affect fluctuations were tested in separate models predicting intimacy in military couples. The same procedures were used to calculate negative affect variability (iSD, iSDw, and MSSD) and these variables will be included in the respective models as controls. In addition, mean level positive and negative affect were calculated by aggregating the average of PA and NA composite scores across all 32 days. All variability predictors were modeled as time-invariant indicators of an individual's characteristic sensitivity to positive mood responses (iSD and iSDw) and instability of positive affect appraisals (MSSD).

Preliminary analyses. The data were examined for normality and outliers. Specifically, descriptive statistics did not indicate problematic skew for the primary study variables. Box plots did not indicate problematic outliers. In addition, examination of level 1 residuals via residual scatterplots and normal probability plots indicated that multi-level assumptions were not violated.

Missingness. Multilevel logistic regressions were conducted to test the likelihood of missed days predicted by study variables such as day of the week and parent status. Analyses revealed that day of week did not significantly predict missed days in intimacy, $F(6,7585)=.004, n s$, or in positive affect $F(6,7585)=.004$, ns. 
Similarly, parent status did not predict missingness in intimacy, $F(1,10174)=.41$, ns, or positive affect, $F(1,10174)=.40, n s$. These results indicate that missingness is not due to day of the week or parent status. However, it is still difficult to determine whether the missingness is random. Therefore, the following analyses include covariates and employ estimation strategies to mitigate issues related to missing data.

In addition, the distribution of observation days was examined to determine how the number of completed days may affect the data. Upon visual inspection, there was not a clear cut-point for the number of days completed. To explore the completed observations further, I examined data from those with 1 or more, 3 or more, or 5 or more completed survey days and conducted bivariate correlations between intimacy and variability scores in an effort to examine the sensitivity of the data to these different criteria. Overall, the significance $(p<.05)$ of the correlations between variables did not change; however, the correlations strengthened when examining data for those who had 3 or more days but did not improve any more after 5 days. Therefore, the primary analyses only include individuals who have 3 or more days.

Nonindependence. First, I examined the distinguishability of the dyad roles. Distinguishability has to do with whether there is a meaningful (if arbitrary) variable that can be used to differentiate individuals within the couples. In this case, whether the partner is the Veteran or spouse is considered the distinguishing variable. Veteran status was assigned to individuals participating in the larger SERVe study and then their spouses were recruited in subsequent recruitment efforts, which is a meaningful 
distinction for the purpose of the SERVe intervention as well as the current study. However, while this constitutes a conceptual distinction, Kenny and colleagues (2006) contend that it is important to confirm with an empirical distinguishability test. Assuming distinguishability when partners are empirically indistinguishable suggests differences in processes and outcomes of population-level roles that the individuals fall into within in the couple (e.g., husband or wife) when, in fact, there may be no such difference in the sample. Distinguishability analyses testing whether there is an empirical distinction between Veteran and spouse roles within the dyad revealed that the role were indistinguishable for all variability predictors on intimacy including positive affect iSD, $\chi^{2}(4)=7.59, p=.11$, iSDw, $\chi^{2}(4)=7.94, p=.09$, and MSSD, $\chi^{2}(4)=$ 8.35, $p=.08$. Kenny, Kashy and Cook (2006) recommend specifying dyadic models based on the empirical test of distinguishability. While the distinguishability tests for iSDw and MSSD are marginal, these tests indicate that Veterans and spouses cannot be empirically differentiated within a given dyad. Therefore, the dyads were treated as indistinguishable in all models by excluding the interaction between role and predictor variables. Further, hypotheses $2 a, 2 b, 4 a, 4 b$, and $5 b$ which predicted differences between spouses and Veterans will not be tested.

Nonindependence between PA mean and PA variability score was also examined. There was a correlation between PA mean and PA variability (iSD; $r=.13, p<.05$ ). However, mean level PA was not related to weekly variability (iSDw; $r=.16, n s$ ) or instability (MSSD; $r=.09, n s$ ). When visually inspecting the scatterplots, there appeared 
to be no visible sign of a curvilinear relationship between PA mean level and iSD and iSDw variability scores. However, scatterplots indicated a slight curvilinear trend between PA MSSD and PA mean level. Thus, curvilinearity was examined.

Finally, nonindependence due to the structure of the data was also examined. Intra-class correlations for time points nested within individuals and individual nested within employment organization were calculated. About $57 \%$ of the variance in intimacy was due the individual $($ ICC $=.569)$. In addition, the ICC for employer was .066 , indicating that little of the variance in intimacy was due to Veteran's organization. This falls below the recommended .10 cut off (Hox, 2010) I used to determine the inclusion of organizational variability, indicating that intimacy likely does not depended on employee structure. In turn, non-independence among dyads was examined via intraclass correlation (rather than bivariate correlation) and indicated that $47 \%$ of the variability in intimacy could be contributed to the dyad (ICC $=.468)$.

Primary analyses. Multilevel models were conducted to test whether an individual's variability in positive mood is associated with daily intimacy in military couples. Analyses examined the degree to which within-person average intimacy is a function of differences in characteristic levels of positive affect variability (iSD, iSDw, and MSSD), average PA level, interaction of level and variability (fragility), and whether these association differ for Veterans and spouses. Further, the degree to which Veteran's PTSS explains the PA variability and intimacy associations was explored. Such analyses model intercepts as random effects, aiming to describe how people differ in 
their average levels of intimacy (level 1) across occasions based on person-level (level 2) components of positive affect. The model consists of three levels including daily observations (level 1) nested within people (level 2) and people nested within romantic relationships (level 3). Therefore, the level 1 model will be as follows, where $i$ represents the time-varying daily measure, $j$ represents the individual-level variables, and $k$ represents the dyad:

$$
\text { Intimacy }_{\mathrm{ijk}}=\beta_{0 \mathrm{jk}}+r_{\mathrm{ijk}}
$$

Daily observations of intimacy were nested within individuals at level 2. Individual-level positive affect variability measures including iSD, iSDw, and MSSD was tested in separate models. Below is the level 2 model using iSD as an example:

$$
\beta_{0 \mathrm{jk}}=\gamma_{00 \mathrm{k}}+\gamma_{01 \mathrm{k}} P A i S D_{\mathrm{jk}}+\gamma_{02 \mathrm{k}} P A m e a n_{\mathrm{jk}}+\gamma_{03 \mathrm{k}} P A i S D X \operatorname{mean}_{\mathrm{jk}}+u_{0 \mathrm{jk}}
$$

For simplicity, the covariates such as mean level of negative affect, negative affect variability, and gender are not depicted in the equations but were included in the tested models. Finally, individuals at level 2 will be nested within couples at level 3 and modeled as follows:

$$
\begin{gathered}
\gamma_{00 \mathrm{k}}=\pi_{000}+P T S D_{\mathrm{k}}+u_{00 \mathrm{k}} \\
\gamma_{01 \mathrm{k}}=\pi_{010} \\
\gamma_{02 \mathrm{k}}=\pi_{020} \\
\gamma_{03 \mathrm{k}}=\pi_{030} \\
\gamma_{04 \mathrm{k}}=\pi_{040}
\end{gathered}
$$


Relationship length, parent status, and shift work were entered at the couplelevel (level 3) as covariates (contingent on bivariate correlation check). Predictors at level 2 and 3 were grand mean centered.

Dyadic multilevel models were conducted in SPSS 24 using the MIXED procedure (Kenny et al., 2006) and Restricted Maximum Likelihood (REML) estimation (default setting for MIXED function in SPSS) which helps account for missing data by weighting the degree to which a person's effect contributes to the total effect relative to the participant's available information. Some researchers suggest that the interaction between level and variability may mask a curvilinear relationship with the outcome (Cole et al., 2011). Therefore, higher order exponential terms were explored within these analyses.

\section{Results}

\section{Descriptive statistics}

Table 3.0 displays descriptive information and bivariate correlations among the aggregated variables of interest. On average individuals rating of closeness with their partner was $3.32(S D=.92$, range $=1-5)$, and averaged $12.48(S D=3.29$, range $=5.6$ 22.38) for positive affect level (averaged across 32 days). Variability scores for the standard deviation (iSD) of positive affect ranged from .5 to $5.67(M=2.06, S D=.80)$. Weekly standard deviation for positive affect (iSDw) ranged from 0 to $5.43(M=1.79, S D$ $=.75$ ) and the mean square of successive differences (MSSD) for positive affect ranged from .5 to $56.47(M=7.65, S D=7.17)$. 
Bivariate correlations revealed that intimacy was only significantly related to PA iSD $(r=.15, p<.05)$ and PA mean level $(r=.63, p<.01)$ but not with PA iSDW $(r=.10$, $p=.12)$. Intimacy was marginally related to MSSD $(r=.10, p=.09)$. Post-traumatic stress symptoms were only significantly related to PA mean level $(r=-.28, p<.01)$ and not related to the variability scores, including PA iSD $(r=.08, p=.18), \mathrm{PA}$ iSDw $(r=-.07, p=$ $.20)$, and PA MSSD $(r=.06, p=.31)$. Therefore, this preliminary evidence does not offer support for Research Question 1 which asked whether PTSS was related to variability in positive affect. Scatter plots between high and low PTSS and variability scores confirm this conclusion (see Figures $3.0-3.2$ ).

\section{Primary analyses}

Multilevel regression models were tested to examine whether an individual's variability in positive mood is associated with daily intimacy within military couples. Random intercept models shown in Table 3.1 indicated intimacy was significantly predicted by PA variability (iSD), after controlling for PA mean level, NA mean level and variability (iSD) and other covariates ( $b=.10, p=.048)$. However, the interaction between PA variability and PA mean level was not significant in this model $(b=-.012$, ns). Models testing weekly PA variability showed a similar pattern, such that neither weekly PA variability nor the interaction of PA iSDw and PA mean level significantly predicted person-level intimacy intercepts $(b=.011, p=.05 ; b=-.018, n s$, respectively). The random intercept model examining how instability (MSSD) in PA predicted intimacy showed both PA MSSD and the interaction of PA MSSD and PA mean level did not 
significantly predict intimacy ( $\mathrm{b}=.011, p=.06 ; b=-.002, n s$, respectively), accounting for covariates. Thus, evidence does not support the majority of my primary hypotheses. While positive affect variability (iSD) did predict intimacy, the relationship is in the opposite direction than predicted. Similarly, the respective relationship between weekly PA variability and PA MSSD on intimacy were marginally significant and also in the opposite direction than predicted. In other words, increased variability in positive affect predicted increased intimacy in participants. As a follow-up analysis, I tested a quadratic association of the variability scores in all models and found no significant results.

\section{Discussion}

Theory and empirical evidence support the salutary effect of positive affect. Yet, recent research highlights the nuances of positive mood for one's health and wellbeing. Growing research examining intraindividual variability in positive affect indicates that variability has the potential to negatively impact one's physical health (Hardy \& Segerstrom, 2017), such as increased alcohol intake (Mohr et al., 2015), poor cortisol profiles (Human et al., 2015), poor sleep (Ong et al., 2013), increased inflammation (Sin et al., 2015), and increased mortality risk (Mroczek et al., 2013). Indeed, emotion dynamics are not only important to health, but fundamental to relationships. It is well known that social connection is critical to health; however, researchers in relationship and health science have identified a gap in this research and call for more work examining the specific mechanisms that can account for this association (e.g., Pietromonaco \& Collins, 2017). Sbarra and Coan (2018) suggest that emotion dynamics 
mediate the relationship between health and close relationships through affective processes. For example, social contexts shape appraisal processes, which in turn shapes emotional responding, critical to intrapersonal regulation and physiological responses. Researchers also note that the influence of relationships on health is not always positive, specifying that, interdependence among couples and health is associated with both risks and benefits (Kiecolt-Glaser \& Wilson, 2017). Therefore, examining positive affect variability, a measure of individual sensitivity to positive appraisals (Kuppens \& Verduyn, 2015), within the context of romantic relationships buttresses literature examining mechanisms through which relationships promote health.

Moreover, positive emotion is critical for building and maintaining interpersonal relationships (Shiota et al., 2004). The aim of this work was to examine the relation of positive affect fluctuation and intimate relationships. For example, while an impressive amount of literature suggests that static conceptualizations of positive affect consistently predict increased well-being (e.g., Lyubomirsky et al., 2005), it is important to note that emotions are dynamic, vary over time, and affective variability may be comparably important to well-being outcomes as static levels (Houben et al., 2015). Therefore, including metrics of the time-varying nature of emotions in the study of positive affect is imperative.

Similar to recent findings regarding health and psychological well-being, I expected that effect of the positive affect is nuanced and leads to differences in relational well-being outcomes for those with higher or lower fluctuation in positive 
mood. While hypotheses were not fully supported, the results indicated that positive affect variability (iSD) predicted greater within-person average intimacy for military couples accounting for mean level positive affect, negative affect mean level and variability, PTSS and covariates. There was no interaction of variability and positive mood, however. An additional aim of this study was to examine different conceptualization of variability including positive affect instability, indexed by mean square of successive differences (MSSD), and by a weekly average variability (iSDw). While the main effects for MSSD and iSDw positive affect, respectively, were trending toward significance, the findings indicated a consistent pattern such that fluctuation in positive affect predicted greater person-level intimacy. Similarly, the interaction between MSSD or iSDw variability indices and mean level positive affect were not significant. Therefore, this study did not support hypotheses regarding positive affect fragility. Finally, the current study aimed to explore the degree to which posttraumatic stress symptoms and positive mood fluctuation interact to contribute to intimacy. The results did not support my assumptions. Correlational analyses, revealed that posttraumatic stress did not related to positive mood fluctuation, nor did PTSS relate to intimacy. While surprising, this finding is supported by literature examining affect and post-traumatic stress disorder (Brown et al., 2016).

While the pattern of findings run counter to the directional hypotheses I proposed, the results suggest fluctuations in positive mood may be beneficial to relationships. This is surprising given the growing literature describing the negative 
affect of fluctuations in mood on psychological and physical health (Hardy \& Segerstrom, 2017; Human et al., 2015). However, the benefits of fluctuation have been supported in literature studying resilience. For example, studies show that fluctuations in emotions are associated with adaptive outcomes supporting psychological benefits (e.g., Kuppens, Allen, \& Sheeber, 2010). Human and colleagues (2015) attempt to reconcile different interpretations of variability by conceptualizing variability on a continuum between emotional rigidity and flexibility, in which there may be an optimal level of variability. In their study they found a curvilinear effect of positive affect variability on cortisol levels, suggesting that moderate variability is related to favorable cortisol profiles. In addition, the current findings support that positive affect may yet be nuanced. For example, it may be that fluctuation in positive mood operates differently for individual physical health than within romantic relationships. For example, disclosures of positive emotions allow opportunities for responsive interactions among romantic partners that help to build and maintain relationships (Reis \& Shaver, 1988). Therefore, fluctuations in positive mood within the context of emotional disclosure to one's partner should build intimacy. Further, boosts or fluctuations in positive mood may draw partners closer together while simultaneously tax physical well-being. This is broadly supported by recent research showing that offering support for a close other's positive or negative event depletes one's personal resources (Gosnell \& Gable, 2017). Thus, fluctuations may prevent restoration of personal physical resources while still supporting close relationship maintenance. 
Within military relationships, emotional expressions are related to increased psychological resources in the case of low combat exposure (Marini et al., 2016). Accordingly, the current findings suggest that controlling for post-traumatic stress symptoms, military couples report that the ups and downs of positive mood promotes feelings of closeness with their partner. This is somewhat consistent with researcher indicating that when military couple hold back their emotions (low fluctuation), their relationship suffers (Zamir et al., 2018). Therefore, this study broadly contributes to literature describing the nuances of positive affect variability in well-being (Ong \& Ram, 2017), extends intraindividual emotion variability to relationship science, and adds to growing research on emotional expression in military families. However, additional work is needed to confirm and expand these modest findings.

\section{Limitations and future directions}

Reis and Shaver (1988) describe intimacy as an interpersonal process through which self-disclosures and partners' responsiveness to self-disclosures contribute to feelings of intimacy. This episodic view helps identify key mechanisms through which relationships may be maintained and built over time. I modeled intimacy as a withinperson average across the 32-days rather than as an interactive process, essentially examining the cross-sectional relationship between individual variability and averaged intimacy. This may be one limitation of this study. However, the current study provides an initial step in investigating the role of intraindividual mood variability in daily intimacy. Future studies may examine positive affect dynamics and the development of 
intimacy over the course of years, or, of import to this sample, following reintegration after deployment in military couples. This time period marks a common transition in military families that can be challenging as romantic partners readjust to their interdependent lives (Bowling \& Sherman, 2008), thus offering an opportunity to examine how individual mood fluctuation predict changes in intimacy over the integration period. Further, this study adds to growing literature examining the effect of emotions on relational well-being within military couples (e.g., Marini et al., 2017). However, like the present research, current studies of emotions in military couples have been cross-sectional in design. Additional work must examine how emotions unfold in daily life specifically for military service members and their partners.

Further, measuring intraindividual variability and instability using the individual standard deviation and mean square of successive difference methods neglects information about proximal events or interactions. While individual variability provides valuable information such as one's capacity for change (Ram \& Gersforf, 2009), I am purposefully ignoring the situational features that may be prompting the variation and instability in mood. This limits the specificity with which we may understand the types of daily interactions or activities that elicit or reduce positive emotions. The current approach was chosen based on recent research in affective and relationship science to serve as an initial step in examining positive affect dynamics and relationships in military couples. Applying time-based models of positive mood variability to the study of relationships should be one avenue for future work. For example, one study by Catalino 
and Frederickson (2011) showed that those with greater flourishing (e.g., thriving) tendencies showed greater positive reactivity to daily positive events as well as increased mindfulness. In other words, specific positive events led to boosts in positive emotion that led to well-being. While reactivity is not a new concept (e.g., the change in emotional response tied to an external influence or event; Ong \& Ram, 2017), Catalino and Frederickson examined the positive emotion reactivity to a positive event which differs from other conceptualizations that focus on reactions to negative events or stress. Therefore, future work may extend the study of positive emotion dynamics to relationships in order to support and strengthen affective and relationship science literatures by including event-based information into estimates of variability.

In addition, this study may be limited in terms of the age and relationship tenure of the couples. For example, the average relationship length was about 12 years and participants were in their late 30s on average. Therefore, affect fluctuation in this sample may differ from other samples at different stages of their relationship. For example, studies examining fluctuation in relationship-relevant perceptions such as relationship satisfaction show that greater fluctuations early in one's relationship predicts a greater likelihood of break-up (Arriaga, 2001; Daily et al., 2017). Therefore, the current sample of established couples may have progressed passed the degree to which fluctuation in positive mood is detrimental to relational well-being. Similarly, it may be that fluctuations in intimacy may predict positive affect. For example, one study showed that changes in intimacy day-to-day by both relationship partners was related 
to increased positive affect as well as increased passion and sexual satisfaction (Rubin \& Campbell, 2012). Thus, fluctuations in intimacy may benefit romantic relationships as well and is an avenue for future study.

Further, theory regarding the taxonomy of variability must be developed to determine at what point variability becomes maladaptive or adaptive. For example, Ong and Ram (2017) argue that the most maladaptive level of variability is when a person experiences generally high positive emotions but is also highly variable, which they term fragility. While this study did not support hypotheses regarding fragility and intimacy within couples, this conceptualization is much needed in affective dynamics. For example, fragility attempts to define maladaptive variability with somewhat clearer boundaries and is an apt avenue for future study within health and relationship science. Likewise, the field may benefit from clearer definitions of adaptive affective variability, for example, for those who have a moderate variability yet perhaps high or low average positive mood. In addition, researchers in positive psychology draw on broaden and build theory to show that positive emotions help to build upward spirals over time (Frederickson, 2001). This concept may be modeled by the upward trend in positive affect variation over time. Researchers examining emotion dynamics may consider how different conceptualizations of positive affect variability may yet describe personal growth trajectories, including the widening of an individual's positive emotional landscape (or repertoire) over time. 
The current study may be limited with regard to how positive affect was assessed. For example, emotions may vary across the day. Multiple measures of affect within a day would more accurately measure variability in positive affect. While the current study examined affect across 32 consecutive days, testing the relationship between daily intimacy and daily affect variability may lead to more consistent findings in future work. Furthermore, affective science researchers contend that positive emotions are discrete and serve specific purpose; thus, they must be studied with greater distinction than a general positive mood scale (Shiota et al., 2017). Variability in gratitude, happiness, or love, for examples, may be uniquely related to intimacy over time, relative to when they are examined together as 'positive affect.' While at least one study on positive affect dynamics did test the separate effect of variability in each positive emotion on health as well as the composite measure and found similar results (Human et al., 2015), additional research must investigate how dynamics of distinct positive emotions contribute to relational well-being.

Finally, recent models hypothesize that emotions may be one key mechanism through with relationships influence health (Slatcher \& Schoebi, 2017). For example, one recent study shows the interdependence of partner's happiness on various health indicators (Chopik \& O’Brien, 2017), indicating that having a happy partner can improve one's health. Future work should examine the interplay between positive affect variability, health, and intimacy.

\section{Conclusion}


This study draws on relationship and affective sciences to examine how the dynamics of positive emotions contribute to relational well-being within military service members and their partners. How individuals differ in the degree to which they are sensitive to positive mood must be examined within the context of relationships because our social context helps to shape these fluctuations and, in turn, affect one's relationship. Surprisingly, results indicated that positive mood fluctuation predicted greater feelings of closeness in military couples. This study supports the complex nature of positive affect dynamics and well-being and calls for more research of affective dynamics within military-connected couples. 


\section{References}

Allen, E. S., Rhoades, G. K., Stanley, S. M., \& Markman, H. J. (2010). Hitting home: relationships between recent deployment, posttraumatic stress symptoms, and marital functioning for Army couples. Journal of Family Psychology, 24(3), 280288. doi:10.1037/a0019405

American Psychiatric Association. (2013). Diagnostic and statistical manual of mental disorders (5th ed.). Washington, DC: Author.

Arpin, S. N., Starkey, A. R., Mohr, C. D., Greenhalgh, A.D., \& Hammer, L. (2018). "A well spent day brings happy sleep": Dyadic study of capitalization support in militaryconnected couples. Journal of Family Psychology, 32(7), 975-985.

http://dx.doi.org.proxy.lib.pdx.edu/10.1037/fam0000469

Arriaga, X. B. (2001). The ups and downs of dating: Fluctuations in satisfaction in newly formed romantic relationships. Journal of personality and social psychology, 80(5), 754-765. doi:10.1037/0022-3514.80.5.754

Black, A. C., Harel, O., \& Matthews, G. (2012). Techniques for analyzing intensive longitudinal data with missing values. In Mehl, M. R., \& Conner, T. S. (Eds.), Handbook of Research Methods for Studying Daily Life, (pp. 339 - 356). New York, NY: Gilford Press.

Bliese, P. D., Wright, K. M., Adler, A. B., Cabrera, O., Castro, C. A., \& Hoge, C. W. (2008). Validating the primary care posttraumatic stress disorder screen and the posttraumatic stress disorder checklist with soldiers returning from combat. 
RELATIONAL THRIVING IN CONTEXT

Journal of Consulting and Clinical Psychology, 76, 272-281. doi: 10.1037/0022-

$006 \times .76 .2 .272$

Bowling, U. B., \& Sherman, M. D. (2008). Welcoming them home: Supporting service members and their families in navigating the tasks of reintegration. Professional Psychology: Research and Practice, 39(4), 451-458. doi:10.1037/07357028.39.4.451

Brown, W. J., Bruce, S. E., Buchholz, K. R., Artime, T. M., Hu, E., \& Sheline, Y. I. (2016). Affective dispositions and PTSD symptom clusters in female interpersonal trauma survivors. Journal of interpersonal violence, 31(3), 407-424. doi:10.1177/0886260514555866

Butler, E. A. (2011). Temporal interpersonal emotion systems: The "TIES" that form relationships. Personality and Social Psychology Review, 15(4), 367-393. doi:10.1177/1088868311411164

Butler, E. A., \& Randall, A. K. (2013). Emotional coregulation in close relationships. Emotion Review, 5(2), 202-210. doi: 10.1177/1754073912451630

Catalino, L. I., \& Fredrickson, B. L. (2011). A Tuesday in the life of a flourisher: The role of positive emotional reactivity in optimal mental health. Emotion, 11(4), 938-950. doi:10.1037/a0024889

Chan, D. K., Zhang, X., Fung, H. H., \& Hagger, M. S. (2016). Affect, affective variability, and physical health: results from a population-based investigation in 
China. International journal of behavioral medicine, 23(4), 438-446. doi:10.1007/s12529-015-9510-2

Chervonsky, E., \& Hunt, C. (2017). Suppression and expression of emotion in social and interpersonal outcomes: A meta-analysis. Emotion, 17(4), 669-683. doi:10.1037/emo0000270

Chopik, W. J., \& O'brien, E. (2017). Happy you, healthy me? Having a happy partner is independently associated with better health in oneself. Health Psychology, 36(1), 21-30. http://dx.doi.org/10.1037/hea0000432

Chow, S. M., Ram, N., Boker, S. M., Fujita, F., \& Clore, G. (2005). Emotion as a thermostat: Representing emotion regulation using a damped oscillator model. Emotion, 5, 208 -225. http://dx.doi.org/10.1037/1528-3542.5.2.208

Cole, M. S., Bedeian, A. G., Hirschfeld, R. R., \& Vogel, B. (2011). Dispersion-composition models in multilevel research: A data-analytic framework. Organizational Research Methods, 14(4), 718-734. doi:10.1177/1094428110389078

Dailey, R. M., Crook, B., Brody, N., \& Lefebvre, L. (2017). Fluctuation in on-again/offagain romantic relationships: Foreboding or functional?. Personal Relationships, 24(4), 748-767. doi:10.1111/pere.12211

Debrot, A., Schoebi, D., Perrez, M., \& Horn, A. B. (2013). Touch as an interpersonal emotion regulation process in couples' daily lives: the mediating role of psychological intimacy. Personality and Social Psychology Bulletin, 39(10), 13731385. doi:10.1177/0146167213497592 
Diener, E., Colvin, C. R., Pavot, W. G., \& Allman, A. (1991). The psychic costs of intense positive affect. Journal of personality and social psychology, 61(3), 492-503. doi:10.1037/0022-3514.61.3.492

Diener, E., Suh, E. M., Lucas, R. E., \& Smith, H. L. (1999). Subjective well-being: Three decades of progress. Psychological bulletin, 125(2), 276-302. doi:10.1037/00332909.125.2.276

Dolphin, K. E., Steinhardt, M. A., \& Cance, J. D. (2015). The role of positive emotions in reducing depressive symptoms among Army wives. Military Psychology, 27(1), 22-35. doi:10.1037/mil0000062

Eaton, L. G., \& Funder, D. C. (2001). Emotional experience in daily life: Valence, variability, and rate of change. Emotion, 1, 413-421. http://dx.doi.org/10.1037/1528-3542.1.4.413

Egloff, B., Tausch, A., Kohlmann, C. W., \& Krohne, H. W. (1995). Relationships between time of day, day of the week, and positive mood: Exploring the role of the mood measure. Motivation and emotion, 19(2), 99-110.

https://doi.org/10.1007/BF02250565

Eid, M., \& Diener, E. (1999). Intraindividual variability in affect: Reliability, validity, and personality correlates. Journal of Personality and Social Psychology, 76(4), 662676. doi:10.1037/0022-3514.76.4.662

Eizenman, D. R., Nesselroade, J. R., Featherman, D. L., \& Rowe, J. W. (1997). Intraindividual variability in perceived control in an older sample: The MacArthur 
successful aging studies. Psychology and Aging, 12, 489-502.

http://dx.doi.org/10.1037/0882-7974.12.3.489

Feeney, B. C., \& Collins, N. L. (2015). A new look at social support: A theoretical perspective on thriving through relationships. Personality and Social Psychology Review, 19(2), 113-147. doi:10.1177/1088868314544222

Fredrickson, B. L. (2001). The role of positive emotions in positive psychology: The broaden-and-build theory of positive emotions. American psychologist, 56(3), 218-226. doi:10.1037/0003-066X.56.3.218

Gable, S. L., Reis, H. T., Impett, E. A., \& Asher, E. R. (2004). What do you do when things go right? The intrapersonal and interpersonal benefits of sharing positive events. Journal of personality and social psychology, 87(2), 228-245. doi:10.1037/0022-3514.87.2.228

Girme, Y. U., Agnew, C. R., VanderDrift, L. E., Harvey, S. M., Rholes, W. S., \& Simpson, J. A. (2018). The ebbs and flows of attachment: Within-person variation in attachment undermine secure individuals' relationship wellbeing across time. Journal of personality and social psychology, 114(3), 397-421. doi:10.1037/pspi0000115

Goff, B. S. N. ,Crow, J. R., Reisbig, A. M. J., \& Hamilton, S. (2007). The impact of individual trauma symptoms of deployed soldiers on relationship satisfaction. Journal of Family Psychology, 21(3), 344-353. doi:10.1037/0893-3200.21.3.344

Gross, J. J. (2007). Handbook of emotion regulation. New York, NY: Guilford Press. 
Gross, J. J., \& John, O. P. (2003). Individual differences in two emotion regulation processes: Implications for affect, relationships, and well- being. Journal of Personality and Social Psychology, 85, 348-362. http://dx.doi.org/10.1037/00223514.85 .2 .348

Gruber, J., Kogan, A., Quoidbach, J., \& Mauss, I. B. (2013). Happiness is best kept stable: Positive emotion variability is associated with poorer psychological health. Emotion, 13(1), 1-6. doi:10.1037/a0030262

Hammer, L. B., Wan, W. H., Brockwood, K. J., Mohr, C. D., \& Carlson, K. F. (2017). Military, work, and health characteristics of separated and active service members from the Study for Employment Retention of Veterans (SERVe). Military Psychology, 29(6), 491-512. doi:10.1037/mil0000196

Hardy, J., \& Segerstrom, S. C. (2017). Intra-individual variability and psychological flexibility: Affect and health in a National US sample. Journal of research in personality, 69, 13-21. doi:10.1016/j.jrp.2016.04.002 0092-6566

Higgins, E. T. (1997). Beyond pleasure and pain. American psychologist, 52(12), 12801300. doi:10.1037/0003-066X.52.12.1280

Houben, M., Van Den Noortgate, W., \& Kuppens, P. (2015). The relation between shortterm emotion dynamics and psychological well-being: A metaanalysis. Psychological bulletin, 141(4), 901-930. doi:10.1037/a0038822

Hox, J. (2010). Multilevel analyses: Techniques and applications, second edition. New York: Routledge. 
Hülür, G., Hoppmann, C. A., Rauers, A., Schade, H., Ram, N., \& Gerstorf, D. (2016).

Empathic accuracy for happiness in the daily lives of older couples: Fluid cognitive performance predicts pattern accuracy among men. Psychology and aging, 31(5), 545-552. doi:10.1037/pag0000109

Human, L. J., Whillans, A. V., Hoppmann, C. A., Klumb, P., Dickerson, S. S., \& Dunn, E. W. (2015). Finding the middle ground: Curvilinear associations between positive affect variability and daily cortisol profiles. Emotion, 15(6), 705-720. doi:10.1037/t03592-000

Jahng, S., Wood, P. K., \& Trull, T. J. (2008). Analysis of affective instability in ecological momentary assessment: Indices using successive difference and group comparison via multilevel modeling. Psychological methods, 13(4), 354-375. doi: $10.1037 / \mathrm{a} 0014173$

Karney, B. R., \& Crown, J. S. (2007). Families under stress: An assessment of data, theory, and reseach on marriage and divorce in the military (Vol. 599). Rand Corporation.

Karney, B. R., \& Trail, T. E. (2017). Associations between prior deployments and marital satisfaction among army couples. Journal of Marriage and Family, 79(1), 147160. doi:10.1111/jomf.12329

Karney, B. R., Loughran, D. S., \& Pollard, M. S. (2012). Comparing marital status and divorce status in civilian and military populations. Journal of Family Issues, 33(12), 1572-1594. doi:10.1177/0192513X12439690 
Kashdan, T. B., Elhai, J. D., \& Frueh, B. C. (2006). Anhedonia and emotional numbing in combat Veterans with PTSD. Behaviour research and therapy, 44(3), 457-467. doi:10.1016/j.brat.2005.03.001

Kashy, D. A., \& Donnellan, M. B. (2008). Comparing MLM and SEM approaches to analyzing developmental dyadic data: Growth curve models of hostility in families. In N. A. Card, J. P. Selig, \& T. D. Little (Eds.), Modeling dyadic and interdependent data in the developmental and behavioral sciences, (pp. 165190). New York: Routledge.

Kelley, H. H. (1983). The situational origins of human tendencies: A further reason for the formal analysis of structures. Personality and Social Psychology Bulletin, 9(1), 8-30. doi:10.1177/0146167283091003

Kenny, D. A., Kashy, D. A., Cook, W. L., \& Simpson, J. A. (2006). Dyadic data analysis (Methodology in the social sciences). New York, NY: Guilford.

Kiecolt-Glaser, J. K., \& Wilson, S. J. (2017). Lovesick: How couples' relationships influence health. Annual review of clinical psychology, 13, 421-443. doi:10.1146/annurevclinpsy-032816-045111

Knobloch, L. K., \& Theiss, J. A. (2012). Experiences of US military couples during the postdeployment transition: Applying the relational turbulence model. Journal of Social and Personal Relationships, 29(4), 423-450.

doi:10.1177/0265407511431186 
Koval, P., Ogrinz, B., Kuppens, P., Van den Bergh, O., Tuerlinckx, F., \& Sütterlin, S. (2013). Affective instability in daily life is predicted by resting heart rate variability. PloS one, 8(11), e81536. https://doi.org/10.1371/journal.pone.0081536

Kreft, I., \& de Leeuw, J. (1998). Introducing multilevel modeling. London: Sage.

Kuppens, P., Allen, N. B., \& Sheeber, L. B. (2010). Emotional inertia and psychological maladjustment. Psychological Science, 21, 984-991.

http://dx.doi.org/10.1177/0956797610372634

Kuppens, P., \& Verduyn, P. (2015). Looking at emotion regulation through the window of emotion dynamics. Psychological Inquiry, 26(1), 72-79. doi:10.1080/1047840X.2015.960505

Kuppens, P., \& Verduyn, P. (2017). Emotion dynamics. Current opinion in psychology, 17, 22-26. doi:10.1016/j.copsyc.2017.06.004

Kurdek, L. A. (1993). Predicting marital dissolution: A 5-year prospective longitudinal study of newlywed couples. Journal of Personality and Social Psychology, 64, 221-242. doi:10.1037/0022-3514.64.2.221

Larsen, R. J., \& Diener, E. (1992). Promises and problems with the circumplex model of emotion. In M. S. Clark (Ed.), Emotion (pp. 25-59). Newbury Park, CA: Sage.

Larsen, R.J., \& Kasimatis M. (1990). Individual differences in entrainment of mood to the weekly calendar. Journal of Personality and Social Psychology, 58 (1), 164-171. 
Laurenceau, J. P., Barrett, L. F., \& Rovine, M. J. (2005). The interpersonal process model of intimacy in marriage: A daily-diary and multilevel modeling approach. Journal of family psychology, 19(2), 314-323. doi:10.1037/0893-3200.19.2.314

Lyubomirsky, S., King, L., \& Diener, E. (2005). The Benefits of Frequent Positive Affect: Does Happiness Lead to Success? Psychological Bulletin, 131(6), 803-855. http://dx.doi.org/10.1037/0033-2909.131.6.803

Marini, C. M., Wadsworth, S. M., Christ, S. L., \& Franks, M. M. (2017). Emotion expression, avoidance and psychological health during reintegration: A dyadic analysis of actor and partner associations within a sample of military couples. Journal of Social and Personal Relationships, 34(1), 69-90. doi:10.1177/0265407515621180

Martin, L. R., Friedman, H. S., Tucker, J. S., Tomlinson-Keasey, C., Criqui, M. H., \& Schwartz, J. E. (2002). A life course perspective on childhood cheerfulness and its relation to mortality risk. Personality and Social Psychology Bulletin, 28(9), 11551165. doi:10.1177/01461672022812001

Milek, A., Butler, E. A., \& Bodenmann, G. (2015). The interplay of couple's shared time, women's intimacy, and intradyadic stress. Journal of Family Psychology, 29(6), 831-842. http://dx.doi.org.proxy.lib.pdx.edu/10.1037/fam0000133

Mohr, C. D., Arpin, S., \& McCabe, C. T. (2015). Daily affect variability and context-specific alcohol consumption. Drug and alcohol review, 34(6), 581-587. doi:10.1111/dar.12253 
Mohr, C.D., McCabe, C., Haverly, S.N., Hammer, LB., \& Carlson, K.F. (2018). Drinking Motives and Alcohol Use: The SERVe Study of U.S. Current and Former Service Members. Journal of Studies on Alcohol and Drugs, 79(1), 79-87. https://doi.org/10.15288/jsad.2018.79.79

Monson, C. M., Taft, C. T., \& Fredman, S. J. (2009). Military-related PTSD and intimate relationships: From description to theory-driven research and intervention development. Clinical psychology review, 29(8), 707-714. doi:10.1016/j.cpr.2009.09.002

Mroczek, D. K., Stawski, R. S., Turiano, N. A., Chan, W., Almeida, D. M., Neupert, S. D., \& Spiro III, A. (2013). Emotional reactivity and mortality: Longitudinal findings from the VA Normative Aging Study. Journals of Gerontology Series B: Psychological Sciences and Social Sciences, 70(3), 398-406. doi:10.1093/geronb/gbt107

Murphy, D., Palmer, E., Hill, K., Ashwick, R., \& Busuttil, W. (2017). Living alongside military PTSD: a qualitative study of female partners' experiences with UK Veterans. Journal of Military, Veteran and Family Health, 3(1), 52-61. doi:10.3138/jmvfh.4011

Nesselroade, J. R. (1991). Interindividual differences in intraindividual change. In L. M. Collins \& J. L. Horn (Eds.), Best methods for the analysis of change: Recent advances, unanswered questions, future directions (pp. 92-105). Washington, DC, US: American Psychological Association. http://dx.doi.org/10.1037/10099-006 
O'Brien, M., \& Peyton, V. (2002). Parenting attitudes and marital intimacy: A longitudinal analysis. Journal of Family Psychology, 16(2), 118-127. doi:10.1037/08933200.16 .2 .118

Ong, A. D., \& Ram, N. (2017). Fragile and enduring positive affect: implications for adaptive aging. Gerontology, 63(3), 263-269. doi:10.1159/000453357

Ong, A. D., Exner-Cortens, D., Riffin, C., Steptoe, A., Zautra, A., \& Almeida, D. M. (2013). Linking stable and dynamic features of positive affect to sleep. Annals of Behavioral Medicine, 46(1), 52-61. doi:10.1007/s12160-013-9484-8.

Peters, B. J., \& Jamieson, J. P. (2016). The consequences of suppressing affective displays in romantic relationships: A challenge and threat perspective. Emotion, 16(7), 1050-1066. doi:10.1037/emo0000202

Pietromonaco, P. R., \& Collins, N. L. (2017). Interpersonal mechanisms linking close relationships to health. American Psychologist, 72(6), 531-542. doi:10.1037/amp0000129

Price, J. L., Monson, C. M., Callahan, K., \& Rodriguez, B. F. (2006). The role of emotional functioning in military-related PTSD and its treatment. Journal of Anxiety Disorders, 20(5), 661-674. doi:10.1016/j.janxdis.2005.04.004

Ram, N., \& Gerstorf, D. (2009). Time-structured and net intraindividual variability: Tools for examining the development of dynamic characteristics and processes. Psychology and aging, 24(4), 778-791. doi:10.1037/a0017915 
Randall, A. K., \& Schoebi, D. (2015). Lean on me: Susceptibility to partner affect attenuates psychological distress over a 12-month period. Emotion, 15(2), 201210. doi:10.1037/emo0000043

Reich, J. W., Zautra, A. J., \& Davis, M. (2003). Dimensions of affect relationships: Models and their integrative implications. Review of General Psychology, 7(1), 66-83. doi:10.1037//1089-2680.7.1.66

Reis, H. T., \& Shaver, P. (1988). Intimacy as an interpersonal process. Handbook of personal relationships, 24(3), 367-389

Reis, H.T., \& Gable, S. (2003). Toward a positive psychology of relationships. In C.L.M. Keyes \& J. Haidt (Eds.) Flourishing: Positive psychology and the life well-lived (pp. 129-159). Washington, DC: American Psychological Association. doi: $10.1037 / 10594-006$

Renshaw, K. D., \& Campbell, S. B. (2017). Deployment-Related Benefit Finding and Postdeployment Marital Satisfaction in Military Couples. Family process, 56(4), 915-925. doi:10.1111/famp.12249

Renshaw, K. D., Rodrigues, C. S., \& Jones, D. H. (2008). Psychological symptoms and marital satisfaction in spouses of Operation Iraqi Freedom Veterans: Relationships with spouses' perceptions of Veterans' experiences and symptoms. Journal of family psychology, 22(4), 586-594. doi:10.1037/08933200.22.3.586 
Röcke, C., Li, S. C., \& Smith, J. (2009). Intraindividual variability in positive and negative affect over 45 days: Do older adults fluctuate less than young adults?. Psychology and aging, 24(4), 863-878. doi: 10.1037/a0016276

Rubin, H., \& Campbell, L. (2012). Day-to-day changes in intimacy predict heightened relationship passion, sexual occurrence, and sexual satisfaction: A dyadic diary analysis. Social Psychological and Personality Science, 3(2), 224-231. https://doi.org/10.1177/1948550611416520

Rusbult, C. E., \& Van Lange, P. A. (2003). Interdependence, interaction, and relationships. Annual Review of Psychology, 54, 351-375. doi: 10.1146/annurev.psych.54.101601.145059

Ryan, R. M., Bernstein, J. H., \& Brown, K. W. (2010). Weekends, work, and well-being: Psychological need satisfactions and day of the week effects on mood, vitality, and physical symptoms. Journal of social and clinical psychology, 29(1), 95-122. https://doi-org.proxy.lib.pdx.edu/10.1521/jscp.2010.29.1.95

Sbarra, D. A., \& Coan, J. A. (2018). Relationships and health: The critical role of affective science. Emotion Review, 10(1), 40-54. doi:10.1177/1754073917696584

Schoebi, D., \& Randall, A. K. (2015). Emotional dynamics in intimate relationships. Emotion Review, 7(4), 342-348. doi:10.1177/1754073915590620

Segal, M. W. (1989). The nature of work and family linkages: A theoretical perspective. In G. L. Bowen \& D. K. Orthner (Eds.), The organization family: Work and family linkages in the U. S. military (pp. 3-36). New York: Praeger. 
Sels, L., Ceulemans, E., Bulteel, K., \& Kuppens, P. (2016). Emotional interdependence and well-being in close relationships. Frontiers in psychology, 7, 283. doi:10.3389/fpsyg.2016.00283

Shiota, M. N., Campos, B., Keltner, D., \& Hertenstein, M. J. (2004). Positive emotion and the regulation of interpersonal relationships. In P. Philippot, \& R.S. Feldman (Eds.), The regulation of emotion (pp. 127-155). New York: Taylor \& Francis.

Shiota, M. N., Campos, B., Oveis, C., Hertenstein, M. J., Simon-Thomas, E., \& Keltner, D. (2017). Beyond happiness: Building a science of discrete positive emotions. American Psychologist, 72(7), 617-643. doi:10.1037/a0040456

Sin, N. L., Graham-Engeland, J. E., Ong, A. D., \& Almeida, D. M. (2015). Affective reactivity to daily stressors is associated with elevated inflammation. Health Psychology, 34(12), 1154-1165. doi:10.1037/hea0000240

Singer J. D. \& Willet, J. B. (2003). Applied longitudinal data analysis: Modeling change and event occurrence. New York: Oxford University Press.

Snijders, T.A.B., \& Bosker, R.J. (2012). Multilevel analysis: An introduction to basic and advanced multilevel modeling (2nd Edition). London: Sage.

Thompson, A., and Bolger, N. (1999). Emotional transmission in couples under stress. J. Marriage Fam. 61, 38-48. doi: 10.2307/353881

Tugade, M. M., \& Fredrickson, B. L. (2004). Resilient individuals use positive emotions to bounce back from negative emotional experiences. Journal of personality and social psychology, 86(2), 320-333. doi:10.1037/0022-3514.86.2.320 
van de Leemput, I. A., Wichers, M., Cramer, A. O., Borsboom, D., Tuerlinckx, F., Kuppens, P., ... \& Derom, C. (2014). Critical slowing down as early warning for the onset and termination of depression. Proceedings of the National Academy of Sciences, 111(1), 87-92. doi:10.1073/pnas.1312114110

Warner, C. H., Appenzeller, G. N., Warner, C., \& Grieger, T. (2009). Psychological effects of deployments on military families. Psychiatric Annals, 39(2), 56-63. doi:10.3928/00485713-20090201-11

Watson, D., \& Clark, L. A. (1994). The PANAS-X: Manual for the Positive and Negative Affect Schedule-Expanded Form. Ames: The University of Iowa.

Watson, D., Clark, L. A., \& Tellegen, A. (1988). Development and validation of brief measures of positive and negative affect: the PANAS scales. Journal of personality and social psychology, 54(6), 1063-1070. doi:10.1037/00223514.54.6.1063

Watson, D., Wiese, D., Vaidya, J., \& Tellegen, A. (1999). The two general activation systems of affect: Structural findings, evolutionary considerations, and psychobiological evidence. Journal of Personality and Social Psychology, 76, 820838. doi:10.1037/0022-3514.76.5.820

Weathers, F., Huska, J., \& Keane, T. (1991). The PTSD checklist military version (PCLM). Boston, MA: National Center for PTSD, 42. 
Wenger, J. W., O'Connell, C. \& Cottrell, L. (2018). Examination of Recent Deployment Experience Across the Services and Components. Santa Monica: RAND Corporation. doi:10.7249/RR1928

Zamir, O., Gerwirtz, A.H., Labella, M., DeGarmo, D.S., \& Snyder, J. (2018). Experiential avoidance, dyadic interaction and relationship quality in the lives of Veterans and their partners. Journal of Family Issues, 39(5) 1191-1212. doi:10.1177/0192513X17698182 
Table 3.0. Descriptive statistics and bivariate correlations aggregated across days and within couples

\begin{tabular}{|c|c|c|c|c|c|c|c|c|c|c|c|c|c|c|c|c|}
\hline & $M$ & SD & $\begin{array}{l}\text { Min/ } \\
\text { Max }\end{array}$ & 1 & 2 & 3 & 4 & 5 & 6 & 7 & 8 & 9 & 10 & 11 & 12 & 13 \\
\hline 1. Intimacy & 3.33 & .83 & $1.32 / 5$ & --- & & & & & & & & & & & & \\
\hline 2. PA iSD & 2.05 & .63 & $.71 / 5.24$ & $.16^{*}$ & --- & & & & & & & & & & & \\
\hline 3. PA iSDw & 1.78 & .62 & $.65 / 4.94$ & .08 & $.91^{* *}$ & --- & & & & & & & & & & \\
\hline 4. PA MSSD & 7.62 & 5.96 & $.5 / 49.7$ & .08 & $.81^{* *}$ & $.86^{* *}$ & --- & & & & & & & & & \\
\hline 5. PA Mean & 12.5 & 3.29 & $6.96 / 20.5$ & $.69^{* *}$ & $.15^{+}$ & .09 & .13 & --- & & & & & & & & \\
\hline 6. PTSS & 1.90 & 1.02 & $1 / 5$ & -.08 & .10 & .12 & .06 & $-.22^{* *}$ & --- & & & & & & & \\
\hline 7. NA iSD & 1.21 & .87 & $0 / 4.39$ & $-.27^{* *}$ & $.37^{* *}$ & $.42^{* *}$ & $.42^{* *}$ & $-.26^{* *}$ & $.28^{* *}$ & --- & & & & & & \\
\hline 8. NA iSDw & .99 & .78 & $0 / 4.29$ & $-.27^{* *}$ & $.29^{* *}$ & $.38^{* *}$ & $.38^{* *}$ & $-.28^{* *}$ & $.28^{* *}$ & $.96^{* *}$ & --- & & & & & \\
\hline 9. NA MSSD & 4.43 & 6.83 & $0 / 53.7$ & $-.16^{+}$ & $.31^{* *}$ & $.38^{* *}$ & $.41^{* *}$ & $-.17^{* *}$ & $.16^{+}$ & $.80^{* *}$ & $.84^{* *}$ & --- & & & & \\
\hline 10. NA Mean & 6.10 & 1.56 & $5 / 16.25$ & $-.32^{* *}$ & .05 & .09 & .13 & $-.30^{* *}$ & $.41^{* *}$ & $.73^{* *}$ & $.77^{* *}$ & $.70^{* *}$ & --- & & & \\
\hline 11. Gender & .50 & .04 & $.5 / 1$ & .05 & .01 & .01 & -.00 & -.02 & -.05 & .03 & .02 & -.01 & -.02 & --- & & \\
\hline 12. Parent & .79 & .41 & $0 / 1$ & -.07 & .10 & .10 & .12 & .08 & .07 & .03 & .01 & .09 & .01 & $-.15^{+}$ & --- & \\
\hline 13. R. length & 11.8 & 8.58 & $.17 / 37.1$ & -.09 & $-.22^{* *}$ & $-.22^{* *}$ & $-.16^{*}$ & .01 & $-.22^{* *}$ & $-.28^{* *}$ & $-.27^{* *}$ & $-.19^{*}$ & $-.21^{* *}$ & -.08 & $.25^{* *}$ & --- \\
\hline
\end{tabular}

Note. $\mathrm{N}=159 ; \mathrm{M}=$ mean; $\mathrm{SD}=$ standard deviation; $\mathrm{PA}=$ Positive Affect; $\mathrm{NA}=$ Negative affect; iSD= intraindividual standard deviation; iSDw = intraindividual weekly standard deviation; MSSD = Mean square of successive differences; PTSS = Posttraumatic stress symptoms; R. length = relationship length (in years). ${ }^{+} p<.10,{ }^{*} p<.05,{ }^{* *} p<.01$. 
Table 3.1. Multilevel random intercept models predicting person-level intimacy

\begin{tabular}{|c|c|c|c|c|c|c|c|c|c|}
\hline \multirow[b]{2}{*}{ Variable } & \multicolumn{3}{|c|}{ Model 1} & \multicolumn{3}{|c|}{ Model 2} & \multicolumn{3}{|c|}{ Model 3} \\
\hline & Estimate & $S E$ & $t(z)$ & Estimate & $S E$ & $t(z)$ & Estimate & $S E$ & $t(z)$ \\
\hline \multicolumn{10}{|l|}{ Fixed } \\
\hline Intercept & 3.73 & 0.11 & $34.23 * *$ & 3.75 & 0.11 & $34.07 * *$ & 3.75 & 0.11 & $33.89 * *$ \\
\hline PA mean & 0.15 & 0.01 & $12.28^{* *}$ & 0.15 & 0.1 & $12.28 * *$ & 0.16 & 0.01 & $12.53^{* *}$ \\
\hline PA Fluctuation & 0.10 & 0.05 & $1.99 *$ & 0.11 & 0.06 & $1.94^{+}$ & 0.01 & 0.01 & $1.88^{+}$ \\
\hline PA Fluctuation X Mean & -0.01 & 0.01 & -0.93 & -0.02 & 0.01 & -1.22 & -0.00 & 0.00 & -1.09 \\
\hline NA Mean & -0.04 & 0.04 & -0.97 & -0.02 & 0.04 & -0.50 & -0.06 & 0.03 & $-2.01^{*}$ \\
\hline NA Fluctuation & -0.74 & 0.06 & -1.18 & -0.12 & 0.08 & -1.54 & 0.00 & 0.01 & 0.14 \\
\hline PTSS & 0.07 & 0.05 & 1.53 & 0.07 & 0.05 & -1.63 & 0.07 & 0.05 & 1.38 \\
\hline Gender & -0.10 & 0.06 & -1.59 & -0.11 & 0.06 & $-1.77^{+}$ & -0.11 & 0.06 & $-1.77^{+}$ \\
\hline Parent Status & -0.24 & 0.11 & $-2.15^{*}$ & -0.25 & 0.11 & $-2.19 *$ & -0.27 & 0.11 & $-2.33^{*}$ \\
\hline R. length & -0.01 & 0.01 & -0.90 & -0.01 & 0.01 & -0.96 & -0.00 & 0.01 & -0.67 \\
\hline Shift work & 0.31 & 0.12 & $2.62 * *$ & 0.28 & 0.12 & $2.33^{*}$ & 0.34 & 0.12 & $2.88^{* *}$ \\
\hline Monday & -0.16 & 0.03 & $-5.20 * *$ & -0.16 & 0.03 & $-5.20 * *$ & -0.15 & 0.03 & $-5.16 * *$ \\
\hline Tuesday & -0.25 & 0.03 & $-7.46 * *$ & -0.25 & 0.03 & $-7.46 * *$ & -0.25 & 0.03 & $-7.44 * *$ \\
\hline Wednesday & -0.26 & 0.03 & $-7.70 * *$ & -0.26 & 0.03 & $-7.70 * *$ & -0.25 & 0.03 & $-7.62 * *$ \\
\hline Thursday & -0.27 & 0.03 & $-8.32 * *$ & -0.27 & 0.03 & $-8.32 * *$ & -0.27 & 0.03 & $-8.19 * *$ \\
\hline Friday & -0.18 & 0.03 & $-5.43 * *$ & -0.18 & 0.03 & $-5.43 * *$ & -0.18 & 0.03 & $-5.44 * *$ \\
\hline Saturday & -0.05 & 0.03 & -1.63 & -0.05 & 0.03 & -1.63 & -0.05 & 0.03 & -1.60 \\
\hline
\end{tabular}

Note: PA = Positive affect; NA = Negative affect; PTSS = Post-traumatic stress. Model 1 is PA iSD predicting intimacy. Model 2 is PA iSDw predicting intimacy averaged across days. Model 3 is PA MSSD predicting intimacy. All models included parent status, relationship length, day of the week, gender, and shift work as covariates.

${ }^{+} \mathrm{p}<.10{ }^{*} p<.05 .{ }^{* *} p<.01$. 
Table 3.1. Multilevel random intercept models predicting person-level intimacy (continued)

\begin{tabular}{|c|c|c|c|c|c|c|c|c|c|}
\hline \multirow[b]{2}{*}{ Variable } & \multicolumn{3}{|c|}{ Model 1} & \multicolumn{3}{|c|}{ Model 2} & \multicolumn{3}{|c|}{ Model 3} \\
\hline & Estimate & $S E$ & $t(z)$ & Estimate & $S E$ & $t(z)$ & Estimate & $S E$ & $t(z)$ \\
\hline \multicolumn{10}{|l|}{ Random } \\
\hline \multicolumn{10}{|l|}{ Level 3} \\
\hline Intercept & 0.17 & 0.04 & $(4.15)^{* *}$ & 0.17 & 0.04 & $(4.35)^{* *}$ & 0.18 & 0.04 & $(4.34)^{* *}$ \\
\hline \multicolumn{10}{|l|}{ Level 2} \\
\hline Intercept & 0.20 & 0.03 & $(6.63)^{* *}$ & 0.20 & 0.03 & $(6.65)^{* *}$ & 0.20 & 0.03 & $(6.58)^{* *}$ \\
\hline \multicolumn{10}{|l|}{ Level 1} \\
\hline Residual & 0.60 & 0.01 & $(53.23)^{* *}$ & 0.60 & 0.01 & $(53.23)^{* *}$ & 0.60 & 0.01 & $(53.10)^{* *}$ \\
\hline Autocorrelation & 0.30 & 0.01 & $(23.13)^{* *}$ & 0.30 & 0.01 & $(23.13)^{* *}$ & 0.30 & 0.01 & $(23.18)^{* *}$ \\
\hline
\end{tabular}

Note: PA = Positive affect; NA = Negative affect; PTSS = Post-traumatic stress. Model 1 is PA iSD predicting intimacy. Model 2 is PA iSDw predicting intimacy averaged across days. Model 3 is PA MSSD predicting intimacy. All models included parent status, relationship length, day of the week, gender, and shift work as covariates.

${ }^{+} p<.10 .{ }^{*} p<.05 .{ }^{* *} p<.01$ 


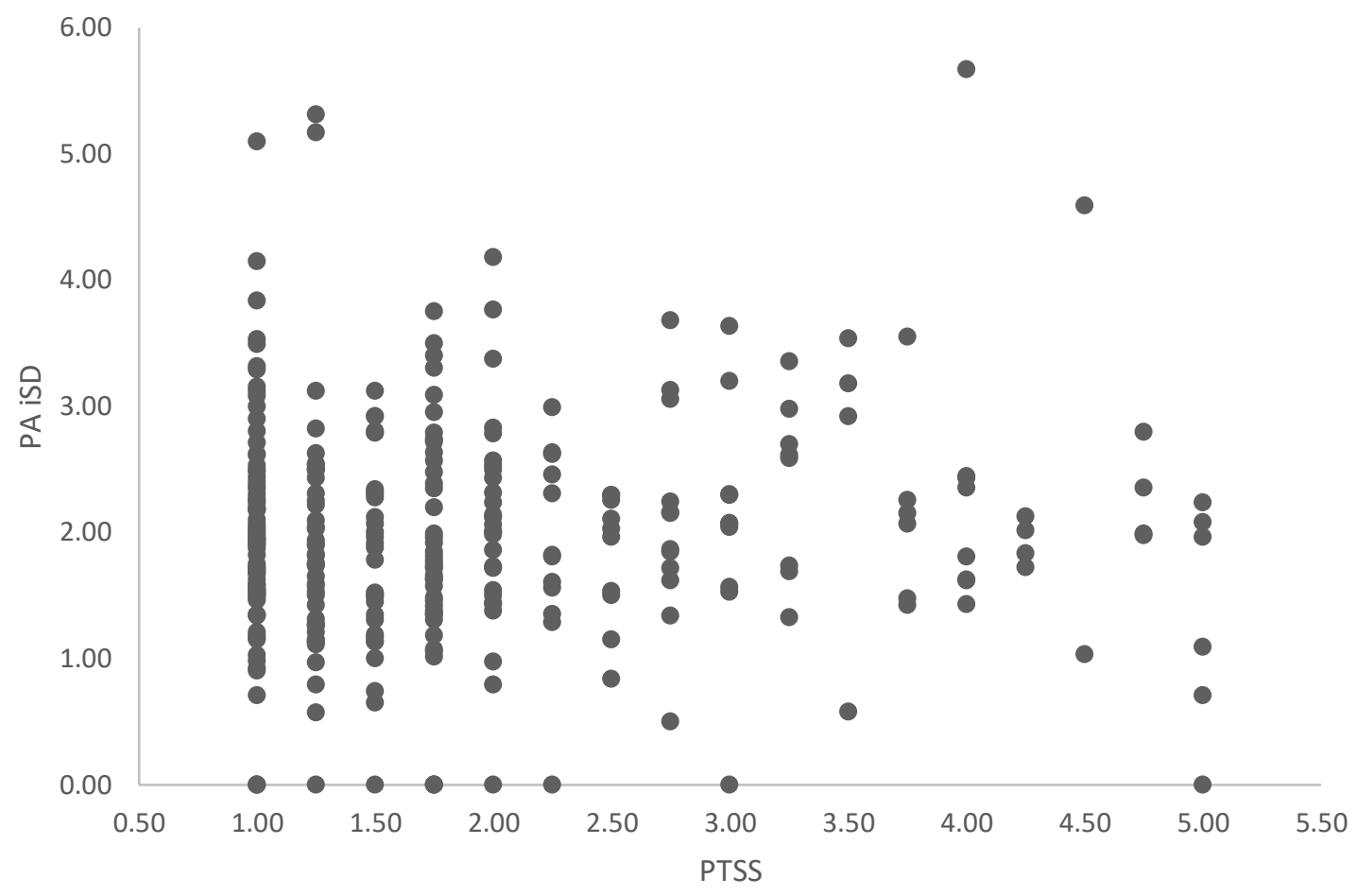

Figure 3.0. Scatterplot of positive affect (PA) intraindividual standard deviation (iSD) and post-traumatic stress symptoms (PTSS). 


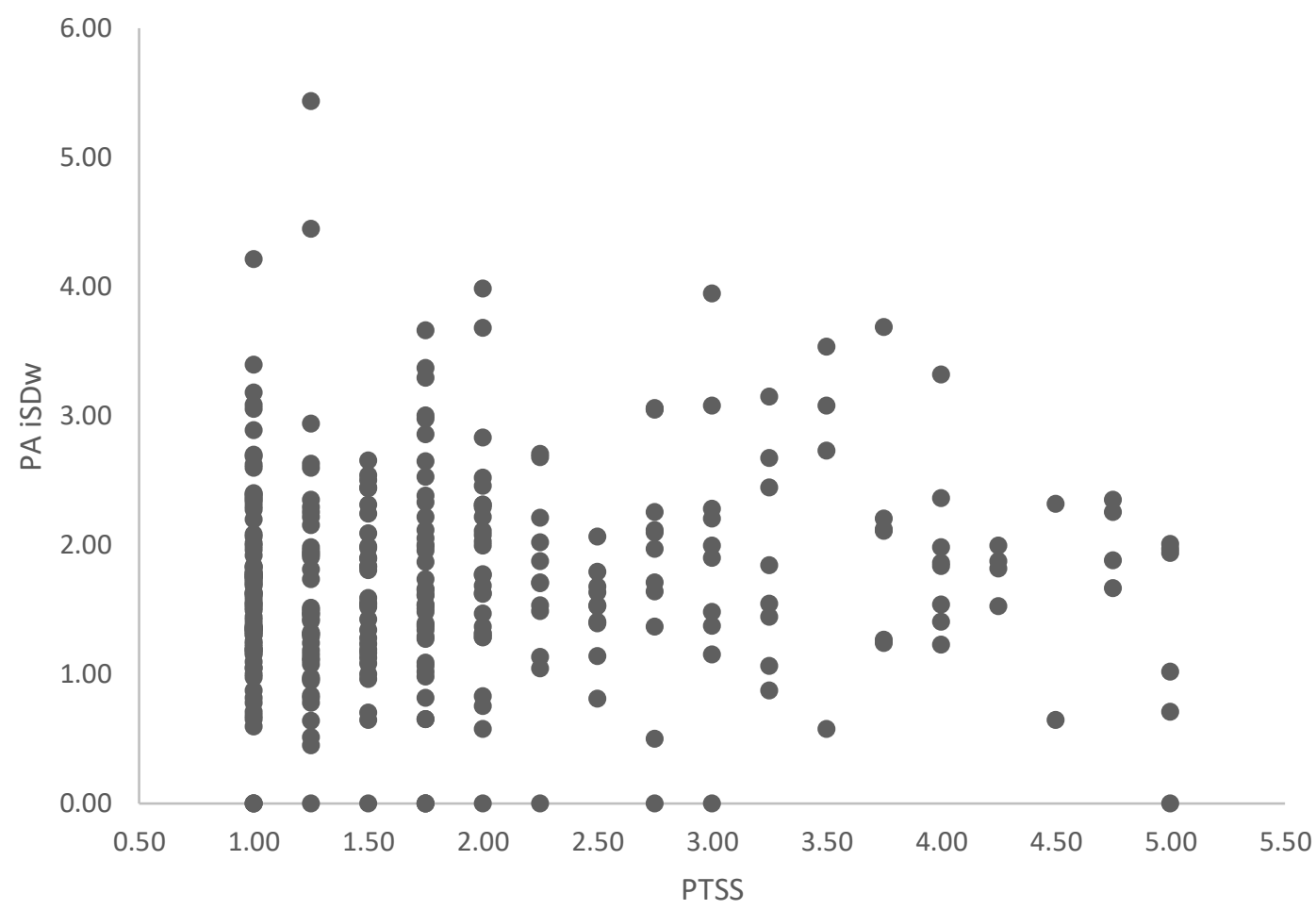

Figure 3.1. Scatterplot of weekly positive affect (PA) intraindividual standard deviation (iSDw) and post-traumatic stress symptoms (PTSS). 


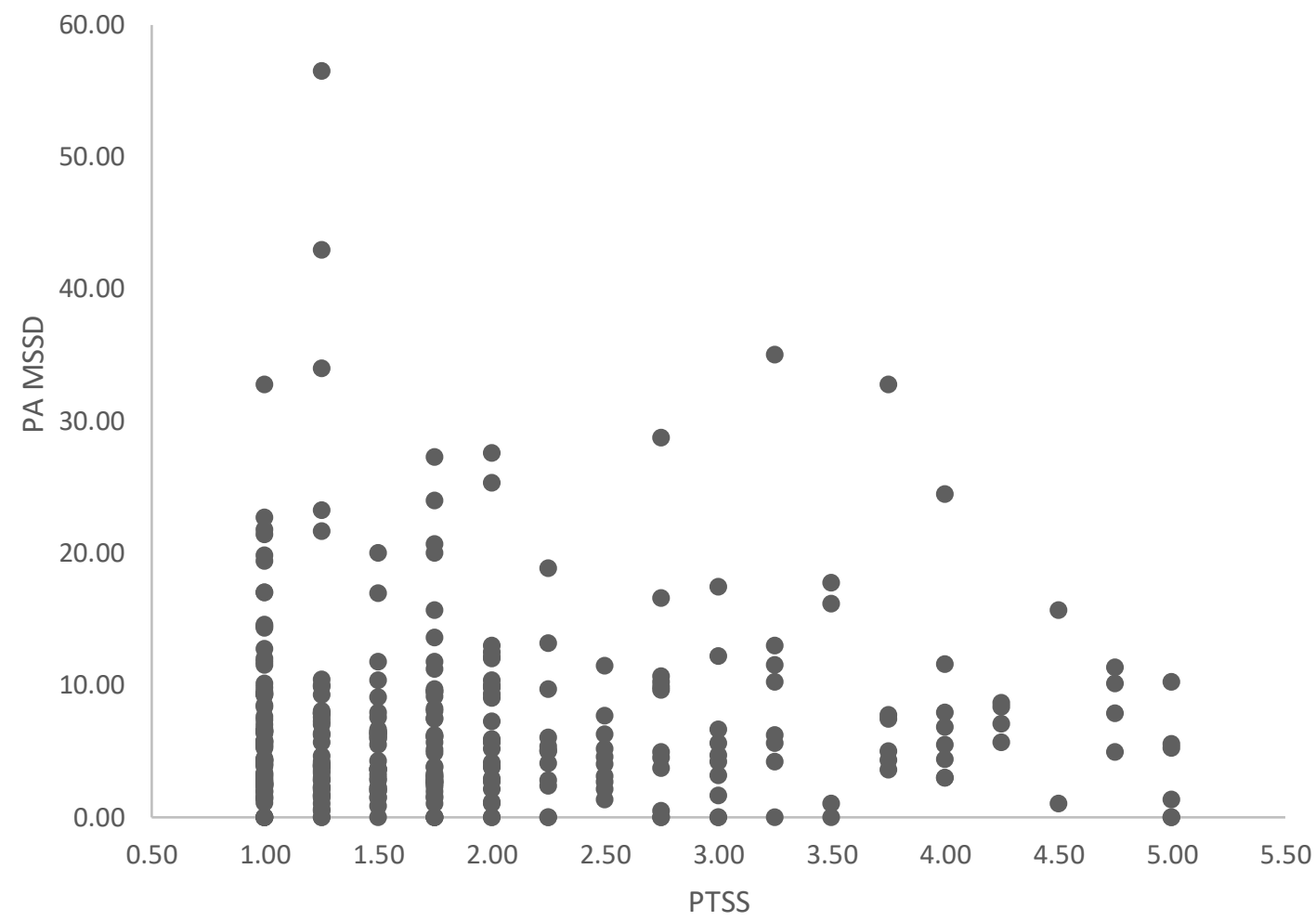

Figure 3.2. Scatterplot of positive affect (PA) mean square successive difference (MSSD) and post-traumatic stress symptoms (PTSS). 
CHAPTER IV. MANUSCRIPT III. RELATIONAL THRIVING IN MILITARY RELATIONSHIPS: THE ROLE OF AFFECTIONATE TOUCH, GRATITUDE, AND SLEEP

\begin{abstract}
Military Veterans and their spouses tend to report greater sleep problems than in the civilian population. Specific relationship interactions may help alleviate these problems such as within responsive support exchanges. This study aims to examine specific affective and behavioral interactions, affectionate touch and gratitude, that communicate responsiveness and promote health outcomes, in this case, sleep quality and duration within military-connected couples. Couples $(N=159)$ completed surveys regarding responsive support, affectionate touch with one's partner, grateful mood, and sleep over 32 consecutive days. A series of over-time actor-partner interdependence moderation models tested the degree to which responsive support to negative events predicts sleep outcomes and grateful affect. In turn, the study examined the degree to which grateful mood predicted sleep outcomes and whether affectionate touch enhanced actor and partner associations over time. Results indicated that Veteran's reports of affectionate touch predicted spouse sleep quality. In addition, spouse responsive support predicted Veteran grateful mood, moderated by Veteran reports of affectionate touch. The remaining results show inconsistent support for hypotheses. This study extends research on sleep in military couples as well as work examining the unique effects that relationship interactions play in sleep well-being.
\end{abstract}




\section{Introduction}

As of 2015, 2.8 million military service members have deployed to Iraq or Afghanistan following 9/11 (Wenger, O'Connell, \& Cottrell, 2018). While deployments are associated with increased challenges for military relationships during and after deployment (Knoblach \& Theiss, 2012; Warner, Appenszeller, Warner, \& Grieger, 2009), it remains unclear the degree to which military experiences have a lasting effect on relationship functioning after accounting for combat-related experiences (e.g., injury and posttraumatic stress; Karney \& Trail, 2017). For example, Karney and Crown (2007, 2011) showed that military marriages are not dissolving at a higher rate than the national average; in fact, more time deployed was associated with less risk of divorce for military couples over all. However, one persistent challenge that Veterans and their spouses face are sleep problems (Holliday, Haas, Shih, \& Troxel, 2016; Plumb, Peachey \& Zelman, 2014). Recent studies suggest that sleep issues extend beyond separation from the military (Fillo et al, 2017; Plumb et al., 2014). While sleep problems are comorbid with physical and mental health outcomes (Gehrman et al., 2013; Swinkels et al., 2013), Troxel and colleagues (2015) argue that sleep problems are an independent health concern for military service members because they often precede other health problems and diagnoses. Therefore, military service members and their partners are considered a high risk group for sleep problems (Holliday \& Troxel, 2017). Researchers call for more work examining the mechanisms through which sleep issues may be alleviated within military relationships, such as through relationship functioning 
(Holliday \& Troxel, 2017). This study aims to examine two relationship-

relevant features that promote health, including sleep, within the context of responsive support: gratitude and affectionate touch.

\section{Responsive support, gratitude, and affectionate touch}

Responsiveness is conceptualized as the degree to which individuals feel understood, validated, and cared for by their close others. Specifically, Partner A's perceptions that Partner B was validating, caring, and understanding after an eliciting event predicts relationship outcomes (Gable \& Reis, 2015). Attachment theory suggests that when negative events happen, individuals seek out their primary caregivers for comfort and support (Bowlby, 1969/1982). In adult relationships, good (i.e. responsive) supporters are those who provide a safe haven for their partners and restore a sense of security that is responsive to one's needs (Collins \& Feeney, 2000; Feeney, 2004). This responsive support may be in the form of actions such as physical closeness and affectionate touch, or simply the perception that a partner is there when needed. For example, one study suggests that both enacted and perceived responsiveness predict intimacy within couples' daily lives (Debrot, Cook, Perrez, \& Horn, 2012).

Touch and gratitude are both implicated as important facets in which responsiveness is communicated to bolster relationship outcomes. For example, touch and gratitude both relate to support behaviors. Kubacka, Finkenauer, Rusbult and Keijsers (2011) argue that gratitude serves two primary functions in relationships: to detect responsiveness and to motivate relationship-maintenance behaviors. This model 
is consistent with find-remind-and-bind theory of gratitude which posits that gratitude helps people find new relationship partners or reconnect with current relationship partners and to strengthen these relationships through increased feelings of responsiveness (Algoe, 2012). In social contexts, gratitude emerges when another provides a benefit to the self in a relationally-relevant manner (Algoe, 2012). In other words, a person may feel grateful when another person provides a benefit that is relevant to their needs. This signals that the benefactor is responsive to the self and understands, validates and cares for one's needs, providing a unique relational appraisal of a social situation. Furthermore, gratitude promotes prosocial behavior even at cost to the self (Bartlett \& Desteno, 2006), and such behaviors extend to relationships. For example, people engage in a variety of behaviors aimed at sustaining valued relationships (e.g., Canary, Stafford, \& Semic, 2002), including routine (e.g., walking together hand in hand or making the morning coffee) and effortful behaviors (e.g., asking one's partner about their feelings; Dainton \& Stafford, 1993). Kubacka and colleagues (2011) support their dyadic model of the dual functions of gratitude with evidence suggesting that Partner A's relationship-maintenance behaviors prompted gratitude from Partner B, partly due to the Partner B's perceptions of Partner A's responsiveness. This effect held after controlling for relationship satisfaction, indicating that gratitude functions in relationships regardless of one's global relationship evaluation, and is supported by literature arguing that gratitude is distinct from other positive emotions, such as happiness (Algoe \& Haidt, 2009). 
Similarly, affectionate touch is a caring gesture that normatively communicates closeness in relationships (Johnson \& Edwards, 1991; Mackey, Diemer, \& O’Brien, 2000). In romantic relationships, affectionate touch could include deliberate actions such as holding hands, kissing, and hugging as well as more passive touch such as maintaining body contact while sitting on a couch (Johnson \& Edwards, 1991; Jones \& Yarbrough, 1985). Affectionate touch is often considered a support behavior in close relationships that helps communicate support needs, provides comfort when distressed, and benefits both members of the interaction (Robinson, Hoplock, \& Cameron, 2015). It is important to note that sexual physical touch may be considered as a kind of affectionate touch; however, sexual behavior is nuanced. For example, sex also serves reproductive functions which may make it different from other types of affectionate touch (BirniePorter \& Lydon, 2013). Thus, this study did not explicitly include sexual physical contact in the conceptualization of affectionate touch.

Jakubiak and Feeney (2017) proposed a model of affectionate touch in adult relationships such that when a person receives affectionate touch from their partner they experience relational-cognitive changes (e.g., self and relational perceptions) and neurobiological changes (e.g., changes in oxytocin and endogenous opioids) that contributes to psychological, relational, and physical well-being directly. Furthermore, touch may promote changes in perceptions and neurobiology indirectly through stressbuffering mechanisms. The authors argue that when affectionate touch is experienced, people are reminded that they are socially connected with a close other. Feelings of 
social inclusion are vital to well-being (Baumeister \& Leary, 1995; Deci \& Ryan, 2000).

Furthermore, when touch is interpreted as affectionate (e.g., showing love, care, fondness; Floyd, 2006), individuals feel more secure and calm (Jakubiak \& Feeney, 2016b), and report feeling cared for and understood by their partners (Debrot, Schoebi, Perrez, \& Horn, 2013). Therefore, touch seems to signal that one's partner is responsive to their needs. Jakubiak and Feeney (2017) also offer support that touch promotes psychological well-being (e.g., positive emotions) as well as physical health. For example, touch is related to increases in positive mood and decreased negative mood on days when partners experienced affectionate touch (Debrot et al., 2013) as well as subsequent days following touch interaction (Burleson et al., 2007). Therefore, touch may promote feelings of gratitude among other positive emotions and reduce negative affect.

Indeed, in some ways gratitude and touch are inextricably connected because touch may communicate the emotion of gratitude (Hertenstein, Keltner, App, Bulleit \& Jaskolka, 2006; Jones \& Yarbrough, 1985). For example, in one of Hertenstein and colleagues' (2006) studies, participants separated by a curtain were randomly assigned to either "decode" a touch on one's arm by correctly guessing the emotions attempting to be communicated (touch receiver) or to "encode" particular emotions via touch (touch provider). Decoders correctly inferred the emotion that encoders attempted to communicate through touch with $48 \%$ to $83 \%$ accuracy. Whereas some emotions had variable accuracy rates, gratitude was accurately communicated in up to $66 \%$ of the 
cases. Furthermore, touch communicates distinct positive emotions, including gratitude, at comparable or even higher rates than other non-verbal communication channels such as facial expression or vocal tone (Elfenbein \& Ambady, 2002; Hertenstein, Holmes, McCullough, \& Keltner, 2009; Scherer et al., 2003). Laypersons also rate affectionate touch, such as hugging, as moderately relevant to the concept of gratitude (Lambert, Graham, \& Fincham, 2009). In an experimental study of Portuguese undergraduates, Simão and Seibt (2015) found that friendly touch (vs. no touch) predicted increased gratitude indirectly via communal feelings (e.g., perceived responsiveness and responsibility) towards their interaction partner. Therefore, both gratitude and touch are objects of communal relationships that help people communicate responsiveness and promote relational well-being (i.e., supporting meaningful social connection as measured by relationship satisfaction, commitment, and low levels of distress; Feeney \& Collins, 2015).

Moreover, gratitude and touch may help people to thrive, leading to increased health and well-being. Based in attachment theory, Feeney and Collins (2015) propose a model of relational thriving which argues that close relationship partners help us thrive in life through providing a safe haven when things go wrong as well as a secure base when life opportunities come along. When people are faced with adversity they can turn to their partner for support that not only alleviates the effects of stress or negative affect but helps to grow beyond one's stressors to affect well-being. In the relational thriving model, responsive support leads to several immediate outcomes that are 
important to well-being, including increases in the emotion of gratitude as well as enhanced health behavior such as sleep quality. As mentioned earlier, providing responsive support increases gratitude, affection (Collins et al., 2014), and the likelihood of reciprocal prosocial behaviors (Reis et al., 2010). Responsive support to life's stressors also has immediate outcomes for health. For example, responsive touch during a stressful task has been shown to reduce heart rate and blood pressure (Ditzen et al., 2007). Further, responsive support to negative events may promote sleep quality through providing a safe haven in which one can down-regulate emotions and decrease vigilance and arousal needed for efficient sleep (Troxel, Robles, Hall, \& Buysse, 2007). Thus, responsive support, gratitude, and affectionate touch, help people thrive beyond adversity to promote health, such as sleep.

\section{Gratitude, affectionate touch and sleep}

Evidence suggests that gratitude and touch are respectively beneficial for health. Dispositional levels of gratitude and general gratefulness, or what Lambert, Graham, and Fincham (2009) describe as "generalized gratitude" (as opposed to "other-focused gratitude" found in interactions), are linked to physical health outcomes including sleep. For example, dispositional gratitude supports subjective psychological health, physical health, and healthy behavior (Hill, Allemand, \& Roberts, 2013), as well as reduces stress, depression, and anxiety (Seligman et al., 2005). In their seminal work, Emmons and McCullough (2003) found that when grateful feelings were induced, individuals reported better sleep quality, increased positive affect, felt more socially connected and reported 
more prosocial behaviors. Furthermore, individuals who tend to experience more feelings of gratitude experience better sleep quality, duration, and less sleep latency (e.g., difficulty falling asleep), specifically, via increased positive cognitions before bed (Wood, Joseph, Lloyd, \& Atkins, 2009). While the link between gratitude and health is likely explained by both intrapersonal and interpersonal psychological resources (Algoe \& Zhaoyang, 2016; Hill et al., 2013; O’Connell, O’Shea, \& Gallagher, 2016), recent theory suggests that affective processes such as gratitude are one mechanism linking responsiveness and health within close relationships (Slatcher \& Schoebi, 2017).

Relatedly, affectionate touch may improve health in close relationships by "getting under the skin," (Diamond, 2001; Field, 2010, 2012; Sbarra \& Hazan, 2008). Affectionate touch is related to lower resting blood pressure and heart rate (Light et al., 2005) and decreased somatic symptoms (Stadler, Snyder, Horn, Shrout, \& Bolger, 2012), including insomnia. One study found that those receiving affectionate touch were less susceptible to cold infections, and those who ended up infected with the cold had reduced symptom severity when they received more touch, in this case, hugs (Cohen, Janicki-Deverts, Turner, \& Doyle, 2015). In addition, this study showed that touch seems to protect people from cold infection by attenuating the effect of stress on health. Ditzen and colleagues (2007) found that touch significantly lowers cortisol and heart rate compared to verbal support. These studies highlight that touch may affect health independently as well as by reducing stress. For example, Jakubiak and Feeney (2016c) found that those who were assigned to imagine affectionate touch support experienced 
less pain and stress during lab tasks compared to those assigned to imagine verbal support from a partner.

To my knowledge, there are no published studies examining the relation between affectionate touch and sleep outcomes within adult romantic relationships. However, there is evidence to suggest that the health benefits associated with affectionate touch may extend to sleep outcomes as well. For example, similar to sleep, touch helps down-regulate arousal (e.g., Ditzen et al., 2007) and increases felt security (Jakubiak \& Feeney, 2016b). Further, researchers argue that sleep (Troxel, 2010) and touch (Jakubiak \& Feeney, 2017) are respectively associated with neurobiological functioning, specifically with regard to oxytocin activity. Oxytocin is a neurohormone produced in the hypothalamus that is associated with many social interactions, including affectionate touch. For example, receiving hugs more frequently is associated with higher oxytocin levels (Light et al., 2005) and couples who were instructed to provide more touch to their partner showed greater oxytocin than couples who were not in the touch condition (Holt-Lunstad, Birmingham, \& Light, 2008). Furthermore, oxytocin is produced in the same brain region, the paraventricular nucleus of the hypothalamus, which is associated with sleep-wake cycles. There is little empirical evidence at this time supporting the role of oxytocin in sleep functioning; however, one study showed that oxytocin moderated the effect of social support and sleep quality in a sample of women with HIV (Fekete et al., 2014). While research examining the relationship between neurobiological functioning, sleep, and affectionate touch is somewhat speculative, 
there is reason to believe that affectionate touch may promote sleep by enhancing relationship and psychological functioning (Slatcher \& Selcuck, 2017). For example, touch may promote sleep by facilitating the process of responsive support within relationships.

\section{Military-connected relationships and sleep}

Sleep is an important health indicator linked to mortality, diabetes, cardiovascular health, heart disease, obesity, and accident risk (for reviews see Itani, Jike, Watanabe, \& Kaneita, 2017; Luyster, Strollo, Zee, \& Walsh, 2012). Although typically modeled as an individual health outcome, the majority of adults tend to sleep with a bed partner (National Sleep Foundation, 2013); thus, sleep is likely a shared behavior. In fact, sleep duration and quality covary between partners (Lee et al., 2017), supporting the dyadic nature of sleep.

Sleep researchers argue that sleep is fundamentally a part of the attachment system because it necessitates the down-regulation of arousal that may come with feeling a sense of security and comfort (e.g., Troxel et al., 2007). Further, studying sleep in the context of relationships is vital and represents a more ecologically-valid understanding of sleep. Moreover, sleep is theorized to share a bidirectional relationship with relational well-being (Troxel et al., 2007). For example, poor sleep tends to predict more relationship conflict (Gordon \& Chen, 2014), while higher relationship satisfaction is related to lower risk of sleep problems and better sleep quality (Ko, Chen, Wang, \& Su, 2014; Troxel, Buysse, Hall, \& Matthews, 2009). Troxel 
and colleagues (2007) suggest that the relation between sleep and relationship quality is through psychological, physiological, and behavioral mechanisms, with the influence of contextual factors such as stress or major life transitions. For example, a recent study found that perceived partner responsiveness predicts lower subjective sleep problems, mediated through lower anxiety and depression (Selcuk, Stanton, Slatcher, \& Ong, 2017) supporting the psychological pathway of Troxel and colleagues' (2007) model. In their review, Holliday and Troxel (2017) note that specific relationship behaviors and interactions have a unique effect on sleep outcomes. For example, Kane, Slatcher, Reynolds, Repetti, and Robles (2014) found that couples who tended to disclose their thoughts and feelings to their partner had better self-reported (women) and physiological (men) assessments of sleep outcomes, above and beyond global reports of relationship satisfaction. This work indicates that it is important to study sleep in the context of relationships as well as the specific relational behaviors and psychological processes that may contribute to sleep, such as affectionate touch and feelings of gratitude.

As noted previously, service members are at high risk for insufficient sleep (Luxton et al., 2011; Seelig et al., 2010). Sleep problems tend to linger post-deployment and may limit ability to reintegrate into everyday life (Pietrzak, Morgan, \& Southwick, 2010; Plumb et al., 2014). Furthermore, sleep problems are prevalent in both service members (Plumb et al., 2014) and their spouses (Holliday, Haas, Shih, \& Troxel, 2016). For example, Holliday and colleagues (2016) found that poor sleep in military spouses 
predicted lower subjective health, marital satisfaction, and more depressive symptoms. As in civilian relationships, relationship behaviors and processes may aid in the abatement of sleep problems within military-connected couples. One study found that Veterans' and their spouses' relational well-being predicted sleep quality via psychological resources (Walker O’Neal, Lucier-Greer, Mancini, Ferraro, \& Ross, 2016). Particularly, greater perceived family functioning was associated with own improved subjective sleep, and this relationship was predicted via increased psychological resources. Interestingly, spouses' endorsement of higher family functioning was related to improved sleep for service members, indicating a cross over effect from spouses to Veterans. Further, a recent study by Fillo and colleagues (2017) found that relationshipenhancing interactions predicts better sleep among military couples in which the service members had previously separated from military service. Therefore, this evidence suggests that perceived relational well-being and relationship interactions are associated with sleep outcomes in military couples, perhaps through psychological resources such as positive emotions.

\section{The present study}

Extensive research emphasizes the relation between close relationships and health outcomes (e.g., Robles, Slatcher, Trombello, \& McGinn, 2014). For example, one meta-analysis showed that people who are more socially connected have a better mortality rate (increased chance of survival) that exceeds the magnitude of other mortality risk factors such as smoking, alcohol consumption, obesity, and exercise (Holt- 
Lunstad, Smith, \& Layton, 2010). However, researchers have identified that the specific mechanisms through which relationships influence health are understudied (Pietormonaco \& Collins, 2017). The present study helps address this gap in literature by examining the role of gratitude and touch in the relation between perceived support after a negative event and dyadic sleep patterns. Furthermore, this study helps to strengthen research on sleep in military relationships by examining specific relational interactions that have interdependent effects on sleep (Holliday \& Troxel, 2017). Finally, this study aims to examine the temporal associations among these variables within relationships using actor-partner longitudinal modeling techniques. The Actor-Partner Interdependence Model (APIM; Kenny, Kashy, \& Cook, 2006) over time framework allows researchers to examine the interdependence of partners' observations occurring repeatedly across time and provides the ability to examine associations between partners from one moment to the next (i.e. both actor-partner cross-over and spillover to subsequent time points). Therefore, this model is useful for examining the associations between Veteran and spouse daily responsive support, gratitude, affectionate touch, and nightly sleep outcomes. The conceptual model for the current investigation is depicted in Figure 4.0.

Specifically, I hypothesized that perceived partner responsiveness to negative events will predict increased self-reported nightly sleep quality (H1a), sleep duration (H2a), and increased grateful mood (H3a; actor effects). Further, own increased nightly sleep quality $(\mathrm{H} 1 \mathrm{~b})$, duration $(\mathrm{H} 2 \mathrm{~b})$, and grateful mood $(\mathrm{H} 3 \mathrm{~b})$ is expected to be predicted 
by increased partner reports of responsive support (partner effects). Actor and partner effects on sleep quality $(\mathrm{H} 1 \mathrm{c})$, sleep duration $(\mathrm{H} 2 \mathrm{c})$, and grateful mood $(\mathrm{H} 3 \mathrm{c})$ were expected to be moderated by reports of affectionate touch such that touch will enhance the degree that responsive support promotes sleep. In addition, actor and partner effects were expected to differ for Veterans and spouses for models in which responsive support predicts sleep quality $(\mathrm{H} 1 \mathrm{~d})$, sleep duration $(\mathrm{H} 2 \mathrm{~d})$, and grateful mood $(\mathrm{H} 3 \mathrm{~d})$.

In turn, grateful mood was expected to predict better nightly sleep quality (H4a) and duration ( $\mathrm{H} 5 \mathrm{a}$; actor effects). Increased sleep quality ( $\mathrm{H} 4 \mathrm{~b})$ and duration ( $\mathrm{H} 5 \mathrm{~b})$, in turn, was expected to be predicted by one's partner's reports of grateful mood (partner effects). Similar to responsive support and sleep, actor and partner effects of gratitude and sleep quality $(\mathrm{H} 4 \mathrm{c})$ and duration $(\mathrm{H} 5 \mathrm{c})$ were expected to depend on affectionate touch wherein higher affectionate touch interacts with grateful mood to increase sleep quality and duration. In addition, actor and partner effects for sleep quality (H4d) and sleep duration ( $\mathrm{H} 5 \mathrm{~d}$ ) were expected to differ for Veterans and spouses.

Lastly, these aforementioned associations were expected to remain after accounting for post-traumatic stress disorder symptoms, other positive mood, negative mood, and relationship and individual characteristic covariates $(\mathrm{H} 7)$ to examine the unique effect of responsive support, gratitude, and affectionate touch on dyadic sleep within military-connected relationships.

Given that gratitude and affectionate touch may be mechanisms through which responsive support promotes sleep, indirect effects will be explored in the models. 
Therefore, I posed the following research questions: Does gratitude share an indirect association between responsive support and sleep in actors and partners over time (RQ1)? Further, does affectionate touch moderate the potential indirect effect between responsive support, grateful mood, and sleep quality and duration (RQ2)?

\section{Methods}

\section{Participants}

The sample for this study consisted of 159 dyads. The majority of the sample were married or in a civil union (89.9\%). Therefore, I henceforth refer to partners of Veterans as "spouses" for simplicity. Couples were in a relationship for 11.90 years on average $(S D=8.59)$, and $76.6 \%$ of the couples indicating having at least one child. Veterans were majority male (89.3\%) and Caucasian (83.0\%). Likewise, most spouses were female (89.9\%) and Caucasian (81.1\%). On average, Veterans were 38.16 years old $(S D=9.12$; range 23 - 67) and spouses were on average 36.22 years old ( $S D=9.04$; range $20-61$ ). About half of Veterans (47.2\%) and spouses (50.3\%) completed college or technical school. The majority of couples reported having children living in their home (68.2\%), and the median household gross income was $\$ 50,000$ - $\$ 74,999$ per year (see Arpin, Starkey, Mohr, Greenhalgh, \& Hammer, 2018; Hammer, Wan, Brockwood, Mohr, \& Carlson, 2017).

\section{Recruitment and Procedure}

This study is a part of a larger project called the Study for Employment Retention of Veterans (SERVe). SERVe was funded by the Department of Defense to test the 
efficacy of a supervisor intervention designed to increase the retention and well-being of Veterans in the workplace in a randomized controlled trial. Thirty-five organizations throughout the state of Oregon were recruited to be a part of pre-intervention and post-intervention surveys. Over 500 separated active duty and current reservists were recruited from within these organizations to take part in SERVe. With regard to military background and deployment history, this sample is diverse and is comprised mostly of separated service members with a smaller group of active reservists (18\%). In addition, most of the sample reported deploying at least once (88.3\%), thus, I collectively refer to all service members as "Veterans" (see Hammer et al., 2017). Relatedly, since the current sample captures Veterans both currently serving and separated from the military, I refer to the couples as being in "military-connected" relationships.

Veterans consented into SERVe were invited to participate in the Daily Family Study (DFS) along with their spouses or cohabitating romantic partners. The DFS was a 32-day daily study taking place prior to supervisor intervention. To be eligible for SERVe and DFS, Veterans must have served in the armed forces following $9 / 11$ and work at least 20 hours a week; couples must be cohabitating (e.g., living together). Of those Veterans and spouses participating in SERVe, 260 were matched couples and eligible for the DFS. Of these, 173 matched couples consented into the DFS and completed at least 1 day of surveys. Nine couples who participated in a pilot version of the DFS were removed due to incompatible data (e.g., pilot surveys differed slightly in formatting and measured variables). Finally, 3 couples were excluded because they did not complete 
the surveys in the same reporting window. Thus, the analyses draw from these 159 couples.

Veterans and spouses participating in the DFS received an email on the first day of the daily study with a secure link to their informed consent form and first web-based daily survey. Following this procedure, participants were emailed a secure link to an online survey each day for 32 consecutive days. Surveys took about 5 to 10 minutes to complete. The survey was designed to be completed at the end of each business day but before bedtime with a reporting window between 5:00 PM and 11:00 PM. To accommodate those with alternative work schedules, a small portion of participants who indicated that they worked an alternative shift (18\%) and their partners completed surveys from 5:00 AM to 11:00 AM. Participants completed about 24 survey days on average comprising a total of 7,916 survey observations (78\% compliance rate). Participants received up to $\$ 90$ compensation for completing the DFS. Participation was voluntary and all SERVe and DFS procedures were approved by an Institutional Review Board and the U.S. Army Medical Research and Material Command, Human Research Protection Office. For additional information about recruitment and procedures, see other study-related papers (Arpin, et al., 2018; Hammer, Wan, Brockwood, Mohr, \& Carlson, 2017; Mohr et al., 2018).

\section{Measures}

Sleep outcomes. Participants responded to two items adapted from the Pittsburgh Sleep Quality Index (PSQI; Buysse et al., 1989) regarding sleep quality and 
duration. To measure sleep quality, participants were asked, "How would you rate last night's sleep quality over all?" with response options ranging from (1) "very bad" to (4) "very good." In addition, sleep duration was measured using one item, "How many hours did you sleep last night?," by choosing from a drop-down menu ranging from 0 to 24 hours, answered in hours and minutes. One-item measures to assess sleep have been used in previous daily studies (e.g., Lee et al., 2017; Sin et al., 2017) and thus are used in the present study.

Grateful mood, positive and negative affect. Mood was measured using 13 items. Positive affect items included happy, relaxed, focused, active, and quiet. Negative affect items included angry, guilty, ashamed, nervous, bored, lonely and sad. These items were drawn from the Positive and Negative Affect Schedule-Extended form (PANAS-X; Watson, Clark, \& Tellegen, 1988; Watson \& Clark, 1994) as well as Larsen and Diener's (1992) mood circumplex model. In addition, a gratitude-related mood, grateful, was drawn from Emmons and McCullough (2003). For all 13 moods, participants answered the degree to which they felt each mood during the past 24 hours on a 5point Likert scale ranging from (1) "not at all" to (5) "a great deal."

While there may be potential measurement issues with using a one-item measure of gratitude, researchers have used single items to measure constructs such as well-being (Deiner, 1984) and intimacy (e.g., Laurenceau, Barrett, \& Rovine, 2005), especially within daily studies. Further, moods can be reliably measured with single items (e.g., Meyers \& Deiner, 1995), which aid in reducing participant fatigue (Larsen \& 
Frederickson, 1999). In addition, gratitude researchers have used one-item grateful mood measures in previous daily studies (e.g., Emmons \& McCullough, 2003; Allan, Steger, \& Shin, 2013; DeWall, Lambert, Pond, Kashdan, \& Fincham, 2012).

The day-level internal consistency for the negative affect and positive affect measures (respectively) were estimated on 3 days randomly selected from the beginning middle and end of the DFS (days 3, 10, and 26). Cronbach's alphas ranged from .69 to .71 for positive affect and between .75 to .79 for negative affect. Composite scores were created by summing negative or positive moods within day, respectively.

Affectionate touch. One item adapted from the Inventory of Small Life Events and Assessment of Daily Experience checklists (Stone \& Neale, 1984; Zautra, Guarnaccia, Reich, \& Dohrenwent, 1988) measured positively-appraised physical touch. Participants rated how positive their experience of pleasing physical contact with spouse/partner that day on a Likert scale ranging from (1) "extremely negative" to (5) "extremely positive." Higher numbers indicate a more positive pleasing touch experience. While one-item measures may be subject to measurement issues, affectionate touch has been measured using a single item in previous daily studies of individuals as well as romantic couples (e.g., Burleson, Trevathan, \& Todd, 2007; Debrot et al., 2013).

Perceived Responsiveness to Negative Event. Responsive support to negative event items were modified for this study from procedures capturing responsive support to positive and negative events (Gable, Conzaga, \& Strachman, 2006). Participants were asked to recall their most negative event that day, whether they shared this event with 
their partner, and if so, how their partner responded to the event disclosure. Over 4 items, participants rated the degree to which they perceived their partner to be responsive to their needs (e.g., when I talked to my spouse/partner about this event, I felt that my spouse/partner made me feel cared for). The items were rated on a 5-point Likert scale ranging from (1) "strongly disagree" to (5) "strongly agree." Similar to affect, internal consistency was examined for response days 3, 10, and 26. Cronbach's alpha ranged from .85 to .95 and a composite score was created by averaging across items within day. Higher numbers indicate greater perceived responsiveness.

Demographic variables and covariates. Demographic variables such as age, gender, parent status, relationship length, race, education, and military demographics were gathered from the baseline assessment. Several control variables were included in the model in order to account for individual and relationship characteristics that previous literature has demonstrated may impact the model, such as posttraumatic stress symptoms (PTSS), gender, relationship length in years, parent status (whether or not a couple had at least one child), day of the week, shift work (those working alternative shifts).

Research indicates that post-traumatic stress may reduce relational well-being in military couples, even after accounting for combat exposure, deployment history, and other military characteristics (e.g., Karney \& Trail, 2017). Therefore, PTSS was included as a covariate in the current analyses. PTSS was measured at baseline by the Posttraumatic Stress Disorder Checklist, Military version (PCL-M; Bliese et al., 2008; 
Weathers, Huska \& Keane, 1991). This 4-item measure primarily serves as a screening tool for military-related post-traumatic stress symptoms. On a 5-point scale from (1) "Not at all" to (5) "Extremely," Veterans rated items regarding how bothered they were by each symptom during the past 30 days. Items were averaged to create composite scores of post-traumatic stress symptomology.

Demographic covariates such as gender, relationship length, parent status and shift work were considered as covariates in the present investigation. These control variables help account for alternative explanations of findings related to individual and relationship characteristics. Past research has described that men and women may differ in feelings of gratitude (Kashdan, Mishra, Breen, \& Froh, 2009) and sleep outcomes (Reyner \& Horne, 1995), particularly when examining the effect relationshipmaintenance behaviors on sleep in couples (Kane et al., 2014). In addition, gender, parent status, and relationship duration are variables that likely covary with relational well-being within military couples and are typically controlled for in military relationships research (Karney \& Crown, 2007; Karney \& Trail, 2017). Moods and sleep behavior tend to vary across days of the week. For example, people report feeling more positive (Ryan, Bernstein, \& Brown, 2010) and getting more sleep (Roepke \& Duffy, 2010) on the weekends compared to weekdays. Finally, shift workers may be particularly at risk of sleep problems (Drake, Roehrs, Richardson, Walsh, \& Roth, 2004) and, thus, was included as a control variable.

\section{Analyses}


Diagnostics. Normality, outliers, and missingness in the data were explored. Histograms and distributions of the reporting days indicated that the variables were fairly normally distributed. Descriptive analyses and box plots revealed no problematic skew or outliers for primary study variables. Normal probability plots and scatterplots of level 1 residuals indicated that normality assumptions were not violated. Multilevel logistic regressions in which relevant study variables, such as day of week and parent status, predicted missingness indicators for all variables of interest (responsive support, touch, gratitude, sleep quality, and sleep duration) were conducted in SPSS. Results of the missingness exploration indicated that missingness in gratitude $[F(6,7585)=.01, n s$; $F(1,10174)=.41, n s]$, sleep quality $[F(6,7585)=.003, n s ; F(6,10174)=.35, n s]$, and sleep duration $[F(6,7585)=.01, n s ; F(1,10174)=.28, n s]$ was not predicted by day of the week or parent status, respectively. However, missingness in perceived responsive support was predicted by day of the week, $\mathrm{F}(6,7585)=7.72, p<.001$ and parent status, $F(1,10174)=4.24, p=.04$. Therefore, there is some evidence that data in this study, particularly for perceived responsive support, are missing at random. The following analyses included day of the week and parent status as covariates and employ estimation strategies that limit the problems with missingness data.

Non-independence. In addition, to the descriptive statistics described previously, Table 4.0 provides within-couple bivariate correlations for study variables. All variables of interest including perceived responsive support $\left(r_{v s}=.22, p<.05\right)$, affectionate touch $\left(r_{v s}=.48, p<.01\right)$, grateful mood $\left(r_{v s}=.33, p<.01\right)$, sleep duration $\left(r_{v s}=.30, p<.01\right)$, and 
sleep quality $\left(r_{v s}=.21, p<.01\right)$, indicated non-independence among Veteran and spouse couples. In addition, intra-class correlations (ICC) examining the nesting of days within individuals indicated non-independence within-person for gratitude $(\rho=.71)$, sleep duration $(\rho=.31)$, and sleep quality $(\rho=.28)$. For example, $71 \%$ of the variability in daily grateful mood could be explained by within-person variation. Non-independence related to employer structure was also examined. For both sleep quality and sleep duration, intra-class correlations indicated low variability related to employer $(\rho=.01, \rho$ $=.02$, respectively). However, intra-class correlations indicated that $19 \%(\rho=.19)$ of the variance in grateful mood could be contributed to Veteran's employer. Given this degree of variation, employer clustering cannot be ignored. For example, different organizations may have a culture that supports an employee's feelings of gratitude in their daily life. While interesting, the current study does not focus on this topic. Therefore, employer was included as a covariate in analyses predicting grateful mood.

Distinguishability. The distinguishability of Veteran and spouse dyad roles was empirically tested by estimating both a distinguishable dyad model and an indistinguishable model and calculating a chi-square difference test of the respective log likelihood information criteria. Veteran and spouse partner roles were indistinguishable for models in which perceived responsive support predicted gratitude, $\chi^{2}(3)=5.72, p=$ .13 , sleep duration, $\chi^{2}(3)=3.05, p=.38$, and sleep quality, $\chi^{2}(3)=4.64, p=.20$. However, chi square tests revealed that Veteran and spouse roles were distinguishable for models in which grateful mood predicted sleep duration, $\chi^{2}(3)=12.08, p=.01$. 
Dyads were not empirically distinguishable for the gratitude-sleep quality model, $\chi^{2}(3)=$ $1.38, p=.71$. While these tests revealed that Veterans may not differ from spouses within the dyads for four out of the five proposed models, there is reason to believe that Veterans and spouses as we have defined them here are theoretically distinguishable based on how participants were recruited into the study. For example, by design of the larger SERVe study Veteran employees were first recruited as participants, who subsequently identified their spouse or romantic partner to be recruited. Therefore, in order to remain consistent between models tested, I treated Veteran and spouse as a distinguishable role in all models.

Primary analyses. Longitudinal actor-partner interdependence moderation models (APIMoM; Garcia, Kenny, \& Ledermann, 2014; Kenny, Kashy, \& Cook, 2006) were conducted in order to examine how daily sleep is predicted from daytime responsive support to negative events, grateful mood, and affectionate touch. Standard over time actor-partner interdependence models (APIM) were estimated for models testing responsive support on gratitude. In this case, all the predictors and outcomes were time-varying. Sleep items assessed a participant's sleep quality and duration last night, thus, lagged actor-partner models must be estimated for models in which responsive support and gratitude predict sleep outcomes. For example, participants' sleep outcomes at time $t$ were predicted from his/her lagged daytime responsive support, gratitude, and affectionate touch moderator at time $t-1$. Therefore, lagged models indicate the degree to which daily responsive support, gratitude, and 
affectionate touch predict sleep outcomes that night. For lagged and standard APIM over time models, individual daily reports (Level 1) are nested within couples (Level 2). Because of problems with convergence, the models included fixed slopes (Kenny et al., 2006). Random effects were allowed to correlate and an autoregressive structure for residual correlations to account for similarity in adjacent-day observations was specified. Predictor variables were grand-mean centered. This longitudinal APIM approach accounts for dyadic dependence (the between dyad members variables at a given time) and autocorrelation (the correlation of measures taken at a single time point with the same measure taken at another time point). Models were tested using multilevel modeling in SPSS 22.0 software with maximum likelihood estimation.

Therefore, hypotheses were tested within five separate actor-partner over time models in which responsive support predicted sleep quality (model 1), duration (model 2) as well as gratitude (model 3). In turn, gratitude predicted sleep quality (model 4) and sleep duration (model 5). All models included affectionate touch reported by Veterans and spouses as a moderator of actor and partner effects. In accordance with recommendations (Kenny et al., 2006), a two-stage approach was used to test APIMs. In the first test, the APIM is tested in which all actor and partner paths are moderated by dyad role. This tests whether the actor and partner effects empirically differs for Veterans and spouses. In the second stage, the APIM is modeled with two intercepts, one for Veterans and one for spouses, in order to examine how and for which dyad member the effect differs. For example, the interaction approach indicates that an actor 
or partner effect differs for Veterans and spouses and the two-intercept approach then reveals the separate effect estimates for Veterans and spouse actor and partner effects.

\section{Results}

\section{Descriptive statistics}

Descriptive information and bivariate correlations for study variables are displayed in Table 4.0. Veterans reported an average perceived partner responsiveness to negative events score of $4.02(S D=.62)$ and $2.82(S D=1.25)$ for grateful mood. In addition, Veteran responses for sleep quality and sleep duration averaged 2.73 (SD = $.39)$ and 6.58 hours $(S D=.93)$, respectively. Spouses $\left(M_{s}=4.04, S D=.60\right)$ reported an average rate of $2.78(S D=.46)$ for sleep quality and $6.96(S D=1.00)$ hours for sleep duration. In addition, spouses average scores for perceived responsiveness and grateful mood were $4.04(S D=.60)$ and $3.29(S D=1.18)$, respectively. Veterans' reports of affectionate touch averaged $2.67(S D=1.37)$, and spouses averaged $2.75(S D=1.29)$. In line with previous literature, perceived responsive support was positively associated with affectionate touch $\left(r_{v}=.49, p<.01 ; r_{s}=.41, p<.01\right)$, gratitude $\left(r_{v}=.45\right.$, $\left.p<.01 ; r_{s}=.45, p<.01\right)$, and sleep quality $\left(r_{v}=.20, p<.05 ; r_{s}=.30, p<.01\right)$. However, responsive support was not significantly related to sleep duration for Veterans $\left(r_{v}=.09\right.$, $p=.32)$ or spouses $\left(r_{s}=.01, p=.87\right)$. Similarly, grateful mood was positively associated with sleep quality $\left(r_{v}=.30, p<.01 ; r_{s}=.31, p<.01\right)$ but not significantly related to sleep duration $\left(r_{v}=.07, p=.40 ; r_{s}=.05, p=.57\right)$. Affectionate touch shared a positive 
relationship with grateful mood $\left(r_{v}=.29, p<.01 ; r_{s}=.43, p<.01\right)$, sleep quality $\left(r_{v}=.35\right.$, $\left.p<.01 ; r_{s}=.27, p<.01\right)$, and sleep duration $\left(r_{v}=.27, p<.01 ; r_{s}=.23, p<.01\right)$.

\section{Hypothesis testing}

A series of actor-partner interdependence over time models were conducted to assess how perceiving responsive support may increase feelings of gratitude and support better sleep. In addition, the present study examined how affectionate touch may strengthen this effect. A summary of the results from these models are presented in Table 4.1. Five main models tested how perceived responsive support to negative events predicted grateful moods, sleep duration, and sleep quality, and in turn the effect of grateful mood on sleep outcomes within the context of military relationships. Affectionate touch was examined as a moderator in all models. In addition, all models included post-traumatic stress (PTSS), gender, relationship length, parent, status, day of week, shift, and positive and negative affect as covariates. Each over time model was tested first by including dyad role as a moderator of actor and partner paths, described by Kenny and colleagues (2006) as the interaction approach and then tested with twointercepts.

Sleep outcomes. Hypotheses 1a and 2a predicted that perceived responsive support to negative events would increase self-reported sleep quality and sleep duration in Veterans and spouses (actor effects). In addition, hypotheses $1 \mathrm{~b}$ and $2 \mathrm{~b}$ proposed that partner's perceived responsive support would predict increased sleep duration and quality (partner effects), and that these effects would differ for Veterans 
and spouses $(\mathrm{H} 1 \mathrm{~d}$ and $\mathrm{H} 2 \mathrm{~d})$. The results indicate that the Veteran and spouse actor and partner effects for responsive support predicting sleep outcomes are not supported. For example, actor effects in which Veteran perceived responsive support predicted Veteran sleep quality $(b=.03, n s)$ and sleep duration $(b=-.03, n s)$ that night were not significant. In addition, spouse actor effects for sleep quality $(b=.13, n s)$ and duration $(b=.33, n s)$ were similarly non-significant. In turn, partners' perceived responsive support reports were not significantly related to sleep quality or duration for Veterans $(b=.20, p=.06 ; b$ $=.06, n s$, respectively) or spouses ( $b=-.01, n s ; b=-.15, n s$, respectively). While there seemed to be a marginal Veteran partner effect for sleep quality, the partner effect was not significant when examining whether one's role moderated the partner effects, indicating that the effect was not significantly different for Vets and spouses.

Hypotheses $1 \mathrm{c}$ and $2 \mathrm{c}$ proposed that affectionate touch would moderate actor and partner effects of perceived responsive support on sleep quality and sleep duration. However, these data do not fully support these hypotheses. For example, the effect of perceived responsive support on sleep did not significantly differ for those reporting more or less affectionate touch (see Table 4.1). Interestingly, there was a main effect of affectionate touch on sleep quality, such that spouse sleep quality was predicted by Veterans increased reports of affectionate touch with their partner $(b=.09, p=.03)$. Therefore, affectionately touching one's partner may lead to better sleep that night, especially for spouses. Moderation results also revealed a marginal actor effect for spouses such that spouses' reports of affectionate touch enhanced perceived 
responsive support, predicting own increased sleep quality that night $(b=.09, p=.08)$. However, the interaction approach reveal that this effect did not significantly differ between Veterans and spouses.

Hypotheses 4a and 5a predicted that daily grateful mood would predict increased sleep quality and sleep duration that night (actor effects). In turn, hypotheses $4 \mathrm{~b}$ and $5 \mathrm{~b}$ proposed that partner's reports of grateful mood would predict sleep quality and duration (partner effects). In addition, the effects were expected to differ for Veterans and spouses ( $\mathrm{H} 4 \mathrm{~d}$ and $\mathrm{H} 5 \mathrm{~d}$ ). None of the proposed hypotheses were supported in these data. Hypotheses $4 c$ and $5 c$ predicted that affectionate touch moderates the effect of grateful mood on sleep outcomes. Similarly, results indicated that these hypotheses were not supported (see Table 4.1).

Grateful mood. Hypothesis 3a proposed that perceived responsive support from one's partner would predict same-day grateful mood for both Veterans and spouses (actor effects). Results indicated that there was a significant actor effect for spouses ( $b$ $=.29, p=.04$ ), indicating that spouses who felt that their partner was more supportive after a negative event felt more grateful that day. However, this must be interpreted with caution; this effect did not significantly differ by role $(\mathrm{H} 3 \mathrm{~d})$ when examining the model using the interaction approach. The data revealed that there were no significant partner effects for perceived responsive support on grateful mood. Thus, hypothesis $3 \mathrm{~b}$ was not supported. 
Moderation analyses revealed a significant interaction effect for Veteran's grateful mood $(b=.17, p=.03)$, indicating that Veteran grateful mood increased when spouses perceived more responsive support depending on Veteran's reports of pleasing physical touch. In addition, there was a significant effect for Veteran's grateful mood predicted by Veteran's reports of partner responsive support moderated by spouses' affectionate touch $(b=-.22, p<.001)$. However, interaction analyses revealed that this effect did not differ across Veteran/spouse role. Similarly, Veteran reports of perceived support predicted spouses' grateful mood moderated by Veteran's reports of affectionate touch ( $b=.13, p=.03)$; however, this effect did not differ across dyad role in the interaction APIM model.

Mediation. In addition to the proposed hypotheses, two research questions aimed to explore whether grateful mood mediated the relation between perceived support and sleep outcomes and whether the mediation would differ depending on affectionate touch. However, the hypothesized models did not yield effects that indicated a mediational relationship among the proposed variables. Since there was no strong indication that gratitude mediated the relationship between responsive support and sleep outcomes within the moderated APIM models, no further tests of mediation or moderated mediation were conducted. Therefore, research questions one and two were not answered with these data.

\section{Discussion}


Sleep is an important health behavior for thriving and critical to the study of intimate relationships and military service. Sleep problems are persistent in both Veterans and spouses (Holliday et al., 2016; Plumb et al., 2014). Further, sleep is a shared behavior within romantic relationships that tends to bi-directionally affect relationship functioning and quality. Social connection is imperative to health (HoltLunstad et al., 2010) and recent efforts support raising relational health to a public health priority given the comparable magnitude of social connection on mortality rates as other disease morbidities (Holt-Lunstad, Robles, \& Sbarra, 2017). Additional research examining how sleep within relationships unfolds in daily life may inform evidencebased recommendations for how social relationships are a health determinant and public health priority.

The primary aim of this study was to examine features of relationships that are linked to health and well-being, specifically, the processes related to gratitude and affectionate touch. While the results of the present study do not fully support previous research and theory suggesting that relationship-specific behavioral and psychological mechanisms inform how relationships predict sleep outcomes (Holiday et al., 2017; Troxel et al., 2007), modest findings suggest that on days when Veterans experienced more affectionate touch their spouses slept better that night. To my knowledge, this is the first study to examine affectionate touch and nightly sleep within relationships. While neurobiological functioning related to oxytocin is implicated for both affectionate touch (Jakubiak \& Feeney, 2017) and sleep (Troxel, et al., 2007), evidence connecting 
sleep and touch remains limited. The present study suggests that affectionate touch is associated with greater sleep quality. Further, the finding indicates a dyadic effect such that Veterans' reports of experiencing touch with their partner was related to their partner's reports of greater sleep quality. This suggests that an intimate partner interaction was related to partner's sleep. This crossover effect also highlights the dyadic nature of sleep such that one's own experiences cross over to one's partners sleep (e.g., Lee et al., 2017; Troxel et al., 2007). In addition, Veteran reports of affectionate touch enhanced spouse reports of responsive partner support to predict increased grateful mood in Veterans, indicating that affectionate touch not only helps communicate support but also strengthens the effect of social support on relationship maintenance emotions such as gratitude. For example, Kubacka and colleagues (2011) showed that greater feelings of gratitude was predicted by relationship maintenance behaviors, such as affectionate touch, partly due to perceptions of partner responsiveness. Therefore, this research supports a dyadic process between responsive support, affectionate touch, and gratitude.

In addition, results show a trending pattern of spouse reports of responsive partner support predicting increased own grateful mood. Likewise, there was a trending moderation effect of spouse touch on Veteran reported responsive support predicting Veteran grateful mood. However, these results must be interpreted with caution. Preliminary evidence suggests that Veteran and spouses role were not empirically distinct for these effects. For example, Veteran and spouse status does not moderate 
the actor and partner paths indicating that within couples it may not matter which partner is more responsive. No other findings emerged in this study.

Broadly speaking these findings offer support for the interplay between responsiveness, touch, and gratitude. Responsiveness engenders feelings of appreciation and gratitude (Kubacka et al., 2011). For example, when individuals feel cared for and appreciated by their partners, they may experience their own feelings of gratitude, particularly when affectionate touch is involved. This is consistent with literature suggesting long-term well-being benefits for benefactors who provide support to their romantic partners (Algoe, Frederickson, \& Gable, 2013) and research examining the how touch communicates gratitude (Hertenstein et al., 2006), responsiveness (Jakubiak \& Feeney, 2016b), and social support (Robinson et al., 2015). In addition, affectionate touch predicted partner sleep. While research has demonstrated the relation between touch and health (e.g., Ditzen et al. 2007; Jakubiak \& Feeney, 2017), this is one of the first studies to examine affectionate touch and sleep in romantic couples. Therefore, this work extends literature on relationship functioning, sleep health, and military relationships.

\section{Limitations and future directions}

While the design of this study had strengths related to examining how partner interactions and physical health unfolds in daily life, this study has several limitations. First and foremost, the study was limited by the number of days in which participants reported discussing a negative event with their partner. Out of the 7,915 of reported 
days in this sample, responsiveness to negative events were only reported on 1,463 days. Therefore, the power to detect daily effects was severely limited and results must be interpreted with caution.

Even after taking into account power concerns, the lack of evidence in this study is surprising in light of recent work examining capitalization support (another specific form of responsive social support; Gable et al., 2004) and sleep in the SERVe sample (Arpin et al., 2018). The present study drew heavily on the thriving through relationships framework proposed by Feeney and Collins (2015), who argue that relationships help people thrive through two main functions: providing a source of strength (SOS) during adversity or negative events and being a relational catalyst $(\mathrm{RC})$ for personal growth during abundance or positive events. Therefore, this study examined responsive support following negative events on sleep (SOS function) and aimed to complement previous work by the SERVe team examining responsive support following positive events (RC function), or capitalization support (Arpin et al., 2018). Arpin and colleagues (2018) successfully showed that intimacy and loneliness mediated the relationship between daily capitalization support and nightly sleep quality and duration. Similarly, an objective of this study was to test whether grateful mood mediated the associations between responsiveness to negative events and sleep. However, no such association emerged and therefore this study was not able to support the SOS function of responsive support with these data. Researchers argue that responsiveness plays a key role in promoting health, but may do so indirectly through psychological mechanisms. Selcuk and 
colleague (2017) found that general perceived partner responsiveness was related to better self-reported and actigraph sleep outcomes mediated by lowered depression and anxiety. Therefore, gratitude may not be a strong mechanism through which negative event responsiveness relates to sleep. Mechanisms such as reduced within-day stress, or lower within-day negative affect that aid in the down regulation necessary for sleep may represent more proximal functions. Similarly, within the tested models capitalization support may have been a more proximal predictor of grateful mood and subsequent sleep. Like capitalization, gratitude grows and maintains relationships (Algoe, 2012; Gable et al., 2004). Therefore, grateful mood may more adequately explain how responsiveness to positive events (capitalization) promotes physical health, including sleep. However, this must be confirmed with additional study. These limited findings point toward promising avenues for future research examining responsive support and sleep and researchers must continue to answer the call for deeper examination of thriving through relationships within daily responsive interactions.

Furthermore, research suggests that the relationships between emotions, such as gratitude and health are complex. For example, there is evidence for both a direct and indirect effect of gratitude on physical health and psychological well-being (Emmons \& McCullough, 2003; O'Connell et al., 2016). This study hypothesized that grateful mood shared a direct relation to sleep, and was proposed as a mechanism through which responsive support predicted sleep. The findings did not support this hypothesis. 
a different mechanism through which responsive support relates to health. Future research should explore other mechanism and perhaps other health indicators of thriving. While sleep health within military couples is a concern, responsive support may have a stronger effect on global measures of health or quality of life and is an apt area for future work.

In addition, the data in this study had mixed findings in terms of the distinguishability of the models. Preliminary analyses revealed that 4 out of the 5 models were empirically indistinguishable, meaning that these models fit better when tested as if partners could be exchangeable. Therefore, perhaps unsurprisingly, several of the actor and partner effects were not differentiated for Veterans and spouses, meaning that the observed effects were equally as strong (or not) for Veterans and spouses. This inconsistency of the analyses made it difficult to interpret findings related to the roles of Veteran and spouse. However, guided by the empirical test of distinguishability, experts recommend using a uniform approach when testing multiple models (Kenny et al., 2006). Therefore, I chose to uniformly test the models as distinguishable based on theoretical and study design-based differentiation of Veteran and spouse roles. Future work should examine the degree to which Veterans and spouses qualitatively differ in their relationship interactions and health outcomes within military couples.

It is also important to note that causality may not be inferred from this study. While the study examined the temporal relation between daily responsive support, 
affectionate touch, gratitude, and nightly sleep quality and duration, this study was not equipped to determine that responsive support causes sleep improvement or increased grateful mood. Rather, it could be that affectionate touch predicts gratitude and sleep at varying degrees of partner responsiveness. For example, one study showed that responsive touch from one's partner was related to increased intimacy and enhanced positive affect (Debrot et al., 2013). Further, researchers suggest that intimacy plays a key role in nightly sleep (Troxel et al., 2010). At this time affectionate touch is still a relatively new area of research within relationship science (Jakubiak \& Feeney, 2017). Therefore, additional work examining the effect of affectionate touch over time as a unique catalyst for growth and mode of social support is needed.

Affectionate touch may also be nuanced and differ by gender. There is conflicting evidence for the degree to which men and women differ in expressions or perceptions of affectionate touch (e.g., Guerrero \& Andersen, 1991; Stier \& Hall, 1984). For example, Hertenstein and colleagues (2006) found that men and women did not differ in how accurately they detected emotions communicated through someone touching their arm. However, other work suggests that women may initiate touch more often than men (Stier \& Hall, 1984). Unfortunately, in the present study gender is confounded with Veteran ( $89.3 \%$ male) and spouse ( $89.9 \%$ female) roles. While this sample is comparable to the gender make-up within military populations (U.S. Department of Defense, 2015) and therefore representative of the population of interest, gender differences in affectionate touch needs additional study in future 
research. Further, physical touch among romantic partners may be a fairly common experience in intimate relationships (Guerrero \& Andersen, 1991). Therefore, drawing on signal detection theory in which romantic partners may miss signals for social support (Gable, Reis, \& Downey, 2003), the meaningfulness of affectionate touch may be hard to detect in couples potentially subtle daily interactions. However, recent research suggests that particularly when intimate partners are distressed, providing affectionate touch is an adequate mode of social support even when the reason behind the touch is unclear to the support provider (Robinson et al., 2015). Future work on daily affectionate touch interactions may consider examining affectionate touch within particular situations or events rather than touch experienced across the day, for example, using event-contingent sampling methodology (see Bolger, Davis, \& Rafaeli, 2003).

This study may be further limited by how gratitude was conceptualized. For example, the current study examined grateful mood as opposed to trait levels of gratitude or expression of gratitude between partners. Recent research indicates that the act of expressing one's gratitude to relationship partners has a unique effect on relational well-being (Algoe \& Zhaoyang, 2016; Lambert \& Fincham, 2011). For example, couples who expressed more gratitude to each other (e.g., other-focused gratitude) showed increased relationship maintenance behavior (Lambert \& Fincham, 2011). While this study offers modest findings for responsive couple interactions, affectionate touch, 
and feeling grateful, future studies may examine responsive support and touch in relation to expressed gratitude within relationships in addition to grateful moods.

While literatures describing the dyadic nature of sleep and sleep problems in military populations is growing, the field may benefit from daily self-report methodology as well as physiological measurements of sleep behavior with the context of military relationships. Several studies have employed the use of both self-report and actigraphical sleep outcomes, resulting in somewhat differing findings. For example, Kane and colleagues (2014) found that increased self-disclosure before bed was related to increased sleep quality via self-reports as well as sleep actigraphy for wives, while husbands showed that greater disclosure was related to increased sleep actigraphy but not self-reported sleep. Therefore, daily self-report methods employed in this study may only have the capacity to describe part of the story. Additional work examining the effect of responsive support and gratitude on sleep actigraphy or nocturnal blood pressure dipping, for examples, within military populations is encouraged.

Furthermore, Troxel and colleagues (2015) reviewed current programs and policies within the U.S. military that aim to address sleep problems. The authors found that current treatments focus on sleep as a symptom of a comorbid diagnosis such as depression or PTSD; however, sleep is argued to be an independent health concern and often precedes other health problems. In addition, service members experience many barriers to receiving care for sleep problems including a military culture that stigmatizes expressing one's need for sleep, as well as a lack of understanding that sleep is 
important and a medical system that lacks proper screening tools or providers for sleep problems. Importantly, the authors identify that family members may play a significant role in detection and diagnosis of sleep problems in service members; however, this mechanism to circumventing barriers to care is underutilized. Therefore, future work should aim to inform policies that support sleep among service members and the inclusion of service member's families in the conceptualization of sleep health.

\section{Support for interventions}

This study identifies promising avenues for future research specifically with regard to interventions supporting relationship functioning and sleep. Further, participants in an intervention in which couples provided "warm" touch showed higher oxytocin and lower blood pressure than the control group (Holt-Lunstad, Birmingham, \& Light, 2008). Gratitude interventions typically increase well-being (e.g., life satisfaction and health) in the short-term (e.g., Wood, Froh, \& Geraghty, 2010); however, long-term effects are experienced when individuals engage in activities that support gratitude (Lyubomirsky, Dickerhoof, Boehm, \& Sheldon, 2011), such as relationship-maintenance behaviors in relationships. The present study provides preliminary evidence suggesting that affectionate touch is related to partner sleep as well as enhances the relation between responsive support and grateful mood. With additional research, interventions targeting affectionate touch within couples may be developed to promote better sleep and increase relationship functioning, including relationship maintenance emotions such as gratitude. 
Furthermore, these specific behavioral and psychological mechanisms linking relationships and sleep may have further implications for interventions targeting military samples. For example, Jain and colleagues (2012) used a randomized controlled trial design to examine a touch intervention based on an alternative medicine approach. The authors found that the touch intervention in combination with guided imagery helped reduce combat-related PTSD compared to treatment as usual in active duty military members. Taken together, the current study supports the need for additional research and development of interventions aimed at improving sleep, relationship functioning, and thriving in military service members and their families as well as civilian couples.

\section{Conclusion}

In sum, research and theory support that interpersonal relationships are vital to health. Indeed, growing literature on health and relationships suggest that researchers are beginning to view health indicators, symptoms, and behaviors, such as sleep, as interdependent outcomes embedded within one's social context rather than purely a product of the individual (Kiecolt-Glaser \& Wilson, 2017; Pietromonaco \& Collins, 2017). Sleep is an important health indicator that covaries with relational well-being most likely due to the social context of sleep (i.e., sharing a bed with one's partner). Further, recent research suggests that military Veterans and their spouses are considered to be a highrisk group for sleep problems. While the current study did not provide consistent findings, this work suggests that affectionate touch may be one important avenue for 
future research examining how relationship interactions support psychological and physical health outcomes. 


\section{References}

Algoe, S. B., \& Haidt, J. (2009). Witnessing excellence in action: The 'other praising' emotions of elevation, gratitude, and admiration. The journal of positive psychology, 4(2), 105-127. doi:10.1080/17439760802650519

Algoe, S. B., \& Zhaoyang, R. (2016). Positive psychology in context: Effects of expressing gratitude in ongoing relationships depend on perceptions of enactor responsiveness. The Journal of Positive Psychology, 11(4), 399-415. doi:10.1080/17439760.2015.1117131

Allan, B. A., Steger, M. F., \& Shin, J. Y. (2013). Thanks? Gratitude and well-being over the Thanksgiving holiday among college students. The Journal of Positive Psychology, 8(2), 91-102. doi:10.1080/17439760.2013.776623

Arpin, S. N., Starkey, A. R., Mohr, C. D., Greenhalgh, A.D., \& Hammer, L. (2018). "A well spent day brings happy sleep": Dyadic study of capitalization support in militaryconnected couples. Journal of Family Psychology, 32(7), 975-985. http://dx.doi.org.proxy.lib.pdx.edu/10.1037/fam0000469

Bartlett, M. Y., \& DeSteno, D. (2006). Gratitude and prosocial behavior: Helping when it costs you. Psychological Science, 17, 319-325. doi:10.1111/j.14679280.2006.01705.x

Bauer, D. J., Preacher, K. J., \& Gil, K. M. (2006). Conceptualizing and testing random indirect effects and moderated mediation in multilevel models: new procedures 
and recommendations. Psychological methods, 11(2), 142-163.

doi:10.1037/1082989X.11.2.142

Baumeister, R. F., \& Leary, M. R. (1995). The need to belong: Desire for interpersonal attachments as a fundamental human motivation. Psychological Bulletin, 117, 497-529. doi:10.1037/0033-2909.117.3.497

Bliese, P. D., Wright, K. M., Adler, A. B., Cabrera, O., Castro, C. A., \& Hoge, C. W. (2008). Validating the primary care posttraumatic stress disorder screen and the posttraumatic stress disorder checklist with soldiers returning from combat. Journal of Consulting and Clinical Psychology, 76, 272-281. doi: 10.1037/0022$006 X .76 .2 .272$

Bolger, N., Davis, A., \& Rafaeli, E. (2003). Diary methods: Capturing life as it is lived. Annual Review of Psychology, 54, 579-616.

Bowlby, J. (1982). Attachment and loss: Vol. 1. Attachment. New York: Basic Books. (Original work published 1969)

Burleson, M. H., Trevathan, W. R., \& Todd, M. (2007). In the mood for love or vice versa? Exploring the relations among sexual activity, physical affection, affect, and stress in the daily lives of mid-aged women. Archives of Sexual Behavior, 36, 357368. doi:10.1007/s10508-006-9071-1

Canary, D. J., Stafford, L., \& Semic, B. A. (2002). A panel study of the associations between maintenance strategies and relational characteristics. Journal of Marriage and Family, 64, 395-406. doi:10.1111/j.1741-3737.2002.00395.x 
Cohen, S., Janicki-Deverts, D., Turner, R. B., \& Doyle, W. J. (2015). Does hugging provide stress-buffering social support? A study of susceptibility to upper respiratory infection and illness. Psychological Science, 26, 135-147.

Collins, N. L., \& Feeney, B. C. (2000). A safe haven: An attachment theory perspective on support-seeking and caregiving in adult romantic relationships. Journal of Personality and Social Psychology, 78, 1053-1073. doi:10.1037/0022-

3514.78.6.1053

Collins, N. L., Kane, H. S., Metz, M. A., Cleveland, C., Khan, C., Winczewski, L., . . Prok, T. (2014). Psychological, physiological, and behavioral responses to a partner in need: The role of compassionate love. Journal of Social and Personal Relationships, 31, 601-629. doi:10.1177/0265407514529069

Dainton, M., \& Stafford, L. (1993). Routine maintenance behaviors: A comparison of relationship type, partner similarity and sex differences. Journal of Social and Personal Relationships, 10, 255-271. doi:10.1177/026540759301000206

Debrot, A., Cook, W. L., Perrez, M., \& Horn, A. B. (2012). Deeds matter: Daily enacted responsiveness and intimacy in couples' daily lives. Journal of Family Psychology, 26(4), 617-627. doi:10.1037/a0028666

Debrot, A., Schoebi, D., Perrez, M., \& Horn, A. B. (2013). Touch as an interpersonal emotion regulation process in couples' daily lives: The mediating role of psychological intimacy. Personality and Social Psychology Bulletin, 39, 13731385. doi:10.1177/0146167213497592 
Deci, E. L., \& Ryan, R. M. (2000). The "what" and "why" of goal pursuits: Human needs and the self-determination of behavior. Psychological Inquiry, 11, 227-268. doi:10.1207/S15327965PLI1104_01

DeWall, C. N., Lambert, N. M., Pond Jr, R. S., Kashdan, T. B., \& Fincham, F. D. (2012). A grateful heart is a nonviolent heart: Cross-sectional, experience sampling, longitudinal, and experimental evidence. Social Psychological and Personality Science, 3(2), 232-240. doi:10.1177/1948550611416675

Diamond, L. M. (2001). Contributions of psychophysiology to research on adult attachment: Review and recommendations. Personality and Social Psychology Review, 5, 276-295. doi:10.1207/S15327957PSPR0504_1

Diener, E. (1984). Subjective well-being. Psychological Bulletin, 95, 542-575. doi:10.1037/0033-2909.95.3.542

Ditzen, B., Neumann, I. D., Bodenmann, G., von Dawans, B., Turner, R. A., Ehlert, U., \& Heinrichs, M. (2007). Effects of different kinds of couple interaction on cortisol and heart rate responses to stress in women. Psychoneuroendocrinology, 32, 565-574. doi:10.1016/j.psyneuen.2007.03.011

Drake, C. L., Roehrs, T., Richardson, G., Walsh, J. K., \& Roth, T. (2004). Shift work sleep disorder: prevalence and consequences beyond that of symptomatic day workers. Sleep, 27(8), 1453-1462. doi:10.3390/min1010049

Elfenbein, H. A., \& Ambady, N. (2002). On the universality and cultural specificity of emotion recognition: A meta-analysis. Psychological Bulletin, 128, 203-235. 
RELATIONAL THRIVING IN CONTEXT

doi:10.1037//00332909.128.2.203

Emmons R.A. \& McCullough M.E. (2003) Counting blessings versus burdens: an experimental investigation of gratitude and subjective well-being in daily life. Journal of Personality and Social Psychology, 84 (2), 377-389. doi:10.1037/00223514.84.2.377

Feeney, B. C. (2004). A secure base: Responsive support of goal strivings and exploration in adult intimate relationships. Journal of Personality and Social Psychology, 87, 631-648. doi:10.1037/0022-3514.87.5.631

Feeney, B. C., \& Collins, N. L. (2015). A new look at social support: A theoretical perspective on thriving through relationships. Personality and Social Psychology Review, 19(2), 113-147. doi:10.1177/1088868314544222

Field, T. (2010). Touch for socioemotional and physical well-being: A review. Developmental Review, 30, 367-383. doi:10.1016/j.dr.2011.01.001

Field, T. (2012). Relationships as regulators. Psychology, 3, 467-479. doi:10.4236/psych.2012.36066

Floyd, K. (2006). Communicating affection: Interpersonal behavior and social context. New York, NY: Cambridge University Press.

Gable, S. L., Gonzaga, G. C., \& Strachman, A. (2006). Will you be there for me when things go right? Supportive responses to positive event disclosures. Journal of personality and social psychology, 91(5), 904-917. doi:10.1037/00223514.91.5.904 
Gable, S. L., Reis, H. T., \& Downey, G. (2003). He said, she said: A quasi-signal detection analysis of daily interactions between close relationship partners. Psychological Science, 14, 100-105. doi: 10.1111/1467-9280.t01-1-01426

Gordon, A. M., \& Chen, S. (2014). The role of sleep in interpersonal conflict: do sleepless nights mean worse fights?. Social Psychological and Personality Science, 5(2), 168-175. doi: $10.1177 / 1948550613488952$

Gosnell, C. L., \& Gable, S. L. (2017). You deplete me: Impacts of providing positive and negative event support on self-control. Personal Relationships, 24(3), 598-622. doi: $10.1111 /$ pere. 12200

Guerrero, L. K., \& Andersen, P. A. (1991). The waxing and waning of relational intimacy: Touch as a function of relational stage, gender and touch avoidance. Journal of Social and Personal Relationships, 8(2), 147-165. https://doi.org/10.1177/0265407591082001

Hammer, L., Wan, W., Brockwood, K., Mohr, C., \& Carlson, K. (2017). Military, work, and health characteristics of separated and active service members from the Study for Employment Retention of Veterans (SERVe). Military Psychology, 29(6), 491512. http://dx.doi.org/10.1037/mil0000196 Hertenstein, M. J., Holmes, R., McCullough, M., \& Keltner, D. (2009). The communication of emotion via touch. Emotion, 9(4), 566-573. doi:10.1037/a0016108 
Hertenstein, M. J., Keltner, D., App, B., Bulleit, B. A., \& Jaskolka, A. R. (2006). Touch communicates distinct emotions. Emotion, 6(3), 528-533. doi:10.1037/15283542.6.3.528

Holliday, S. B., Haas, A., Shih, R. A., \& Troxel, W. M. (2016). Prevalence and consequences of sleep problems in military wives. Sleep Health: Journal of the National Sleep Foundation, 2(2), 116-122. doi:10.1016/j.sleh.2016.03.004

Holt-Lunstad, J., Birmingham, W., \& Light, B. Q. (2008). Influence of a "warm touch" support enhancement intervention among married couples on ambulatory blood pressure, oxytocin, alpha amylase, and cortisol. Psychosomatic Medicine, 70, 976-985. doi:10.1097/PSY.0b013e318187aef7

Holt-Lunstad, J., Smith, T. B., \& Layton, J. B. (2010). Social relationships and mortality risk: a meta-analytic review. PLoS medicine, 7(7), e1000316. doi:10.1371/journal.pmed.1000316 https://doi-org.proxy.lib.pdx.edu/10.1521/jscp.2010.29.1.95

Itani, O., Jike, M., Watanabe, N., \& Kaneita, Y. (2017). Short sleep duration and health outcomes: a systematic review, meta-analysis, and meta-regression. Sleep medicine, 32, 246-256. doi:10.1016/j.sleep.2016.08.006

Jain, S., McMahon, G. F., Hasen, P., Kozub, M. P., Porter, V., King, R., \& Guarneri, E. M. (2012). Healing touch with guided imagery for PTSD in returning active duty military: A randomized controlled trial. Military medicine, 177(9), 1015-1021. 
Jakubiak, B. K., \& Feeney, B. C. (2016b). A sense of security: Touch promotes state attachment security. Social Psychological and Personality Science, 7(7), 745-753. doi:10.1177/1948550616646427

Jakubiak, B. K., \& Feeney, B. C. (2016c). Keep in touch: The effects of imagined touch support on stress and exploration. Journal of Experimental Social Psychology, 65, 59-67. doi:10.1177/0265407517702012

Jakubiak, B. K., \& Feeney, B. C. (2017). Affectionate touch to promote relational, psychological, and physical well-being in adulthood: A theoretical model and review of the research. Personality and Social Psychology Review, 21(3), 228-252. doi:10.1177/1088868316650307

Johnson, K. L., \& Edwards, R. (1991). The effects of gender and type of romantic touch on perceptions of relational commitment. Journal of Nonverbal Behavior, 15, 4355. doi:10.1007/BF00997766

Jones, S. E., \& Yarbrough, A. (1985). A naturalistic study of the meanings of touch. Communication Monographs, 52, 19-56. doi:10.1007/BF00997766

Karney, B. R., \& Crown, J. S. (2007). Families under stress: An assessment of data, theory, and research on marriage and divorce in the military (Vol. 599). Rand Corporation.

Kashdan, T. B., Mishra, A., Breen, W. E., \& Froh, J. J. (2009). Gender differences in gratitude: Examining appraisals, narratives, the willingness to express emotions, 
RELATIONAL THRIVING IN CONTEXT

and changes in psychological needs. Journal of personality, 77(3), 691-730.

doi:10.1111/j.1467-6494.2009.00562.x

Kashy, D. A., \& Donnellan, M. B. (2012). Conceptual and methodological issues in the analysis of data from dyads and groups.In K. Deaux \& M. Snyder (Eds.), The Oxford handbook of personality and social psychology (pp. 209-238). Oxford: Oxford University Press.

Kenny, D. A., Kashy, D. A., Cook, W. L., \& Simpson, J. A. (2006). Dyadic data analysis (Methodology in the social sciences). New York, NY: Guilford.

Kubacka, K., Finkenauer, C., Rusbult, C., \& Keijsers, L. (2011). Maintaining Close Relationships. Personality and Social Psychology Bulletin, 37(10), 1362-1375. doi:10.1177/0146167211412196

Lambert, N. M., \& Fincham, F. D. (2011). Expressing gratitude to a partner leads to more relationship maintenance behav- ior. Emotion, 11, 52-60. doi:10.1037/a0021557 Larsen, R. J., \& Diener, E. (1992). Promises and problems with the circumplex model of emotion. In M. S. Clark (Ed.), Emotion (pp. 25-59). Newbury Park, CA: Sage.

Larsen, R. J., \& Fredrickson, B. L. (1999). Measurement issues in emotion research. In D. Kahneman, E. Diener, \& N. Schwarz (Eds.), Well-being: The foundations of hedonic psychology (pp.40-60). New York: Russell Sage Foundation. doi:10.1111/j.1468-2850.2007.00098.x 
Laurenceau, J. P., Barrett, L. F., \& Rovine, M. J. (2005). The interpersonal process model of intimacy in marriage: A daily-diary and multilevel modeling approach. Journal of family psychology, 19(2), 314-323. doi:10.1037/0893-3200.19.2.314

Ledermann, T.,\& Bodenmann, G. (2006). Moderatorund Mediatoreffekte bei dyadischen Daten: Zwei Erweiterungen des Akteur-Partner-Interdependenz-Modells [Moderator and mediator effects in dyadic research: Two extensions of the Actor-Partner Interdependence Model]. Zeitschrift f"ur Sozialpsychologie, 37, 27-40. doi:10.1024/0044-3514.37.1.27

Lee, S., Martire, L. M., Damaske, S. A., Mogle, J. A., Zhaoyang, R., Almeida, D. M., \& Buxton, O. M. (2018). Covariation in couples' nightly sleep and gender differences. Sleep Health: Journal of the National Sleep Foundation, 4(2), 201208. doi:10.1016/j.sleh.2017.10.009

Light, K. C., Grewen, K. M., \& Amico, J. A. (2005). More frequent partner hugs and higher oxytocin levels are linked to lower blood pressure and heart rate in premenopausal women. Biological Psychology, 69, 5-21. doi:10.1016/j.biopsycho.2004.11.002 Luyster, F. S., Strollo, P. J., Zee, P. C., \& Walsh, J. K. (2012). Sleep: a health imperative. Sleep, 35(6), 727-734. doi:10.5665/sleep.1846

Mackey, R. A., Diemer, M. A., \& O’Brien, B. A. (2000). Psychological intimacy in the lasting relationships of heterosexual and same-gender couples. Sex Roles, 43, 201-227. doi:10.1023/A:1007028930658 
McCullough, M. E., Tsang, J. A., \& Emmons, R. A. (2004). Gratitude in intermediate affective terrain: links of grateful moods to individual differences and daily emotional experience. Journal of personality and social psychology, 86(2), 295309. doi:10.1037/0022-3514.86.2.295

Mohr, C.D., McCabe, C., Haverly, S.N., Hammer, LB., \& Carlson, K.F. (2018). Drinking Motives and Alcohol Use: The SERVe Study of U.S. Current and Former Service Members. Journal of Studies on Alcohol and Drugs, 79(1), 79-87. https://doi.org/10.15288/jsad.2018.79.79

Myers, D. G., \& Diener, E. (1995). Who is happy? Psychological Science, 6(1), 10-19. doi:10.1111/j.1467-9280.1995.tb00298.x

National Sleep Foundation. (2013). International bedroom poll: Summary of Findings. Arlington, VA: Author.

O’Connell, B.H., O'Shea, D., \& Gallagher, S. (2016). Mediating effects of loneliness on the gratitude-health link. Personality and Individual Differences, 98, 179-183. doi:10.1016/j.paid.2016.04.042

Pietromonaco, P. R., \& Collins, N. L. (2017). Interpersonal mechanisms linking close relationships to health. American Psychologist, 72(6), 531-542. doi:10.1037/amp0000129

Preacher, K. J., Rucker, D. D., \& Hayes, A. F. (2007). Addressing moderated mediation hypotheses: Theory, methods, and prescriptions. Multivariate behavioral research, 42(1), 185-227. doi:10.1080/00273170701341316 
Preacher, K. J., Zyphur, M. J., \& Zhang, Z. (2010). A general multilevel SEM framework for assessing multilevel mediation. Psychological methods, 15(3), 209-233. doi:10.1037/a0020141

Reis, H. T., Crasta, D., Rogge, R. D., Maniaci, M. R., \& Carmichael, C. L. Perceived Partner Responsiveness Scale (PPRS). In D. L. Worthington \& G. D. Bodie (Eds.), The Sourcebook of Listening Research: Methodology and Measures (pp. 516-521). Hoboken, New Jersey; John Wiley \& Sons, Inc.

Reis, H. T., Smith, S., Carmichael, C., Caprariello, P., Tsai, F., Rodrigues, A., \& Maniaci, M. R. (2010). Are you happy for me? How sharing positive events with others provides personal and interpersonal benefits. Journal of Personality and Social Psychology, 99, 311-329. doi:10.1037/a0018344

Reyner, A., \& Horne, J. A. (1995). Gender-and age-related differences in sleep determined by home-recorded sleep logs and actimetry from 400 adults. Sleep, 18(2), 127-134.

Robles, T. F., Slatcher, R. B., Trombello, J. M., \& McGinn, M. M. (2014). Marital quality and health: A meta-analytic review. Psychological bulletin, 140(1), 140-187. doi:10.1037/a0031859

Roepke, S. E., \& Duffy, J. F. (2010). Differential impact of chronotype on weekday and weekend sleep timing and duration. Nature and science of sleep, 2, 213- 220. doi: $10.2147 /$ NSS.S12572 
Ryan, R. M., Bernstein, J. H., \& Brown, K. W. (2010). Weekends, work, and well-being: Psychological need satisfactions and day of the week effects on mood, vitality, and physical symptoms. Journal of social and clinical psychology, 29(1), 95-122.

Sbarra, D. A., \& Hazan, C. (2008). Coregulation, dysregulation, self-regulation: An integrative analysis and empirical agenda for understanding adult attachment, separation, loss, and recovery. Personality and Social Psychology Review, 12, 141-167. doi:10.1177/1088868308315702

Scherer, K. R., Johnstone, T., \& Klasmeyer, G. (2003). Vocal expression of emotion. In R. J. Davidson \& H. H. Goldsmith (Eds.), Handbook of affective sciences (pp. 433456). London: Oxford University Press.

Selcuk, E., Stanton, S. C., Slatcher, R. B., \& Ong, A. D. (2017). Perceived partner responsiveness predicts better sleep quality through lower anxiety. Social Psychological and Personality Science, 8(1), 83-92. doi:10.1177/1948550616662128

Simão, C., \& Seibt, B. (2015). Friendly touch increases gratitude by inducing communal feelings. Frontiers in psychology, 6, 815. doi:10.3389/fpsyg.2015.00815

Sin, N. L., Almeida, D. M., Crain, T. L., Kossek, E. E., Berkman, L. F., \& Buxton, O. M. (2017). Bidirectional, temporal associations of sleep with positive events, affect, and stressors in daily life across a week. Annals of Behavioral Medicine, 51(3), 402-415. doi:10.1007/s12160-016-9864-y 
Slatcher, R. B., \& Selcuk, E. (2017). A social psychological perspective on the links between close relationships and health. Current Directions in Psychological Science, 26(1), 16-21. doi: 10.1177/0963721416667444.

Sobel, M. E. (1982). Asymptotic confidence intervals for indirect effects in structural equation models. Sociological methodology, 13, 290-312. doi:10.2307/270723

Stadler, G., Snyder, K. A., Horn, A. B., Shrout, P. E., \& Bolger, N. P. (2012). Close relationships and health in daily life: A review and empirical data on intimacy and somatic symptoms. Psychosomatic Medicine, 74, 398-409. doi:10.1097/PSY.0b013e31825473b8

Stier, D. S., \& Hall, J. A. (1984). Gender differences in touch: An empirical and theoretical review. Journal of Personality and Social Psychology, 47, 440-459. http://dx.doi.org/10.1037/0022-3514.47.2.440

Stone, A. A., \& Neale, J. M. (1982). Development of a methodology for assessing daily experiences. In A. Baum \& J. Singer (Eds.), Environment and health (Vol. 4, pp. 49-83). New York: Erlbaum.

Troxel, W. M. (2010). It's more than sex: Exploring the dyadic nature of sleep and implications for health. Psychosomatic medicine, 72(6), 578.

Troxel, W. M., Buysse, D. J., Hall, M., \& Matthews, K. A. (2009). Marital happiness and sleep disturbances in a multi-ethnic sample of middle-aged women. Behavioral Sleep Medicine, 7(1), 2-19. doi:10.1080/15402000802577736 
Troxel, W. M., Robles, T. F., Hall, M., \& Buysse, D. J. (2007). Marital quality and the marital bed: Examining the covariation between relationship quality and sleep. Sleep Medicine Reviews, 11(5), 389-404. doi:10.1016/j.smrv.2007.05.002

Troxel, W. M., Shih, R. A., Pedersen, E. R., Geyer, L., Fisher, M. P., Griffin, B. A., ... \& Steinberg, P. S. (2015). Sleep in the military: Promoting healthy sleep among US service members. Rand health quarterly, 5(2).

U.S. Department of Defense. (2015). Demographics report: Profile of the military. Washington, DC: Author.

Watson, D., \& Clark, L. A. (1994). The PANAS-X: Manual for the Positive and Negative Affect Schedule-Expanded Form. Ames: The University of lowa.

Watson, D., Clark, L. A., \& Tellegen, A. (1988). Development and validation of brief measures of positive and negative affect: the PANAS scales. Journal of personality and social psychology, 54(6), 1063-1070. doi:10.1037/00223514.54.6.1063

Weathers, F., Huska, J., \& Keane, T. (1991). The PTSD checklist military version (PCLM). Boston, MA: National Center for PTSD, 42.

Wenger, J. W., O'Connell, C. \& Cottrell, L. (2018). Examination of Recent Deployment Experience Across the Services and Components. Santa Monica: RAND Corporation. doi:10.7249/RR1928 
Wood, A. M., Froh, J. J., \& Geraghty, A. W. (2010). Gratitude and well-being: A review and theoretical integration. Clinical psychology review, 30(7), 890-905. doi:10.1016/j.cpr.2010.03.005

Wood, A. M., Joseph, S., Lloyd, J., \& Atkins, S. (2009). Gratitude influences sleep through the mechanism of pre-sleep cognitions. Journal of Psychosomatic Research, 66(1), 43-48. http://dx.doi.org/10.1016/j.jpsychores.2008.09.002.

Zautra, A., Guarnaccia, C., Reich, J., \& Dohrenwend, B. (1988). The contribution of small events to stress and distress. In L. Cohen (Ed.), Life events and psychological functioning (pp. 123-148). Newbury Park, CA: Sage. 


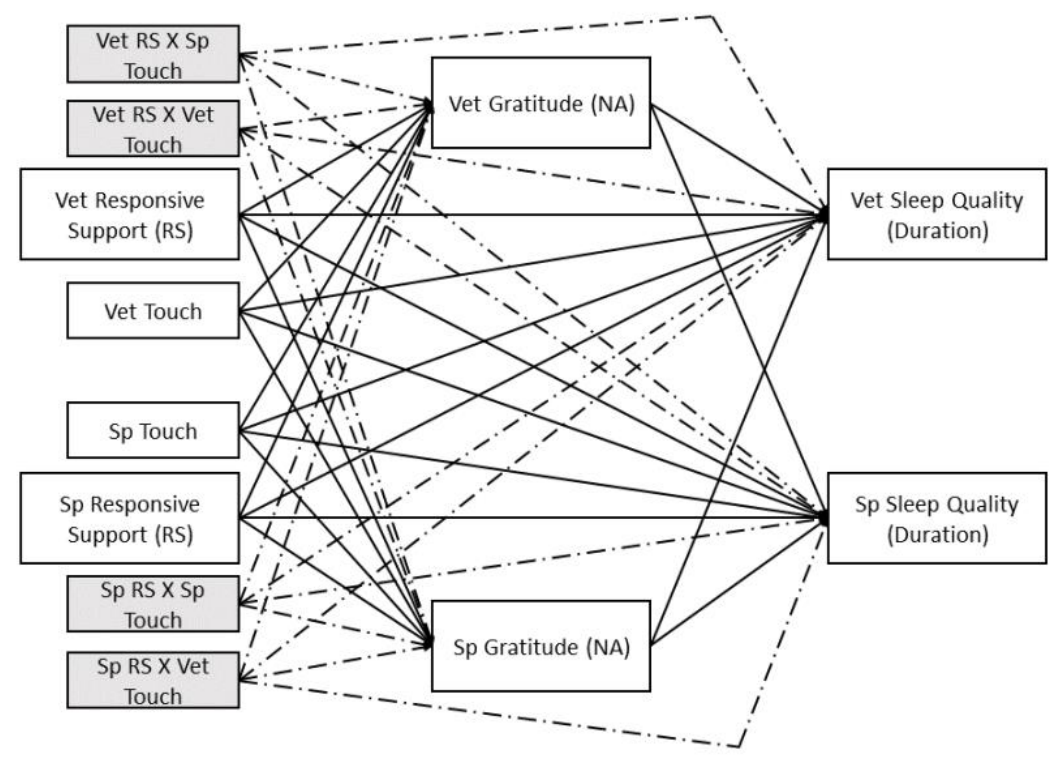

Figure 4.0. Conceptual model for actor-partner interdependence moderated mediation model over time. Parentheses denote that sleep duration is considered as separate outcomes. Gray boxes and dotted lines denote moderation effects. Vet $=$ Veteran. $\mathrm{Sp}=$ Spouse. 
Table 4.0. Veteran, spouse, within-couple correlations and descriptive statistics among study variables aggregated across 32 days.

\section{Veteran $(\mathrm{N}=159)$}

\begin{tabular}{|c|c|c|c|c|c|c|c|c|c|c|c|}
\hline $\begin{array}{l}\text { Spouse (N = } \\
159 \text { ) }\end{array}$ & 1. & 2. & 3. & 4. & 5. & 6. & 7. & 8. & 9. & 10. & 11. \\
\hline 1. PRS & $.22^{*}$ & $.49^{* *}$ & $.45^{* *}$ & .09 & $.20^{*}$ & -.10 & $.43^{* *}$ & .06 & .04 & -.02 & .13 \\
\hline 2. Touch & $.41^{* *}$ & $.48^{* *}$ & $.29^{* *}$ & $.28^{* *}$ & $.35^{* *}$ & $-.25^{* *}$ & $.38^{* *}$ & .09 & -.07 & -.10 & -.08 \\
\hline 3. Grat. & $.45^{* *}$ & $.43^{* *}$ & $.33^{* *}$ & .07 & $.30^{* *}$ & $-.20^{*}$ & $.66^{* *}$ & .07 & .04 & -.19 & $.16^{*}$ \\
\hline 4. SlpDur. & .01 & $.23^{* *}$ & .05 & $.30^{* *}$ & $.54^{* *}$ & $-.27^{* *}$ & $.19^{*}$ & .09 & .06 & $-.29^{* *}$ & -.11 \\
\hline 5. SIpQual. & $.30^{* *}$ & $.27^{* *}$ & $.31^{* *}$ & $.50^{* *}$ & $.21^{* *}$ & $-.40^{* *}$ & $.53^{* *}$ & .13 & $.16^{*}$ & $-.52^{* *}$ & -.03 \\
\hline 6. NA & $-.22^{* *}$ & $-.17^{*}$ & $-.19^{*}$ & $-.22^{* *}$ & $-.35^{* *}$ & $.51^{* *}$ & $-.30^{* *}$ & .03 & $-.22^{* *}$ & $.51^{* *}$ & -.05 \\
\hline 7. PA & $.37^{* *}$ & $.35^{* *}$ & $.61^{* *}$ & .15 & $.45^{* *}$ & $-.31^{* *}$ & $.40^{* *}$ & .10 & .09 & $-.28^{* *}$ & .03 \\
\hline 8. Gender & -.12 & .04 & $.18^{*}$ & .05 & .09 & -.01 & -.04 & $-.97^{* *}$ & -.12 & -.08 & -.12 \\
\hline 9. R.Length & -.11 & -.06 & $-.16^{*}$ & -.01 & .11 & $-.15^{\dagger}$ & -.01 & .10 & $.99^{* *}$ & $-.21^{* *}$ & $.25^{* *}$ \\
\hline 10. vPTSS & -.06 & -.09 & -.02 & -.13 & -.08 & $.25^{* *}$ & -.12 & .07 & $-.21^{* *}$ & $1.00^{* *}$ & .07 \\
\hline 11. Parent & -.03 & -.09 & .11 & -.08 & .05 & .05 & .02 & .08 & $.26^{* *}$ & .07 & $1.00^{* *}$ \\
\hline \multicolumn{12}{|c|}{ Descriptive Statistics } \\
\hline \multicolumn{12}{|c|}{ Mean (SD) } \\
\hline Veteran & $\begin{array}{l}4.02 \\
(.62)\end{array}$ & $\begin{array}{c}2.67 \\
(1.37)\end{array}$ & $\begin{array}{c}2.82 \\
(1.25)\end{array}$ & $\begin{array}{l}6.58 \\
(.93)\end{array}$ & $\begin{array}{l}2.73 \\
(.39)\end{array}$ & $\begin{array}{c}6.00 \\
(1.50)\end{array}$ & $\begin{array}{c}9.36 \\
(2.44)\end{array}$ & $\begin{array}{l}.11 \\
(.31)\end{array}$ & $\begin{array}{l}12.07 \\
(8.59)\end{array}$ & $\begin{array}{c}1.90 \\
(1.02)\end{array}$ & $\begin{array}{l}.79 \\
(.41)\end{array}$ \\
\hline Spouse & $\begin{array}{l}4.04 \\
(.60)\end{array}$ & $\begin{array}{c}2.75 \\
(1.29)\end{array}$ & $\begin{array}{c}3.29 \\
(1.18)\end{array}$ & $\begin{array}{c}6.96 \\
(1.00)\end{array}$ & $\begin{array}{l}2.78 \\
(.46)\end{array}$ & $\begin{array}{c}6.21 \\
(2.09)\end{array}$ & $\begin{array}{c}9.48 \\
(2.29)\end{array}$ & $\begin{array}{l}.90 \\
(.30)\end{array}$ & $\begin{array}{l}11.74 \\
(8.61)\end{array}$ & $\begin{array}{c}1.90 \\
(1.02)\end{array}$ & $\begin{array}{l}.79 \\
(.41)\end{array}$ \\
\hline
\end{tabular}

Note. PRS = Perceived responsive support; Grat. = Grateful mood; SlpDur = Sleep Duration; SlpQual = Sleep Quality; NA = Negative affect; PA = Positive affect; R.Length = Relationship Length; vPTSS = Post-Traumatic Stress Symptoms (Veteran); Parent = parent status; Withincouple correlations in bold, Veteran correlations presented above the diagonal, and spouse correlations presented below the diagonal. ${ }^{\dagger} p<.10 ;{ }^{*} p<.05 ;{ }^{* *} p \leq .01$. 
Table 4.1. Summary of over time actor-partner interdependence model (APIM) multilevel regression coefficients predicting sleep and grateful mood

\begin{tabular}{|c|c|c|c|c|c|c|c|c|c|c|c|c|}
\hline \multirow[b]{2}{*}{ Predictor } & \multicolumn{2}{|c|}{$\begin{array}{c}\text { Veteran } \\
\text { Sleep_Quality }\end{array}$} & \multicolumn{2}{|c|}{$\begin{array}{c}\text { Spouse } \\
\text { Sleep_Quality }\end{array}$} & \multicolumn{2}{|c|}{$\begin{array}{c}\text { Veteran } \\
\text { Sleep_Duration }\end{array}$} & \multicolumn{2}{|c|}{$\begin{array}{c}\text { Spouse } \\
\text { Sleep_Duration }\end{array}$} & \multicolumn{2}{|c|}{$\begin{array}{c}\text { Veteran } \\
\text { Grateful Mood }\end{array}$} & \multicolumn{2}{|c|}{$\begin{array}{c}\text { Spouse } \\
\text { Grateful Mood }\end{array}$} \\
\hline & $b$ & $S E$ & $b$ & $S E$ & $b$ & $S E$ & $b$ & $S E$ & $b$ & $S E$ & $b$ & $S E$ \\
\hline V PRS & .02 & .09 & -.03 & .09 & -.06 & .16 & -.20 & .16 & .14 & .11 & -.06 & .11 \\
\hline S PRS & $.21^{+b}$ & .11 & .13 & .11 & .09 & .20 & $.34^{+a}$ & .20 & .12 & .15 & $.29 * a$ & .14 \\
\hline V Touch & .03 & .04 & $.09^{*}$ & .04 & -.01 & .07 & .09 & .07 & .03 & .05 & .03 & .05 \\
\hline S Touch & -.03 & .03 & .02 & .03 & -.01 & .06 & .03 & .06 & .01 & .04 & .03 & .04 \\
\hline V PRS X V Touch & -.01 & .05 & .06 & .05 & .03 & .09 & .05 & .10 & -.01 & .06 & $.13^{* a}$ & .06 \\
\hline S PRS X S Touch & -.06 & .06 & .09 & .06 & -.05 & .10 & -.01 & .10 & .06 & .07 & .01 & .07 \\
\hline S PRS X V Touch & .04 & .06 & -.07 & .06 & .14 & .10 & -.01 & .11 & $.17^{*}$ & .08 & -.11 & .07 \\
\hline V PRS X S Touch & .09 & .05 & -.05 & .05 & -.03 & .10 & -.03 & .10 & $-.22^{* * a}$ & .06 & -.06 & .06 \\
\hline V Grat & .01 & .01 & -.00 & .01 & -.01 & .03 & -.03 & .03 & -- & -- & -- & -- \\
\hline S Grat & .00 & .01 & .00 & .01 & -.03 & .03 & -.00 & .03 & -- & -- & -- & -- \\
\hline V Grat X V Touch & .00 & .01 & .00 & .01 & -.02 & .01 & -.01 & .01 & -- & -- & -- & -- \\
\hline S Grat X S Touch & .00 & .01 & .00 & .01 & .01 & .01 & .00 & .01 & -- & -- & -- & -- \\
\hline S Grat X V Touch & -.00 & .01 & -.01 & .01 & .01 & .01 & .01 & .01 & -- & -- & -- & -- \\
\hline V Grat X S Touch & -.01 & .01 & -.00 & .01 & -.01 & .01 & -.01 & .01 & -- & -- & -- & -- \\
\hline
\end{tabular}

Note: $\mathrm{V}=$ Veteran; $\mathrm{S}$ = spouse; $\mathrm{PRS}=$ perceived responsive support; Grat = grateful mood; Touch = affectionate touch; table reports unstandardized coefficients; ${ }^{a}$ not a significant difference across Veteran and spouses roles (only significant when run with 2-intercept approach); ${ }^{b}$ marginal $(p<.10)$ difference across Veteran and spouse roles; ${ }^{\dagger} p<.10 ;{ }^{*} p<.05 ;{ }^{* *} p \leq .01$. 


\section{CHAPTER V. DISCUSSION}

Our close connections influence our health and well-being (Holt-Lunstad, Smith, \& Layton, 2010; Robles, Slatcher, Trombello, \& McGinn, 2014; Uchino, 2006).

Relationships also allow people to grow, find personal meaning, and recover from negative experiences (Feeney \& Collins, 2015). The thriving through relationships model identifies several ways in which relationship interactions and intrapersonal emotions promote thriving such as supportive interactions with one's close other and feelings of positive emotions that broaden and build resources (Feeney \& Collins, 2015;

Fredrickson, 2001). These relational and intrapersonal experiences are expected to increase one's personal health and well-being as well as promote healthy relationships, including increased feelings of closeness and partner responsiveness. Consistent with the thriving through relationships model, this dissertation aimed to contribute to research within positive psychology, relationship and affective science, and health psychology fields by examining how positive emotions improve personal physical health and relational well-being, and how interactions with one's partner predict positive emotional responses and better physical health. Across three studies, I examined health and well-being within the contexts of nursing work and military relationships - both of which offer a unique perspective to the study of thriving. Results underscore that positive emotions play an important role in well-being; however, emotions are complex and share a nuanced relationship with physical health and within intimate relationships. For example, Study 1 found that expressions of gratitude for nurses was related to 
nurses' positive physical health outcomes indirectly through psychological resources. In addition, positive affect predicted increased intimacy within military couples in Study 2. Finally, Study 3 provided modest evidence that increased affectionate touch related to better nightly sleep within military dyads. Further, affectionate touch enhanced a partner's perception of responsive support and was associated with increased daily gratitude. Examining the interplay between positive emotions, physical health, and romantic partner interactions represent important avenues for future research and contributes to the theory of thriving through relationships.

\section{Strengths and contributions}

The studies composing this dissertation have several strengths and contribute to growing interdisciplinary literature examining responsiveness, emotions, and health within relationships. The aim of the dissertation was to examine specific hypotheses proposed in the thriving through relationships model (Feeney \& Collins, 2015), namely how responsiveness, affective processes, and affectionate touch promote physical health within specific contexts of nursing work and military relationships. For example, Study 3 applied the thriving through relationships framework to examining responsive support to negative events, gratitude, affectionate touch, and sleep. This study drew from previous literature examining the impact of partner responsiveness on health. For example, Slatcher and Schoebi (2017) highlight partner responsiveness as a key mechanism in relationships that promote health. Although patterns of association in Study 3 were largely not supported, this work accompanies research examining partner 
responsiveness and health outcomes over time (e.g., Slatcher, Selcuk, \& Ong, 2015).

Moreover, Study 3 aimed to address a gap in research examining affectionate touch and sleep in romantic couples. Both affectionate touch and sleep are behaviors related to building and maintaining attachment with our close others (e.g., Jakubiak \& Feeney, 2017; Troxel, 2010; Troxel et al., 2007) and theorized to aid in the down-regulation of arousal in adults. To my knowledge, Study 3 is the first to examine how affectionate touch predicts sleep in couples. Furthermore, few studies have explicitly examined how physical touch and gratitude interact to predict well-being, though research indicates that touch can communicate gratitude (Hertenstein et al., 2006). Therefore, Study 3 extends literature examining the interpersonal interactions of gratitude, affectionate touch, and sleep within the context of relationships.

Furthermore, Study 1 adds to literature examining the benefits of gratitude by looking at the "other side" of gratitude interactions. For example, much of the research studying gratitude and physical health or well-being outcomes focus on the individual who benefits and feels grateful (Wood et al., 2010). Study 1 examined how receiving expressions of gratitude affects a person's psychological well-being and physical health in the context of work. Interpersonal expressions of gratitude are theorized to build and maintain high quality relationships (Algoe, 2012). However, the degree to which expressions of gratitude improve physical health is understudied. Therefore, Study 1 extended research in areas related to expressions of gratitude and the gratitude-health link. 
Emotions are complex and change over time. Recent evidence suggests that fluctuations in positive emotions is related to adverse health outcomes (Hardy \& Segerstrom, 2017; Human et al., 2015). Study 2 takes an exploratory look at how fluctuations in positive affect predicts relational well-being in military couples. While the results are run counter to hypotheses, the findings indicate that fluctuation in positive affect may be nuanced and instead benefit relationships rather than be maladaptive. Researchers note that the construct and operationalization of positive affect variability or fluctuation may represent different processes (Human et al., 2015). For example, variability in positive mood may be adaptive depending on the situation at hand; however, an inappropriate variation in positive mood may lead to negative outcomes. Therefore, this study contributes to literature on intraindividual variability in positive emotions and highlights the need for additional research and theory building with regard to the processes underlying affective dynamics.

Another aim of the present work was to examine thriving within specific contexts, including nursing and military relationships. Nurses report feeling overworked and underappreciated (Morrison \& Korol, 2014). While nurses describe that the most rewarding part of their job is working with patients and fellow nurses (Adams \& Bond, 2000; Newman \& Maylor, 2002), nurses' job demands negatively affect their well-being and physical health (Aiken et al., 2002; Hasson \& Gustavson, 2010; Lin, Huang, \& Wu, 2007). By applying a positive psychological approach to the study of nurses' health, we were able to examine how positive everyday interactions with their patients, patients' 
families, and coworkers, namely gratitude expressions, contribute to their psychological resources and subsequently their health. This research extends current work focusing on the negative impact of nursing work relating to poor health, by examining how gratitude expressions build positive resources for nurses and promote health. In addition, military relationships are an important context within which to study thriving. Service members and their partners experience challenges related to deployment and service (Knoblach \& Theiss, 2012; Segal, 1989; Warner, Appenszeller, Warner, \& Grieger, 2009), which may impact relationship outcomes. For example, after accounting for combat exposure and post-traumatic stress symptoms, marital satisfaction was reduced for couples in which the service member had never deployed compared to couples who had been through multiple deployments (Karney \& Trail, 2017). While examining relationship outcomes such as marital satisfaction and relationship quality are important within this population, little research to date has examined specific relationship interactions within military couples. Studies 2 and 3 examine how intrapersonal emotions related to feelings of intimacy and how perceptions of partners' support and affectionate interactions related to positive emotions and sleep. While the findings are modest, these studies contribute to literature on the dyadic nature of emotions, responsiveness and sleep. Further, Studies 1 and 2 target understudied areas - emotion dynamics, romantic partner interactions, and sleep health in service members and their partners. 
Finally, all studies used longitudinal survey designs and multilevel or over time analyses that help examine how phenomena unfold in everyday life, representing a methodological strength. Daily or weekly survey methodology allows researchers to obtain reliable person-level information and examine within-person variation (Bolger, Davis \& Rafaeli, 2003). For example, Study 1 examined weekly reports of gratitude expressions, work-related satisfaction, and physical health. Therefore, models accounted for the nested nature of weekly reports within nurses as well as nurse-level associations. Similarly, Study 2 accounted for the nesting of daily intimacy within persons and within military dyads. Study 3 attempted to examine the temporal associations of daily perceived responsive support to negative events and gratitude on nightly sleep. While these findings were inconsistent with literature examining selfreported sleep over time (Lee et al., 2017), Study 3 extended current work by employing daily dyadic analysis to the study of responsiveness, affect, and sleep.

\section{What have we learned about thriving through social connections?}

Generally, people flourish in domains related to their social, psychological (i.e., emotional), and physical well-being (among others; Diener et al., 2010; Feeney \& Collins, 2015; Ryff \& Singer, 1998, 2000; Seligman, Steen, Paker, \& Peterson, 2005). Feeney and Collins (2015) suggest that people flourish in these domains through events and experiences with their close others. The present studies show how emotional expressions from others may improve our health, how fluctuating positive emotions may lead to greater intimacy, how positive physical interactions with one's partner may 
improve partner's sleep quality and enhance social support and positive relationship maintenance emotions. Therefore, these studies offer support that our social connections play a role in thriving.

Thriving was examined within nursing work and military relationship contexts. This may make it hard to generalize beyond theses specific populations studied within this dissertation. However, the studies allowed us to learn more about how particular social interactions and experiences contribute to thriving domains within context. For example, Study 1 highlights how receiving thanks at work may lead to greater physical health and may inform healthcare organizations' initiatives to improve occupation health among their employees. Further, Studies 2 and 3, target positive emotions and intimate partner interactions as ways to improve health and well-being among military couples. Military installations offer many programs aimed to support families (e.g., Gottman, Gottman, \& Atkins, 2011). While many of these programs are specifically related to deployment, this research may inform how couples and families may be supported in their everyday lives and after separation from the military.

Finally, this research approached the study of thriving using process-oriented methodology and advanced analytical techniques. For example, Studies 1 and 3 aimed to examine within-week (Study 1) and within-day (Study 3) associations related to gratitude, health, and relational interactions. In addition, Study 2 aimed to examine how a metric of fluctuation in positive mood related to within-person average intimacy. Study 1 employed multi-level mediation techniques, in order to learn how receiving 
gratitude expressions contribute to physical health at multiple levels of analysis. For example, we learned that satisfaction with care mediated the relationship between gratitude reception and physical health within a nurses' work week. However, this process did not seem to operate at the aggregate level, meaning that the process has more to do with weekly experiences rather than the characteristic-levels of nurse gratitude reception, satisfaction, and physical health. In addition, Study 2 examined multiple techniques to the study emotion dynamics. While there are a many techniques available to studying emotion variability and change (Kuppens \& Verdyn, 2015; Ram \& Gerstorf, 2009), examining intra-individual standard deviations and mean square of successive differences represents a conservative approach to studying mood fluctuation. Examining fluctuation in this format allowed me to get a glimpse of emotional locomotion, by obtaining an operationalization of a person's emotional range and how that may relate to their intimate relationships. Study 3 employed dyadic daily analytical techniques in order to examine how daily interactions with one's partner relates to that night's sleep in romantic partners. This technique allowed me to model the dependence of sleep and relationship variables people within the same relationship as well as the dependence of variables studied repeatedly over time (autocorrelation). In this way, I was able to examine both within-couple and within-day associations. Further, these models included moderated paths which allowed me to assess how affectionate touch may alter the within-couple and within-day associations. Therefore, we were able to not only see a snapshot of thriving but also learn about how thriving 
phenomena may unfold over time. While the results were not as consistent with the thriving through relationships model (Feeney \& Collins, 2015) as first expected, these studies highlight the importance of examining thriving as a process that occurs over time and points toward the study of real-time and long-term thriving as valuable avenues for future work.

\section{Future Directions}

This dissertation examined intrapersonal and interpersonal processes theorized to contribute to thriving. The roles of gratitude, affectionate touch, responsive support, and sleep in well-being was examined in work and relationship contexts. While this dissertation was one of the first to examine specific pathways within the model of thriving through relationships, this work may be developed in future studies. Gratitude interventions (e.g., journaling, letter writing) has been shown to be an effective intervention for boosting psychological resources (Wood et al., 2010). Study 1 examined the effect of gratitude expressions on health via psychological resources. Gratitude expressions within relationships is associated with increased feelings of responsiveness and psychological resources (i.e. resilience; Algoe \& Zhaoyang, 2016). Future work should consider how gratitude expressions within couple interactions relates to physical health and represents one important extension of the thriving through relationships model (Feeney \& Collins, 2015). Furthermore, positive affect is theorized to be a mechanism linking relationships to physical health (Slatcher \& Schoebi, 2017). Recent work suggests that variation in emotions is related to reduced psychological and 
physical well-being (Hardy \& Segerstrom, 2017; Human et al., 2015). Further delineation of the role positive emotion dynamics play in relationships and physical health is one apt avenue for future research.

The present study sought to examine processes related to thriving with specific contexts. Additional work is need to examine thriving in work relationships as well as unique family contexts. For example, future work may focus on the features of relationships between supervisors and employees that promote thriving. Research examining work-family conflict and work-family enrichment (Hammer \& Zimmerman, 2011), for example, may be applied to the study of thriving beyond one's work stressors or home stressors, or how home and work-life may bolster personal growth. Recent literature has begun examining responsiveness in the workplace, a key ingredient to healthy and high functioning relationships. For example, Reis and colleagues (2008) found that patient perceptions of health care provider responsiveness predicted patient satisfaction and positive health outcomes. In addition, thriving through relationships may not be a purely dyadic process, for example, relationships may thrive through collective units. Research in resilience, a related but distinct construct to thriving (Feeney \& Collins, 2015), suggest a concept of social resilience that describes the capacity to form and maintain positive relationships and recover from adversity or social isolation (Cacioppo, Reis, \& Zautra, 2011). Therefore, the interplay between individuals, relationships and group structures is important to responding and growing from life's stressors. Applied to this dissertation, as the study of military couples grows, future 
studies must examine thriving and resilience within family units including parents and children in order to get a comprehensive understanding of what it means to thrive through relationships.

Finally, this dissertation aimed to examine sleep and affectionate touch as components of thriving. Sleep is an important health indicator related to accident risk, chronic disease, and mortality (Itani, Jike, Watanabe, \& Kaneita, 2017; Luyster, Strollo, Zee, \& Walsh, 2012). Furthermore, affectionate touch has been linked to important health indicators related to reduced cortisol levels, lower susceptibility to colds, and higher oxytocin (Cohen et al., 2015; Ditzen et al., 2007; Light et al., 2005). Study 3 found affectionate touch was related to partner sleep quality. This is the first to my knowledge to examine affectionate touch and sleep. The majority of adults sleep with a bed partner (National Sleep Foundation, 2013) and it is likely that affectionate touch happens around bed time, such as cuddling in bed. Future work should focus on how physically interacting with a partner after a long day relates to better sleep and subsequent psychological and physical well-being benefits. For example, research may experimentally examine touch interactions and sleep actigraphy measurements within couples to complement daily studies of dyadic sleep patterns. Both approaches would identify the key features of affectionate touch that contribute to restful sleep within couples.

\section{Conclusion}


The goal of the three dissertation studies was to examine aspects of thriving related to gratitude interactions, responsive support and affectionate interactions within relationships, and physical health outcomes, such as sleep. Taking into account the mixed findings, the studies broadly suggest that positive emotions share a complex relationship with health and relational well-being, within which gratitude and affectionate interactions play a defining role. Further, these studies identify promising areas of future study and add to recent research and theory by examining thriving within the context of nursing and military relationships. 


\section{References}

Adams A. \& Bond S. (2000). Hospital nurses' job satisfaction, individual and organizational characteristics. Journal of Advanced Nursing 32, 536-543. doi:10.1046/j.13652648.2000.01513.x

Aiken L.H., Clarke S.P., Sloane D.M., Sochalski J. \& Silber J.H. (2002). Hospital nursing staffing and patient mortality, nurse burnout and job dissatisfaction. Journal of the American Medical Association, 23, 1987-1993.

doi:10.1001/jama.288.16.1987

Algoe, S. B. (2012). Find, remind, and bind: The functions of gratitude in everyday relationships. Social and Personality Psychology Compass, 6, 455-469. doi:10.1111/j.1751-9004.2012.00439.x

Algoe, S. B., \& Zhaoyang, R. (2016). Positive psychology in context: Effects of expressing gratitude in ongoing relationships depend on perceptions of enactor responsiveness. The Journal of Positive Psychology, 11(4), 399-415. doi:10.1080/17439760.2015.1117131

Bolger, N., Davis, A., \& Rafaeli, E. (2003). Diary methods: Capturing life as it is lived. Annual Review of Psychology, 54, 579-616.

Cacioppo, J. T., Reis, H. T., \& Zautra, A. J. (2011). Social resilience: the value of social fitness with an application to the military. American Psychologist, 66(1), 43. doi: $10.1037 / \mathrm{a} 0021419$ 
Cohen, S., Janicki-Deverts, D., Turner, R. B., \& Doyle, W. J. (2015). Does hugging provide stress-buffering social support? A study of susceptibility to upper respiratory infection and illness. Psychological Science, 26, 135-147.

Diener, E., Suh, E. M., Lucas, R. E., \& Smith, H. L. (1999). Subjective well-being: Three decades of progress. Psychological bulletin, 125(2), 276-302. doi:10.1037/00332909.125.2.276

Diener, E., Wirtz, D., Tov, W., Kim-Prieto, C., Choi, D., Oishi, S., \& Biswas-Diener, R. (2010). New well-being measures: Short scales to assess flourishing and positive and negative feelings. Social Indicators Research, 97, 143-156.

Ditzen, B., Neumann, I. D., Bodenmann, G., von Dawans, B., Turner, R. A., Ehlert, U., \& Heinrichs, M. (2007). Effects of different kinds of couple interaction on cortisol and heart rate responses to stress in women. Psychoneuroendocrinology, 32, 565-574. doi:10.1016/j.psyneuen.2007.03.011

Feeney, B. C., \& Collins, N. L. (2015). A new look at social support: A theoretical perspective on thriving through relationships. Personality and Social Psychology Review, 19(2), 113-147. doi:10.1177/1088868314544222

Fredrickson, B. L. (2001). The role of positive emotions in positive psychology: The broaden-and-build theory of positive emotions. American Psychologist, 56, 218226. doi:10.1037/0003-066X.56.3.218 
Gottman, J. M., Gottman, J. S., \& Atkins, C. L. (2011). The Comprehensive Soldier Fitness program: family skills component. American Psychologist, 66(1), 52. doi: $10.1037 / \mathrm{a} 0021706$

Hammer, L. B., \& Zimmerman, K. L. (2011). Quality of work life. In S. Zedeck (Ed.), APA Handbooks in Psychology. APA handbook of industrial and organizational psychology, Vol. 3. Maintaining, expanding, and contracting the organization (pp. 399-431). Washington, DC, US: American Psychological Association. Hardy, J., \& Segerstrom, S. C. (2017). Intra-individual variability and psychological flexibility: Affect and health in a National US sample. Journal of Research in Personality, 69, 13-21. doi:10.1016/j.jrp.2016.04.002 0092-6566

Hasson, D., \& Gustavsson, P. (2010). Declining sleep quality among nurses: a populationbased four-year longitudinal study on the transition from nursing education to working life. PloS One, 5(12), e14265. doi:10.1371/journal.pone.0014265 Hertenstein, M. J., Keltner, D., App, B., Bulleit, B. A., \& Jaskolka, A. R. (2006). Touch communicates distinct emotions. Emotion, 6(3), 528-533. doi:10.1037/15283542.6.3.528

Holt-Lunstad, J., \& Smith, T. B. (2012). Social relationships and mortality. Social \& Personality Psychology Compass, 6, 41-53. doi:10.1111/j.17519004.2011.00406.x

Human, L. J., Whillans, A. V., Hoppmann, C. A., Klumb, P., Dickerson, S. S., \& Dunn, E. W. (2015). Finding the middle ground: Curvilinear associations between positive 
affect variability and daily cortisol profiles. Emotion, 15(6), 705-720.

doi:10.1037/t03592-000

Itani, O., Jike, M., Watanabe, N., \& Kaneita, Y. (2017). Short sleep duration and health outcomes: a systematic review, meta-analysis, and meta-regression. Sleep Medicine, 32, 246-256. doi:10.1016/j.sleep.2016.08.006

Jakubiak, B. K., \& Feeney, B. C. (2017). Affectionate touch to promote relational, psychological, and physical well-being in adulthood: A theoretical model and review of the research. Personality and Social Psychology Review, 21(3), 228-252. doi:10.1177/1088868316650307

Karney, B. R., \& Trail, T. E. (2017). Associations between prior deployments and marital satisfaction among army couples. Journal of Marriage and Family, 79(1), 147160. doi:10.1111/jomf.12329

Knobloch, L. K., \& Theiss, J. A. (2012). Experiences of US military couples during the postdeployment transition: Applying the relational turbulence model. Journal of Social and Personal Relationships, 29(4), 423-450.

doi:10.1177/0265407511431186

Kuppens, P., \& Verduyn, P. (2015). Looking at emotion regulation through the window of emotion dynamics. Psychological Inquiry, 26(1), 72-79. doi:10.1080/1047840X.2015.960505

Lee, S., Martire, L. M., Damaske, S. A., Mogle, J. A., Zhaoyang, R., Almeida, D. M., \& Buxton, O. M. (2018). Covariation in couples' nightly sleep and gender 
differences. Sleep Health: Journal of the National Sleep Foundation, 4(2), 201208. doi:10.1016/j.sleh.2017.10.009

Light, K. C., Grewen, K. M., \& Amico, J. A. (2005). More frequent partner hugs and higher oxytocin levels are linked to lower blood pressure and heart rate in premenopausal women. Biological Psychology, 69, 5-21. doi:10.1016/j.biopsycho.2004.11.002

Lin, K. C., Huang, C. C., \& Wu, C. C. (2007). Association between stress at work and primary headache among nursing staff in Taiwan. Headache: The Journal of Head and Face Pain, 47(4), 576-584. doi:10.1111/j.1526-4610.2007.00759.x

Luyster, F. S., Strollo, P. J., Zee, P. C., \& Walsh, J. K. (2012). Sleep: a health imperative. Sleep, 35(6), 727-734. doi:10.5665/sleep.1846

Morrison, K. B., \& Korol, S. A. (2014). Nurses' perceived and actual caregiving roles: identifying factors that can contribute to job satisfaction. Journal of Clinical Nursing, 23(23-24), 3468-3477. doi:10.1111/jocn.12597

National Sleep Foundation. (2013). International bedroom poll: Summary of Findings. Arlington, VA: Author.

Newman K. \& Maylor U. (2002) Empirical evidence for "the nurse satisfaction, quality of care and patient satisfaction chain. International Journal of Health Care Quality Assurance 15, 80-88. doi:10.1108/09526860210421482 
Ram, N., \& Gerstorf, D. (2009). Time-structured and net intraindividual variability: Tools for examining the development of dynamic characteristics and processes. Psychology and Aging, 24(4), 778 791. doi:10.1037/a0017915

Robles, T. F., Slatcher, R. B., Trombello, J. M., \& McGinn, M. M. (2014). Marital quality and health: A meta-analytic review. Psychological bulletin, 140(1), 140-187. doi:10.1037/a0031859

Ryff, C. D., \& Singer, B. H. (1998). The contours of positive human health. Psychological Inquiry, 9, 1-28. doi:10.1207/s15327965pli0901_1

Ryff, C. D., \& Singer, B. H. (2000). Interpersonal flourishing: A positive health agenda for the new millennium. Personality and Social Psychology Review, 4, 30-44. doi:10.1207/S15327957PSPR0401_4

Segal, M. W. (1989). The nature of work and family linkages: A theoretical perspective. In G. L. Bowen \& D. K. Orthner (Eds.), The organization family: Work and family linkages in the U. S. military (pp. 3-36). New York: Praeger.

Seligman, M. E. P., Steen, T. A., Park, N., \& Peterson, C. (2005). Positive psychology progress: Empirical validation of interventions. American Psychologist, 60, 410421. doi:10.1037/t02942-000

Slatcher, R. B., \& Schoebi, D. (2017). Protective processes underlying the links between marital quality and physical health. Current Opinion in Psychology, 13, 148-152. doi:10.1016/j.copsyc.2016.09.002 
Slatcher, R. B., Selcuk, E., \& Ong, A. D. (2015). Perceived partner responsiveness predicts diurnal cortisol profiles 10 years later. Psychological Science, 26(7), 972-982.

Troxel, W. M. (2010). It's more than sex: Exploring the dyadic nature of sleep and implications for health. Psychosomatic medicine, 72(6), 578.

Troxel, W. M., Robles, T. F., Hall, M., \& Buysse, D. J. (2007). Marital quality and the marital bed: Examining the covariation between relationship quality and sleep. Sleep Medicine Reviews, 11(5), 389-404. doi:10.1016/j.smrv.2007.05.002

Uchino, B. N. (2006). Social support and health: a review of physiological processes potentially underlying links to disease outcomes. Journal of behavioral medicine, 29(4), 377-387.

Warner, C. H., Appenzeller, G. N., Warner, C., \& Grieger, T. (2009). Psychological effects of deployments on military families. Psychiatric Annals, 39(2), 56-63. doi:10.3928/00485713-20090201-11

Wood, A. M., Froh, J. J., \& Geraghty, A. W. (2010). Gratitude and well-being: A review and theoretical integration. Clinical psychology review, 30(7), 890-905. doi:10.1016/j.cpr.2010.03.005 
APPENDIX A: Study 2 Measures

PANAS-X and Gratitude (from Emmons \& McCullough, 2003; Watson \& Clark, 1994;

Watson et al., 1988)

This is a list of feelings and emotions. Indicate to what extent you feel this way RIGHT NOW.

\begin{tabular}{|c|c|c|c|c|c|}
\hline & Not at all (1) & $\begin{array}{c}\text { Slightly } \\
(2)\end{array}$ & $\begin{array}{c}\text { Moderately } \\
(3)\end{array}$ & $\begin{array}{c}\text { Very Much } \\
(4)\end{array}$ & $\begin{array}{c}\text { Extremely } \\
\text { Happy }\end{array}$ \\
Relaxed & 0 & 0 & 0 & 0 & 0 \\
Quiet & 0 & 0 & 0 & 0 & 0 \\
Bored & 0 & 0 & 0 & 0 & 0 \\
Sad & 0 & 0 & 0 & 0 & 0 \\
Nervous & 0 & 0 & 0 & 0 & 0 \\
Angry & 0 & 0 & 0 & 0 & 0 \\
Focused & 0 & 0 & 0 & 0 & 0 \\
Lonely & 0 & 0 & 0 & 0 & 0 \\
Active & 0 & 0 & 0 & 0 & 0 \\
Ashamed & 0 & 0 & 0 & 0 & 0 \\
Grateful & 0 & 0 & 0 & 0 & 0 \\
Guilty & 0 & 0 & 0 & 0 & 0 \\
\hline
\end{tabular}

Interpersonal intimacy (Laurenceau et al., 2005)

How close did you feel to your spouse/partner TODAY? (intimacy)

Not at all close (1)

Somewhat close (2)

O Moderately close (3)

O Very close (4)

O Extremely close (5) 
PTSD Checklist - Military version (PCL-M) (Bliese, Wright, Adler, Cabrera, Castro, \& Hoge, 2008)

Below is a list of reactions that Veterans sometimes have in response to stressful military experiences. Please read each one carefully and select how much you have been bothered by that problem in the PAST 30 DAYS.

$$
\begin{aligned}
& 1=\text { Not at all } \\
& 2=\text { A little bit } \\
& 3=\text { Moderately } \\
& 4=\text { Quite a bit } \\
& 5=\text { Extremely }
\end{aligned}
$$

1. Repeated disturbing memories, thoughts, or images of the stressful experience

2. Having physical reactions (like heart pounding, trouble breathing, sweating) when something reminded you of the stressful experience)

3. Avoiding activities or situations because they reminded you of the stressful experience

4. Having difficulty concentrating

\section{Demographic Covariates}

1. Gender

What is your gender?

$0=$ Male

$1=$ Female

2. Relationship length

How long (in years) have you been with your current partner?

[Drop down menu]

3. Parent status

$1=$ Yes, parent

$0=$ Not parent

4. Shift

$1=$ Regular shift

2 = Shift worker 
APPENDIX B: Study 3 Measures

Daily Pittsburgh Sleep Quality Index (from Buysse et al., 1989)

The following questions ask about your sleep. Please think of your experience of sleep over the (reporting period).

How would you rate last night's sleep quality overall? (sleep quality)

O Very Bad (1)

Fairly Bad (2)

Fairly Good (3)

Very Good (4)

How many hours did you sleep last night? (sleep duration)

\begin{tabular}{|l|l|}
\hline 0 & $0 \ldots$ \\
\hline 1 & 0.5 \\
\hline 2 & 1 \\
\hline 3 & 1.5 \\
\hline 4 & 2 \\
\hline 5 & 2.5 \\
\hline 6 & 3 \\
\hline 7 & 3.5 \\
\hline 8 & 4 \\
\hline 9 & 4.5 \\
\hline 10 & 5 \\
\hline 11 & 5.5 \\
\hline 12 & 6 \\
\hline 13 & 6.5 \\
\hline 14 & 7 \\
\hline 15 & 7.5 \\
\hline 16 & 8 \\
\hline
\end{tabular}

\begin{tabular}{|l|l|}
\hline 17 & 8.5 \\
\hline 18 & 9 \\
\hline 19 & 9.5 \\
\hline 20 & 10 \\
\hline 21 & 10.5 \\
\hline 22 & 11 \\
\hline 23 & 11.5 \\
\hline 24 & 12 \\
\hline 25 & 12.5 \\
\hline 26 & 13 \\
\hline 27 & 13.5 \\
\hline 28 & 14 \\
\hline 29 & 14.5 \\
\hline 30 & 15 \\
\hline 31 & 15.5 \\
\hline 32 & 16 \\
\hline 33 & 16.5 \\
\hline
\end{tabular}

\begin{tabular}{|l|l|}
\hline 34 & 17 \\
\hline 35 & 17.5 \\
\hline 36 & 18 \\
\hline 37 & 18.5 \\
\hline 38 & 19 \\
\hline 39 & 19.5 \\
\hline 40 & 20 \\
\hline 41 & 20.5 \\
\hline 42 & 21 \\
\hline 43 & 21.5 \\
\hline 44 & 22 \\
\hline 45 & 22.5 \\
\hline 46 & 23 \\
\hline 47 & 23.5 \\
\hline 48 & 24 \\
\hline
\end{tabular}


PANAS-X and Gratitude (from Emmons \& McCullough, 2003; Watson \& Clark, 1994; Watson et al., 1988)

This is a list of feelings and emotions. Indicate to what extent you feel this way RIGHT NOW.

\begin{tabular}{|c|c|c|c|c|c|}
\hline & Not at all (1) & $\begin{array}{c}\text { Slightly } \\
(2)\end{array}$ & Moderately & Very Much & Extremely \\
\hline Happy & 0 & 0 & 0 & $(4)$ & $(5)$ \\
Relaxed & 0 & 0 & 0 & 0 & 0 \\
Quiet & 0 & 0 & 0 & 0 & 0 \\
Bored & 0 & 0 & 0 & 0 & 0 \\
Sad & 0 & 0 & 0 & 0 & 0 \\
Nervous & 0 & 0 & 0 & 0 & 0 \\
Angry & 0 & 0 & 0 & 0 & 0 \\
Focused & 0 & 0 & 0 & 0 & 0 \\
Lonely & 0 & 0 & 0 & 0 & 0 \\
Active & 0 & 0 & 0 & 0 & 0 \\
Ashamed & 0 & 0 & 0 & 0 & 0 \\
Grateful & 0 & 0 & 0 & 0 & 0 \\
Guilty & 0 & 0 & 0 & 0 & 0 \\
\hline
\end{tabular}

Daily Events Checklist - Affectionate touch (Zatura et al., 1988; Stone \& Neale, 1984) Please rate how positive the following events were. If the event did not occur, please select "Did not happen."

\begin{tabular}{|c|c|c|c|c|c|c|}
\hline & $\begin{array}{c}\text { Did not } \\
\text { happen } \\
(0)\end{array}$ & $\begin{array}{c}\text { Extremely } \\
\text { Negative } \\
(1)\end{array}$ & $\begin{array}{c}\text { Moderately } \\
\text { Negative (2) }\end{array}$ & $\begin{array}{c}\text { Neither } \\
\text { Negative } \\
\text { nor Positive } \\
\text { (3) }\end{array}$ & $\begin{array}{c}\text { Moderately } \\
\text { Positive (4) }\end{array}$ & $\begin{array}{c}\text { Extremely } \\
\text { Positive (5) }\end{array}$ \\
\hline $\begin{array}{c}\text { Had pleasing physical } \\
\text { contact with } \\
\text { spouse/partner } \\
\text { (affectionate touch) }\end{array}$ & 0 & 0 & 0 & 0 & 0 & 0 \\
\hline
\end{tabular}


Negative Event - Perceived responsiveness (Gable et al., 2006)

Please think about the most NEGATIVE event that occurred over the (reporting period).

What type of event was this?

O Work (1)

Money and financial (2)

O Household (3)

O Social (4)

Recreation (5)

O Spouse/partner (6)

Children (if applicable) (7)

Family (8)

Military (9)

Other happenings (10)

Please indicate whether this event occurred LAST NIGHT and/or TODAY.

\section{Happened LAST NIGHT}

Happened TODAY

(1)

Did you experience this event with your partner?

No (0)

Y Yes (1)

Did you tell anyone about the most negative event you experienced in the (reporting period)?

$\square$ No (0)

Yes, spouse/partner

$\square$ Yes, someone else 
Rate the extent to which the following statements apply to your spouse/partner's response: "When I talked to my spouse/partner about this event, I felt that..."

\begin{tabular}{|c|c|c|c|c|c|}
\hline & $\begin{array}{c}\text { Strongly } \\
\text { Disagree (1) }\end{array}$ & $\begin{array}{c}\text { Disagree } \\
\text { (2) }\end{array}$ & $\begin{array}{c}\text { Neither Agree } \\
\text { nor Disagree } \\
\text { (3) }\end{array}$ & $\begin{array}{c}\text { Agree } \\
\text { (4) }\end{array}$ & $\begin{array}{c}\text { Strongly } \\
\text { Agree (5) }\end{array}$ \\
\hline $\begin{array}{c}\text { My spouse/partner } \\
\text { understood me. }\end{array}$ & 0 & 0 & 0 & 0 & 0 \\
$\begin{array}{c}\text { My spouse/partner } \\
\text { liked/valued my abilities } \\
\text { and opinions. }\end{array}$ & 0 & 0 & 0 & 0 & 0 \\
$\begin{array}{c}\text { My spouse/partner made } \\
\text { me feel cared for. }\end{array}$ & 0 & 0 & 0 & 0 & 0 \\
$\begin{array}{c}\text { My spouse/partner was } \\
\text { responsive to my needs. }\end{array}$ & 0 & 0 & 0 & 0 & 0 \\
\hline
\end{tabular}

PTSD Checklist - Military version (PCL-M) (Bliese, Wright, Adler, Cabrera, Castro, \& Hoge, 2008)

Below is a list of reactions that Veterans sometimes have in response to stressful military experiences. Please read each one carefully and select how much you have been bothered by that problem in the PAST 30 DAYS.

$$
\begin{aligned}
& 1=\text { Not at all } \\
& 2=\text { A little bit } \\
& 3=\text { Moderately } \\
& 4=\text { Quite a bit } \\
& 5=\text { Extremely }
\end{aligned}
$$

5. Repeated disturbing memories, thoughts, or images of the stressful experience

6. Having physical reactions (like heart pounding, trouble breathing, sweating) when something reminded you of the stressful experience)

7. Avoiding activities or situations because they reminded you of the stressful experience

8. Having difficulty concentrating

\section{Demographic Covariates}

1. Gender

What is your gender? 
$0=$ Male
$1=$ Female

2. Relationship length

How long (in years) have you been with your current partner?

[Drop down menu]

3. Parent status

$1=$ Yes, parent

$0=$ Not parent

4. Shift

$1=$ Regular shift

2 = Shift worker 